ESCOLA POLITÉCNICA DA UNIVERSIDADE DE SÃO PAULO

IGOR BRANDÃO MACHADO MATSUO

SISTEMA ESPECIALISTA PARA ANÁLISE PÓS-EVENTO DA PROTEÇÃO EM SUBESTAÇÕES DISTRIBUIDORAS 
IGOR BRANDÃO MACHADO MATSUO

\section{SISTEMA ESPECIALISTA PARA ANÁLISE PÓS-EVENTO DA PROTEÇÃO EM SUBESTAÇÕES DISTRIBUIDORAS}

Dissertação apresentada ao Programa de Pós Graduação em Engenharia Elétrica da Escola Politécnica da Universidade de São Paulo, na área de concentração de Sistemas de Potência, como parte dos requisitos exigidos para a obtenção do título de Mestre em Engenharia Elétrica. 
IGOR BRANDÃO MACHADO MATSUO

\section{SISTEMA ESPECIALISTA PARA ANÁLISE PÓS-EVENTO DA PROTEÇÃO EM SUBESTAÇÕES DISTRIBUIDORAS}

Dissertação apresentada ao Programa de Pós Graduação em Engenharia Elétrica da Escola Politécnica da Universidade de São Paulo, na área de concentração de Sistemas de Potência, como parte dos requisitos exigidos para a obtenção do título de Mestre em Engenharia Elétrica.

Área de Concentração: Sistemas de Potência

Orientador: Prof. Dr. José Antonio Jardini 
Autorizo a reprodução e divulgação total ou parcial deste trabalho, por qualquer meio convencional ou eletrônico, para fins de estudo e pesquisa, desde que citada a fonte.

Este exemplar foi revisado e corrigido em relação à versão original, sob responsabilidade única do autor e com a anuência de seu orientador.

São Paulo, de de

Assinatura do autor:

Assinatura do orientador:

\section{Catalogação-na-publicação}

Matsuo, Igor Brandão Machado

Sistema especialista para análise pós-evento da proteção em subestações distribuidoras / I. B. M. Matsuo -- versão corr. -- São Paulo, 2015.

$103 \mathrm{p}$.

Dissertação (Mestrado) - Escola Politécnica da Universidade de São Paulo. Departamento de Engenharia de Energia e Automação Elétricas.

1.Proteção de Sistemas Elétricos 2.Sistemas Especialistas 3.Subestações Elétricas 4.Distribuição de Energia Elétrica 5.Proteção de Equipamentos Elétricos I.Universidade de São Paulo. Escola Politécnica. Departamento de Engenharia de Energia e Automação Elétricas II.t. 
A meus familiares, amigos

e colegas de trabalho,

os quais me incentivam e me mantêm firme nessa caminhada. 


\section{AGRADECIMENTOS}

A conclusão desse projeto de mestrado foi possível graças ao investimento de pesquisa e desenvolvimento da Agência Nacional de Energia Elétrica (ANEEL) junto à Companhia Paulista de Força e Luz (CPFL).

Agradeço também ao professor e orientador José Antonio Jardini, ao professor Luiz Carlos Magrini e aos colegas Ferdinando Crispino e Paula Kayano, cujos conhecimentos e experiências foram de extrema importância.

Agradeço ao meu pai, Nelson, cujos conhecimentos na área de sistemas de potência foram de grande valia para clarificar muitos aspectos importantes ao projeto.

Por último, agradeço à minha esposa, Livia, pela revisão do texto e a meus familiares Maluh (mãe), Nelson (pai), Marcel (irmão), Eric (irmão) e Claire (sobrinha), que mantêm apoio e constantes incentivos, sejam na vida pessoal, sejam na vida profissional. 
"Mantenha seus pensamentos positivos, porque seus pensamentos tornam-se suas palavras. Mantenha suas palavras positivas, porque suas palavras tornam-se suas atitudes. Mantenha suas atitudes positivas, porque suas atitudes tornam-se seus hábitos. Mantenha seus hábitos positivos, porque seus hábitos tornam-se seus valores. Mantenha seus valores positivos, porque seus valores tornam-se seu destino." 


\section{RESUMO}

MATSUO, I. B. M. Sistema especialista para análise pós-evento da proteção em subestações distribuidoras. 103f. Dissertação (Mestrado) - Escola Politécnica da Universidade de São Paulo, São Paulo, 2015.

É importante que as redes elétricas tenham altos índices de confiabilidade, de forma a se manter a agilidade e a manutenção ideais para um melhor funcionamento. Por outro lado, o crescimento inesperado da carga, falhas em equipamentos e uma parametrização inadequada das funções de proteção tornam a análise de eventos de proteção mais complexas e demoradas. Além disso, a quantidade de informações que pode ser obtida de relés digitais modernos tem crescido constantemente. Para que seja possível uma rápida tomada de decisão e manutenção, esse projeto de pesquisa teve como objetivo a implementação de um sistema completo de diagnóstico que é ativado automaticamente quando um evento de proteção ocorrer. As informações a serem analisadas são obtidas de uma base de dados e de relés de proteção, via protocolo de comunicação IEC 61850 e arquivos de oscilografia. O trabalho aborda o sistema Smart Grid completo incluindo: a aquisição de dados nos relés, detalhando o sistema de comunicação desenvolvido através de um software com um cliente IEC61850 e um servidor OPC e um software com um cliente OPC, que é ativado por eventos configurados para dispará-lo (por exemplo, atuação da proteção); o sistema de pré-tratamento de dados, onde os dados provenientes dos relés e equipamentos de proteção são filtrados, pré-processados e formatados; e o sistema de diagnóstico. Um banco de dados central mantém atualizados os dados de todas essas etapas. O sistema de diagnóstico utiliza algoritmos convencionais e técnicas de inteligência artificial, em particular, um sistema especialista. O sistema especialista foi desenvolvido para lidar com diferentes conjuntos de dados de entrada e com uma possível falta de dados, sempre garantindo a entrega de diagnósticos. Foram realizados testes e simulações para curtos-circuitos (trifásico, dupla-fase, dupla-fase-terra e fase-terra) em alimentadores, transformadores e barras de uma subestação. Esses testes incluíram diferentes estados do sistema de proteção (funcionamento correto e impróprio). O sistema se mostrou totalmente eficaz tanto no caso de disponibilidade completa quanto parcial de informações, sempre fornecendo um diagnóstico do curto-circuito e analisando o funcionamento das funções de proteção da subestação. Dessa forma, possibilita-se uma manutenção muito mais eficiente pelas concessionárias de energia, principalmente no que diz respeito à prevenção de defeitos em equipamentos, rápida resposta a problemas, e necessidade de reparametrização das funções de proteção. O sistema foi instalado com sucesso em uma subestação de distribuição da Companhia Paulista de Força e Luz.

Palavras-chave: análise da proteção, manutenção, proteção de sistemas elétricos de potência, sistemas especialistas, sistemas inteligentes. 


\begin{abstract}
MATSUO, I. B. M. Expert system for post-event analysis of the protection system in distribution substations. 103p. Thesis (master's degree) - Polytechnic School of the University of Sao Paulo, Sao Paulo, Brazil, 2015.

It is important that electrical networks have high levels of reliability in order to maintain the ideal agility and maintenance for better functioning. On the other hand, the often unexpected load growth, failures of protectionrelated equipment and inadequate parameterization of protection functions make the analyses of protection events more complex and time-consuming. Besides, the amount of information that can be retrieved from modern digital relays is constantly increasing. In order to aid a quick decision-making and maintenance practices, this research project aimed to implement a complete diagnosis system that is automatically activated whenever a protection-related event occurs. Information to be analyzed is obtained from a database and from the protection relays, via IEC 61850 communication protocol and oscillography files. The full smart grid system is addressed, including: the data acquisition and communication system developed through a software with an IEC61850 client and an OPC server and another software with an OPC client, which is activated by set triggering events (e.g. protection tripping); the data pre-processing system, in which the data is filtered, preprocessed and formatted; and the diagnostic system. A central database maintains updated all the data. For the diagnostic system, conventional algorithms and artificial intelligence techniques are applied; particularly, an expert system is implemented. The expert system was designed to deal with different sets of input information and uses different techniques to deal with a possible lack of data, always ensuring the delivery of diagnoses. Tests and simulations were performed for short-circuits (three-phase, phase-to-phase, double-phase-to-ground and phase-to-ground) on feeders, transformers and bus bars of a substation. These tests included different states of the protection system (proper functioning and malfunctioning). The diagnostic system proved to be fully effective under both complete and partial availability of information, always providing the fault diagnosis and the analysis of the protection functions. In brief, the system enables a much more efficient maintenance to power distribution utilities, especially when preventing equipment malfunctioning, quick responses towards system problems and the need to re-define some protection functions are required. It was successfully installed in a distribution substation of Companhia Paulista de Força e Luz, a Brazilian power distribution utility.
\end{abstract}

Keywords: expert systems, intelligent systems, maintenance, power system protection, protection analysis. 


\section{LISTA DE FIGURAS}

Figura 1 - Arquitetura para sistema de aquisição de dados

Figura 2 - Exemplo de buffered report control block em uma arquitetura cliente-servidor (fonte: "IEC 61850: International Standard - Communication Networks and Systems for

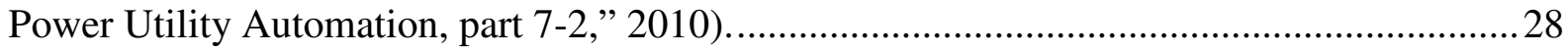

Figura 3 - Curvas características genéricas de um relé de sobrecorrente temporizado............31

Figura 4 - Esquema de proteção do relé de religamento.

Figura 5 - Ciclo de operações de um relé de religamento de três operações com filosofia fuse saving.....

Figura 6 - Ciclo de operações de um relé de religamento de três operações sem filosofia fuse saving e em conjunto com apenas unidades instantâneas de sobrecorrente.

Figura 7 - Ciclo de operações de um relé de religamento de três operações sem filosofia fuse saving e em conjunto com apenas unidades temporizadas de sobrecorrente. .33

Figura 8 - Esquema unifilar de proteção diferencial.

Figura 9 - Esquema unifilar de proteção diferencial com bobinas de restrição. 35

Figura 10 - Característica de operação do relé diferencial. .36

Figura 11 - Circuito trifásico em componentes de fase (a) e componentes simétricas (b).......38

Figura 12 - Circuito dupla-fase em componentes de fase (a) e componentes simétricas (b)...39 Figura 13 - Circuito dupla-fase-terra em componentes de fase (a) e componentes simétricas (b).

Figura 14 - Circuito fase-terra em componentes de fase (a) e componentes simétricas (b).....41

Figura 15 - Rede de nós sem proveito da similaridade estrutural.

Figura 16 - Rede de nós com proveito da similaridade estrutural...........................................50

Figura 17 - Fluxo de dados do sistema de automação...........................................................53

Figura 18 - Oscilografia da variável digital do Trip da função 51.........................................57

Figura 19 - Curto-circuito seguido de abertura do disjuntor. ..................................................58

Figura 20 - Interface Web com a relação dos relatórios gerados pelo sistema especialista.....61

Figura 21 - Interface Web para a visualização do relatório gerado pelo sistema especialista. 61

Figura 22 - Módulos de diagnóstico do sistema especialista.

Figura 23 - Modelo RBM de proteção de sobrecorrente temporizada na fase A. ....................67

Figura 24 - Gráfico da curva de atuação da proteção diferencial............................................68

Figura 25 - Modelo RBM de proteção diferencial na fase A. ................................................69

Figura 26 - Modelo RBM da abertura do disjuntor................................................................. 79 


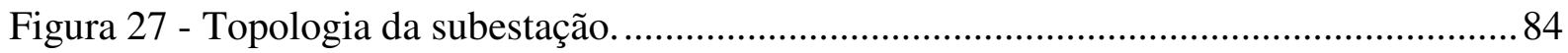

Figura 28 - Arquitetura de comunicação da subestação ........................................................... 85 


\section{LISTA DE QUADROS}

Quadro 1 - Estrutura XML do arquivo gerado pelo sistema especialista................................60

Quadro 2 - Relatório emitido pelos módulos de análise da proteção de sobrecorrente, curto-

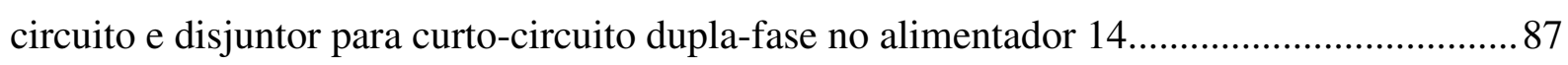

Quadro 3 - Relatório emitido pelo módulo da proteção diferencial para curto-circuito monofásico no enrolamento da fase A do transformador 1 .................................................. 88 


\section{LISTA DE TABELAS}

Tabela 1 - Classificação do tipo de falta. 83

Tabela 2 - Valores das correntes para curto-circuito dupla-fase no alimentador 14. 86 


\section{LISTA DE ABREVIATURAS}

$\begin{array}{ll}\text { ANSI } & \text { American National Standards Institute } \\ \text { CLIPS } & \text { C Language-Integrated Production System } \\ \text { COS } & \text { Centro de Operação do Sistema } \\ \text { CPFL } & \text { Companhia Paulista de Força e Luz } \\ \text { DFT } & \text { Discrete Fourier Transform (Transformada Discreta de Fourier) } \\ \text { DWT } & \text { Discrete Wavelet Transform (Transformada Wavelet Discreta) } \\ \text { IEC } & \text { International Electrotechnical Commission } \\ \text { IED } & \text { Intelligent Electronic Device } \\ \text { IHM } & \text { Interface Homem-Máquina } \\ \text { OLE } & \text { Object Linking and Embedding } \\ \text { OPC } & \text { Open Platform Communications } \\ \text { PDRI } & \text { Programa Brasileiro de Redes Elétricas Inteligentes } \\ \text { PROLOG } & \text { PROgramming in LOGic } \\ \text { RBM } & \text { Raciocínio Baseado em Modelos } \\ \text { RCB } & \text { Report Control Block } \\ \text { SCADA } & \text { Supervisory Control and Data Acquisition (Sistema de Supervisão e Aquisição } \\ \text { SCL } & \text { de Dados) } \\ \text { SVM } & \text { Support Vector Machine } \\ \text { TC } & \text { Transformador de Corrente } \\ \text { TCP/IP } & \text { Transformador de Potencial } \\ \text { XML } & \text { eXtensible Markup Language } \\ & \end{array}$




\section{SUMÁRIO}

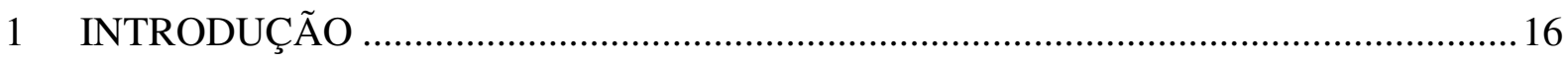

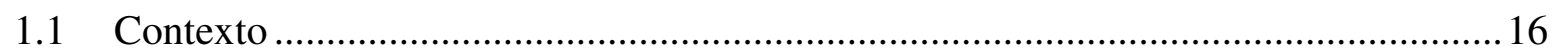

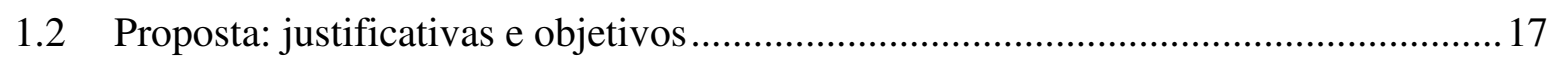

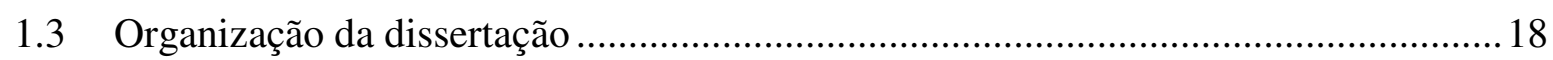

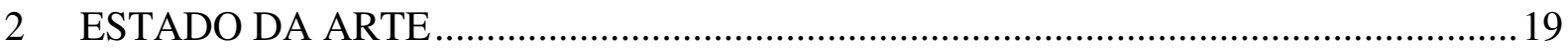

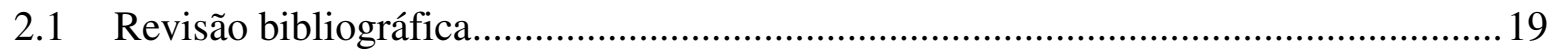

2.1.1 Sistemas de análise da atuação da proteção..........................................................19

2.1.2 Localização de faltas em alimentadores primários de distribuição .........................20

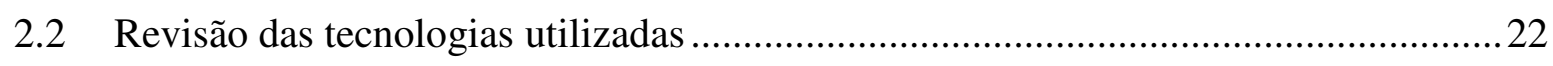

2.2.1 Transformada discreta de Fourier..............................................................22

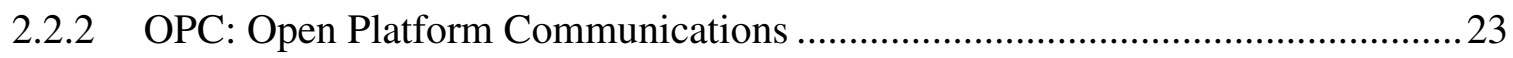

2.2.3 Linguagens para sistemas especialistas e o CLIPS ………………………….......24

3 SISTEMAS AUTOMATIZADOS, PROTEÇÃO E INTELIGÊNCIA ARTIFICIAL .....25

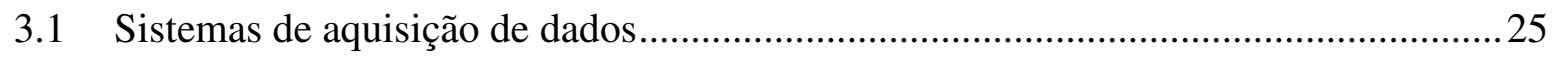

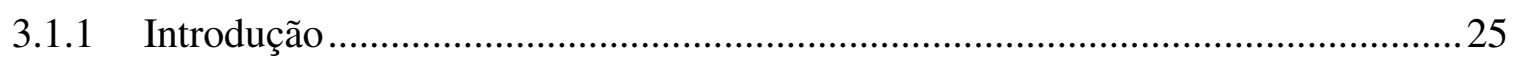

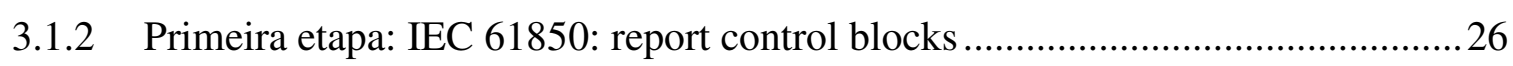

3.1.3 Segunda etapa: callback entre servidor OPC e cliente OPC ………………….....28

3.2 Proteção em subestações de distribuição ...................................................................29

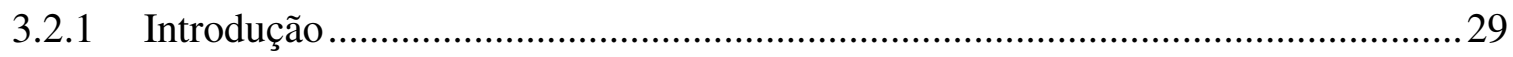

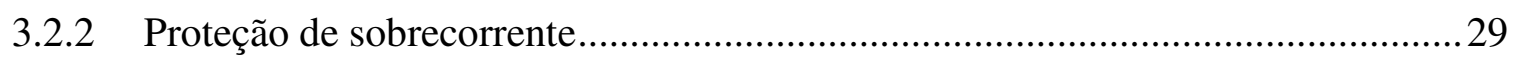

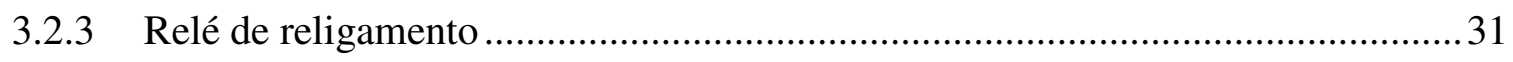

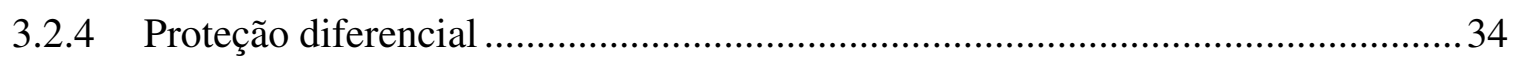

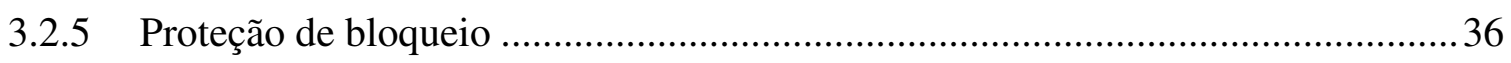

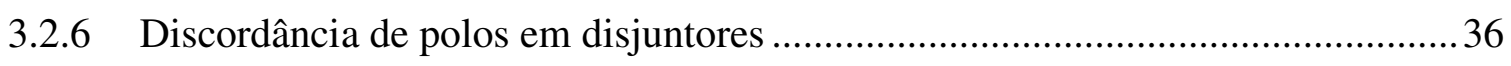

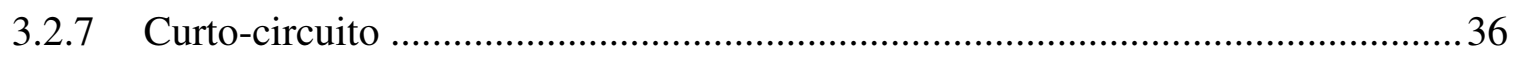

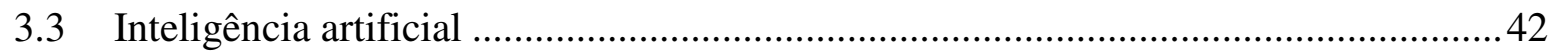

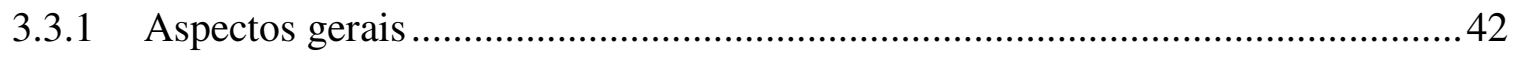

3.3.2 Sistemas especialistas baseados em regras de produção .......................................... 43

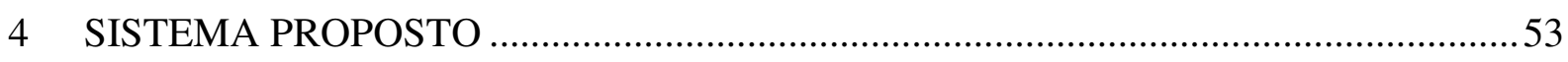

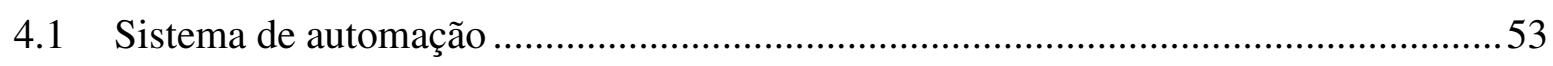

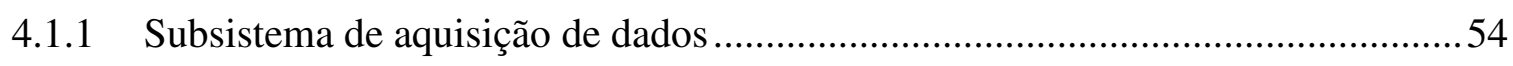

4.1.2 Subsistema de armazenamento de dados...........................................................54

4.1.3 Subsistema de pré-tratamento de dados............................................................56

4.1.4 Subsistema de processamento de dados ..........................................................59 
4.1.5 Interface Web: visualização do diagnóstico ........................................................59

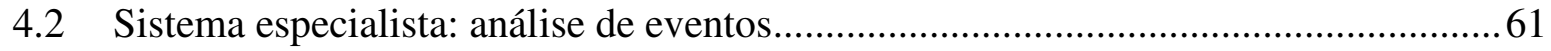

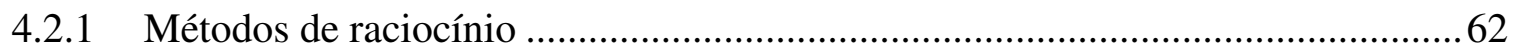

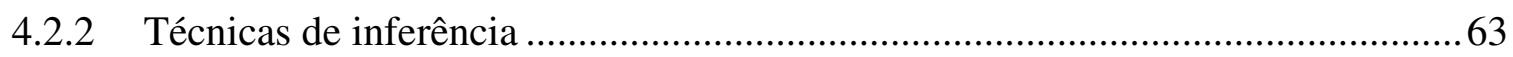

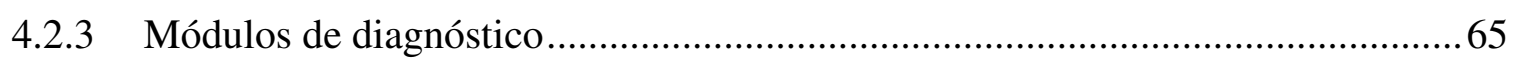

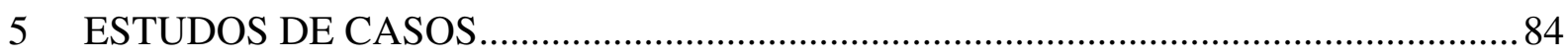

5.1 Curto-circuito no alimentador 14 e atuação não ideal da proteção de sobrecorrente e

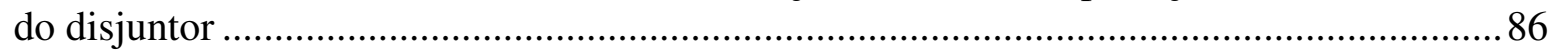

5.2 Curto-circuito em um enrolamento do transformador com atuação da proteção

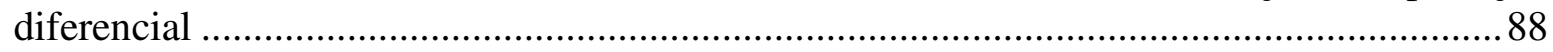

5.3 Arquitetura de hardware e software e desempenho do sistema................................89

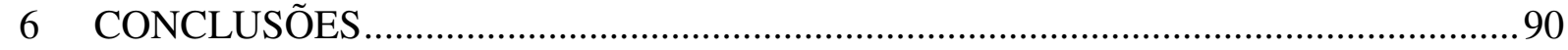

6.1 Conclusões sobre o sistema desenvolvido ......................................................... 90

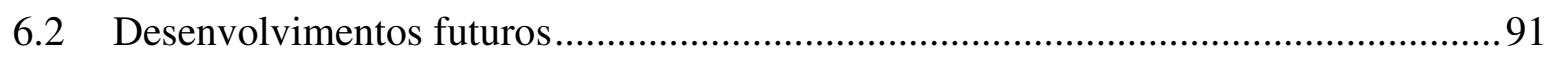

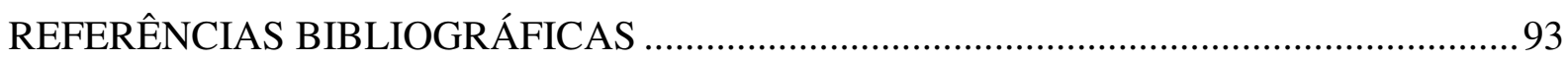

APÊNDICE A - Relação de dados de entrada para o sistema especialista.............................97 


\section{INTRODUÇÃO}

\subsection{Contexto}

Muito se fala atualmente sobre o conceito smart grid. Muito mais do que um conceito do momento, representa uma tendência mundial na área de sistemas elétricos de potência, integrando a rede elétrica com sistemas de comunicação, tecnologia de informação e automação de sistemas. Nos últimos anos, o Brasil tem aplicado grande esforço em pesquisa e desenvolvimento no setor com o objetivo de migrar o estado atual de tecnologia para um estado modernizado de redes inteligentes. Tendo isso em vista, a ANEEL desenvolveu o chamado Programa Brasileiro de Redes Elétricas Inteligentes (PDRI) (KAGAN, 2013), o qual teve a participação de diversas empresas e centros de pesquisa. Durante o ano de 2011, o PDRI organizou seis workshops e consolidou 33 relatórios com o objetivo de avaliar a situação das redes de distribuição de energia elétrica brasileiras, o estado da arte das tecnologias mundiais, os custos e benefícios da implantação de smart grids, entre outros temas. Dessa forma, procura-se que as redes elétricas tenham desempenho otimizado, gerando economia, facilidade de operação e expansão, participação ativa dos consumidores e, conforme é definido por Houseman (2013), que as redes possuam os quatro "R's" para promover uma qualidade otimizada no fornecimento de energia elétrica.

Houseman define que um smart grid deve ter quatro características, em inglês: resiliency (resiliência), reliability (confiabilidade), response (resposta) e repair (reparo). Resiliência é a capacidade de o sistema voltar ao seu estado de funcionamento normal após quaisquer problemas. Confiabilidade é a capacidade de o sistema manter funcionamento normal mesmo em situações adversas. Resposta é a capacidade de o sistema tomar ações rapidamente após quaisquer problemas. Finalmente, reparo é a capacidade de consertar ou substituir componentes com falha. É nesse contexto que este projeto de mestrado desenvolvido se encaixa.

Ultimamente, tem sido possível observar frequentes problemas no que diz respeito à continuidade no fornecimento de energia elétrica no sistema elétrico brasileiro. É importante que essas redes tenham altos índices de confiabilidade e resiliência, assim como deve proporcionar agilidade e manutenção ideais para um melhor funcionamento. Curtos-circuitos, desligamentos súbitos da rede elétrica e, consequentemente, longas paradas no fornecimento de energia, têm sido objetos frequentes de reclamações, o que nos serve de alerta para criar 
sistemas para uma manutenção ágil e correta no sistema elétrico. Estes sistemas devem também ser capazes de lidar com eventos não previstos que influam no desempenho do sistema de proteção, tais como aumentos inesperados da carga, falhas nos equipamentos e ajustes inadequados da proteção.

\subsection{Proposta: justificativas e objetivos}

Para um funcionamento adequado, o sistema de proteção da rede deve atuar sempre de maneira correta, atuando sempre e somente quando necessário e de forma seletiva, segura e rápida. Quaisquer eventos que ocorrerem, como por exemplo, curtos-circuitos e aberturas de disjuntores, devem ser analisados rapidamente de forma a se assegurar uma ágil tomada de decisões, quando necessárias. Além disso, é importante que essas análises pós-evento detectem anormalidades corretamente para proceder com as ações e reparos necessários, garantindo a manutenção adequada. No contexto dos quatro "R's" de Doug Houseman, para que seja possível manter a resiliência e confiabilidade de um sistema de proteção, é necessário criar sistemas que ajam nas áreas de resposta e reparo, promovendo assim, grandes melhorias na qualidade do fornecimento de energia elétrica.

Com a crescente utilização de relés de proteção modernos (IEDs - Intelligent Electronic Devices), uma quantidade cada vez maior de dados está sendo disponibilizada, tornando possíveis análises mais detalhadas. Contudo, dado tal fato, somado com a quantidade de subestações que uma concessionária de energia deve ser capaz de gerir, é recomendável a utilização de uma ferramenta que saiba lidar com esse grande volume de informações. Ademais, os dados brutos não carregam informações explícitas relativas ao estado do sistema de proteção, sendo necessária uma ferramenta que os interprete e proporcione um diagnóstico correto. Por fim, é sabido que, para que haja uma análise correta acerca de um evento de proteção, deve ser fornecido um conjunto de dados de entrada que possibilite um diagnóstico completo. Entretanto, nem sempre as informações de entrada consideradas importantes podem ser disponibilizadas, seja decorrente da utilização de relés que não possuam tais informações, a impossibilidade de resgatar dados em outros relés do sistema de proteção, falhas de comunicação ou mesmo pela não obrigatoriedade de disponibilização de certos dados pela norma utilizada para a fabricação do relé de proteção.

Neste trabalho é proposto um sistema automático e integrado que é ativado após a ocorrência de eventos relacionados à proteção do sistema elétricos. Além de utilizar algoritmos convencionais, o sistema utiliza inteligência artificial, no caso um sistema 
especialista, que se faz necessário por haver uma quantidade muito grande de situações que podem ocorrer na rede elétrica, tornando a programação convencional isolada incapaz de cercar todas as alternativas de forma eficiente. Além disso, facilitam-se abordagens que procurem lidar com a indisponibilidade ou ausência de informações a princípio consideradas essenciais para o diagnóstico completo do evento de proteção analisado.

\subsection{Organização da dissertação}

O capítulo 1 apresenta o contexto em que se encaixa o projeto desenvolvido que resultou nesta dissertação de mestrado, indicando razões para o desenvolvimento do mesmo e introduzindo um panorama do sistema implementado.

O capítulo 2 apresenta o estado da arte, com uma revisão da literatura que apresenta alguns dos principais trabalhos anteriores que se encaixam nos temas dessa dissertação e também uma breve revisão das tecnologias utilizadas neste trabalho.

O capítulo 3 apresenta a fundamentação teórica na qual o projeto foi embasado no que diz respeito a sistemas de automação, proteção de sistemas elétricos de potência e inteligência artificial, em especial, sistemas especialistas.

O capítulo 4 apresenta o sistema implementado. Primeiramente é mostrado o desenvolvimento da automação do sistema de análise da proteção, no qual serão mostrados os subsistemas de aquisição, armazenamento, pré-tratamento e processamento de dados. A seguir, é detalhado o subsistema de processamento de dados, focando na descrição do sistema especialista, o qual analisa a proteção de sobrecorrente, proteção diferencial para transformadores de potência, relés auxiliares de bloqueio para transformadores, religadores, disjuntores e curtos-circuitos.

O capítulo 5 mostra alguns estudos de casos realizados com os resultados apresentados e comentados.

O capítulo 6 oferece as conclusões finais e avanços que puderam ser alcançados com o sistema implementado, o qual foi instalado com sucesso em uma subestação de distribuição da CPFL (Companhia Paulista de Força e Luz). Além disso, são apontadas algumas possibilidades de estudo para o futuro. 


\section{ESTADO DA ARTE}

\subsection{Revisão bibliográfica}

\subsubsection{Sistemas de análise da atuação da proteção}

A modernização de subestações e o crescente avanço tecnológico têm permitido que o monitoramento das redes elétricas seja possível de forma cada vez mais eficiente. O diagnóstico de eventos de proteção pode fornecer uma boa visão acerca do funcionamento do sistema de proteção e da rede elétrica em momentos em que são altamente requisitados. Sistemas de análise da proteção permitem maior agilidade e facilidade nas tomadas de decisão pós-evento quando são automatizados. Popovic e Kezunovic (2012) explicam a automação da análise de dados de eventos de proteção, a qual inclui a conversão de medições para dados a serem analisados, o processamento de dados e a extração de conhecimento do tipo causaefeito. Há outros sistemas práticos na análise automática da proteção, como em Davidson, McArthur, et al. (2008) e em Popovic, Kezunovic e Krstajic (2013). Este último é voltado para a análise em sistemas de transmissão de energia. Ambos utilizam sistemas especialistas como base para a análise de eventos de proteção, os quais estão consolidados nos dias atuais como sistemas eficientes para a transformação de dados implícitos (dados de IEDs que aparentemente e individualmente não carregam muita informação analisável, especialmente por seres humanos) em dados explícitos (dados que carregam informação facilmente interpretável por seres humanos). A literatura na pesquisa sobre análise de eventos costuma construir modelos de conhecimento que descrevem o comportamento do que se quer analisar. O trabalho de Sherwali e Crossley (1996) também foca em sistemas de transmissão de energia, mas fornece mais explicações sobre como realizar o diagnóstico da proteção, o qual utiliza um sistema especialista baseado em dois modelos de conhecimento superficial e um modelo de conhecimento profundo. McArthur, McDonald, et al. (1996) apresentam os conceitos básicos sobre processamento de alarmes que podem ser recuperados de IEDs e também sobre raciocínio baseado em modelos, que é uma técnica de análise de dados para diagnosticar o comportamento real de um sistema comparando-o com o seu comportamento esperado. Davidson, McArthur e McDonald (2003) descrevem uma ferramenta que auxilia no desenvolvimento de sistemas que utilizam o raciocínio baseado em modelos para diagnosticar 
o sistema de proteção. Xin, Liao e Wen (2010) apresentam um sistema de processamento de alarmes e diagnóstico de faltas em subestações digitais.

A grande maioria dos trabalhos publicados na área de diagnóstico de eventos de proteção foca no diagnóstico de faltas. Um trabalho clássico referenciado ainda nos dias atuais pode ser encontrado em Girgis e Johns (1989) que apresenta um sistema especialista desenvolvido para identificar a seção na qual ocorreu a falta, classificá-la e selecionar algoritmos de localização de faltas. Há ainda outros métodos possíveis para o diagnóstico de faltas. Livani e Evrenosoglu (2012) propõem um método que utiliza a Transformada Wavelet Discreta (Discrete Wavelet Transform - DWT) e Support Vector Machine (SVM) aplicável tanto para sistemas de transmissão quanto para sistemas de distribuição. Em Torabi (2011) o sistema de classificação e localização de faltas em sistemas de distribuição utiliza a transformada de Clark e redes neurais. Em Gao, Chen e Shi(2010) é utilizada uma rede de Petri que utiliza informações de associações de disjuntores e equipamentos protegidos em conjunto com os valores de curto-circuito e ajustes de proteção.

É interessante ainda mencionar que sistemas de aquisição de dados para subestações em sistemas smart grid podem ser modelados diretamente por cada desenvolvedor, como é mostrado possível em Su e Wang (2010). Porém, vem sido estabelecida a utilização do Open Platform Communications (OPC - que substituiu o OLE for Process Control, após substituição da tecnologia $O L E$ pela Active $X$ ) para a aquisição de dados em IEDs como forma de fácil implementação e eficiente de aquisição de dados para implementação de sistemas multi-agentes, controle hierárquico e diagnóstico e monitoramento (SRINIVASAN, KUMAR e VAIN, 2013). Em Chen, Wang, et al. (2012) podemos encontrar uma forma de aquisição de dados que utiliza um sistema SCADA a partir de um software chamado Elipse E3, da Elipse Software, que também oferece a opção de utilização do OPC.

\subsubsection{Localização de faltas em alimentadores primários de distribuição}

Historicamente, a grande parte dos algoritmos de localização de faltas foi desenvolvida para sistemas de transmissão. Entretanto, mais recentemente têm surgido sistemas de localização de faltas para redes de distribuição, com métodos que foram demonstrados eficientes, como em Zhu, Lubkeman e Girgis (1997), Senger, Manassero Jr., et al. (2005) e Kagan, Matsuo, et al. (2003). Existem algumas particularidades na aplicação de localizador de faltas na distribuição em comparação com sistemas de transmissão, como o fato de que as redes de distribuição (principalmente as aéreas) possuem topologias com várias 
ramificações, possuem cargas distribuídas ao longo dos alimentadores, podem utilizar diferentes padrões de construção de linha ao longo de um alimentador, sofrem alterações constantes da configuração do alimentador ao longo do tempo, podem possuir resistência de falta da mesma ordem de grandeza que a resistência do arco elétrico na abertura de disjuntores, entre outros fatores. Encontram-se na literatura alguns diferentes sistemas propostos, desde os que utilizam dados de medição (provenientes de oscilografias) na origem do alimentador até outros que utilizam detectores de faltas instalados ao longo do alimentador.

A formulação baseada em Zhu, Lubkeman e Girgis (1997) é uma abordagem interessante a ser utilizada, a qual utiliza medições de tensões e correntes no início do alimentador. Neste método é proposto um algoritmo de cálculo de tensões e correntes em trechos de alimentadores em função do tipo de falta, dos parâmetros de linha e das correntes de carga. A procura do local de falta é iniciada na origem do alimentador, na subestação, onde se encontram os medidores de grandezas elétricas, que fornecem as tensões e as correntes no início do alimentador. As correntes de carga são calculadas pelo módulo de fluxo de potência. O algoritmo determina a distância mais provável do ponto de localização de falta no alimentador através de um processo de cálculo que envolve utilização de valores de impedâncias e correntes de trechos e permite também estimar a(s) impedância(s) de defeito. Partindo da subestação, o processo é repetido para trechos subsequentes do alimentador, até determinar o possível ponto de falta. Como os alimentadores primários são usualmente radiais e ramificados, o algoritmo pode achar múltiplos pontos a partir de uma mesma condição de medição. Utilizando outras informações disponíveis, podem-se efetuar análises para fazer distinção dos locais de defeito mais prováveis.

Há ainda métodos que usam técnicas de inteligência artificial, como em Dehghani e Nezami (2013), onde implementaram redes neurais, e outros que utilizam ondas viajantes, como em Feizifar, Haghifam, et al. (2013) e Ghaderi, Mohammadpour e Ginn (2015). O trabalho de Mirzaei, Kadir, et al. (2009) mostra uma revisão dos métodos encontrados para localização de faltas em redes de distribuição. 


\subsection{Revisão das tecnologias utilizadas}

\subsubsection{Transformada discreta de Fourier}

Para recuperar os valores dos fasores de variáveis analógicas discretizadas, aplica-se a transformada discreta de Fourier (DFT - Discrete Fourier Transform), a qual é capaz de converter um sinal no domínio do tempo para o campo da frequência. A DFT, a partir de uma lista de amostras de um sinal no tempo, converte-a para uma lista de números complexos que representam senóides ordenadas por frequência. A DFT pode ser definida por:

$$
y(k)=\sum_{n=0}^{N-1} x(n) * e^{(-i * 2 * p i * k * n / N)}
$$

onde:

$\begin{array}{ll}x & \text { é a lista de amostras de um sinal no domínio do tempo; } \\ y & \text { é a lista de números complexos no campo da frequência; } \\ N & \text { é a quantidade de amostras na janela de dados; } \\ k & \text { é o índice da frequência; } \\ n & \text { é uma amostra no domínio do tempo. }\end{array}$

Dos números complexos resultantes, podemos recuperar a magnitude e o ângulo de fase das componentes contínua, fundamental e harmônicas do sinal analógico discretizado. $\mathrm{O}$ método deve ser preferencialmente aplicado a janelas de ciclos completos em relação à componente fundamental.

É interessante deixar ressaltado o fato de que há outros métodos de análise de sinais para recuperação de informações como magnitudes e fases de um sinal analógico discretizado, como por exemplo, o método dos mínimos quadrados. Deve-se, no entanto, tomar cuidado se o sinal analisado contém apenas a componente fundamental ou se contém componentes de corrente contínuas ou harmônicas também. Considerando que a oscilografia contém dados de um sinal que já passou por um filtro anti-aliasing (na amostragem no IED), a DFT é uma solução que pode ser aplicada sem tais preocupações, pois fornece os resultados de todas as componentes até a harmônica $\left(N_{a} / 2-1\right)$, sendo $N_{a}$ a quantidade de amostras em um ciclo do sinal (critério de Nyquist). Dessa forma, se o interesse é em relação à componente fundamental, basta utilizar os resultados de magnitude e fase dessa componente. 


\subsubsection{OPC: Open Platform Communications}

O OPC é um padrão internacional de interoperabilidade e conectividade industrial que permite a transferência de dados entre equipamentos de automação e softwares. A OPC Foundation é responsável pela definição e manutenção das especificações do padrão OPC (OPC FOUNDATION, 2015). O OPC é baseado na arquitetura cliente/servidor onde o OPC faz o papel de servidor e os softwares de clientes.

Servidores OPC são comumente implementados em softwares que funcionam como gateways (pontes de ligação) entre protocolos de comunicação diferentes. Dessa forma, esses softwares realizam a aquisição de dados em dispositivos através de diferentes padrões de comunicação. Para isso, são também providos de diferentes tipos de clientes, como por exemplo, IEC 61850, IEC 60870-5-103, DNP3, Modbus, entre outros. O software realiza então a tradução dos dados de outros protocolos para itens OPC, que por sua vez podem ser utilizados por um cliente OPC.

Há diversos softwares disponíveis no mercado que realizam tais funções, como por exemplo o SCADA Data Gateway da Triangle MicroWorks (TRIANGLE MICROWORKS, 2015), o IEC 61850 OPC Server da Matrikon (MATRIKON, 2015) e o IOSERVER da IOServer (IOSERVER, 2015).

Para realizar a função de aquisição de dados em IEDs, a escolha pela utilização do OPC pode ser bastante vantajosa. Isso se deve principalmente ao baixo custo envolvido e à característica de padrão aberto para conectividade entre equipamentos, permitindo interoperabilidade entre diferentes fabricantes e entre protocolos diferentes de comunicação (desde que sejam compatíveis com o servidor OPC utilizado).

Outras soluções são possíveis para efetuar a aquisição de dados. Uma forma é recorrer a sistemas SCADA (Supervisory Control and Data Acquisition - Sistema de Supervisão e Aquisição de Dados). No entanto, não há necessidade de utilização de IHM (Interface Homem-Máquina) e nem de funções de controle que justifiquem seu uso quando a única função necessária é realizar a aquisição de dados. Outra opção é a implementação direta de um cliente no protocolo desejado. Se o IED se comunicar em IEC 61850, essa opção costuma ser mais custosa se o desenvolvedor não tiver bastante conhecimento da norma (que é bastante extensa), além da necessidade de dedicar mais tempo para a implementação do cliente IEC 61850 quando um gateway que realize tal função já poderia realizar a tarefa necessária. 


\subsubsection{Linguagens para sistemas especialistas e o CLIPS}

Linguagens de lógica costumam ser as bases de linguagens de programação para a construção de sistemas especialistas baseados em regras. Entre as principais linguagens de lógica utilizadas encontra-se o PROLOG, que se baseia na lógica de primeira ordem. O PROLOG expressa o conhecimento através de relações representadas por fatos e regras. É uma linguagem declarativa, ou seja, ao contrário de linguagens imperativas (ou procedurais), constrói os elementos e estruturas de um programa através de lógica de computação sem descrever sequências de ações, enunciados e comandos.

Há ainda ferramentas de software que integram mais funções, como é exemplo o CLIPS (C Language-Integrated Production System). O CLIPS é uma ferramenta que utiliza uma linguagem própria híbrida que combina linguagens procedurais, linguagens orientadas ao objeto e linguagens de lógica de forma a proporcionar maiores capacidades e flexibilidade de programação. Esta ferramenta para desenvolvimento de sistemas especialistas foi desenvolvida originalmente pela Software Technology Branch, NASA/Lyndon B. Johnson Space Center (Clips Reference Manual: Basic Programming Guide, 2008). É um software que recebe constantes atualizações e melhorias (em relação ao momento de publicação desse texto (maio de 2015), foi verificado que a última versão do CLIPS foi lançada em 26 de abril de 2015), sendo utilizado por milhares de pessoas em todo o mundo, além de ser de domínio público. Uma característica importante é a facilidade de programação a partir do uso de estruturas gramaticais e semânticas de fácil entendimento para um programador.

Há outras linguagens que podem ser utilizadas para a implementação de sistemas especialistas. Uma delas é a LISP, que é uma linguagem bastante flexível e poderosa por ser de propósito geral, incluindo uma grande quantidade de tipos e estruturas internas de dados. No entanto, é uma linguagem mais complexa de se aprender que as anteriores, incluindo a necessidade de descrever a forma como o computador resolverá um problema. Já o CLIPS e o PROLOG contam com um motor de inferência que descreve a forma como o computador resolverá o problema (WINGWIT: CONHECIMENTO COMPUTADOR, 2015). Outras linguagens incluem ferramentas como o JESS, que não é de domínio público, além do NeOpus e do JEOPS, que são menos utilizadas do que as linguagens apresentadas anteriormente. 


\section{SistemAS AUTOMATIZADOS, PROTEÇÃO E INTELIGÊNCIA ARTIFICIAL}

Este capítulo é responsável pela fundamentação teórica associada ao trabalho dessa dissertação, apresentando conceitos e aspectos relacionados a sistemas de aquisição de dados, proteção em subestações de distribuição de energia e inteligência artificial, que são as áreas abrangidas na implementação do sistema automático de análise da proteção.

\subsection{Sistemas de aquisição de dados}

\subsubsection{Introdução}

Serão apresentados neste item alguns aspectos importantes relacionados a sistemas de aquisição de dados. Atualmente, é tendência mundial utilizar IEDs que utilizem a norma IEC 61850 como padrão de comunicação de dados. Além disso, a utilização do padrão OPC em plataforma operacional Windows para interconectividade entre sistemas oferece facilidade e flexibilidade. A figura 1 apresenta uma arquitetura para um sistema de aquisição de dados. A seguir serão apresentados alguns aspectos importantes sobre este sistema.

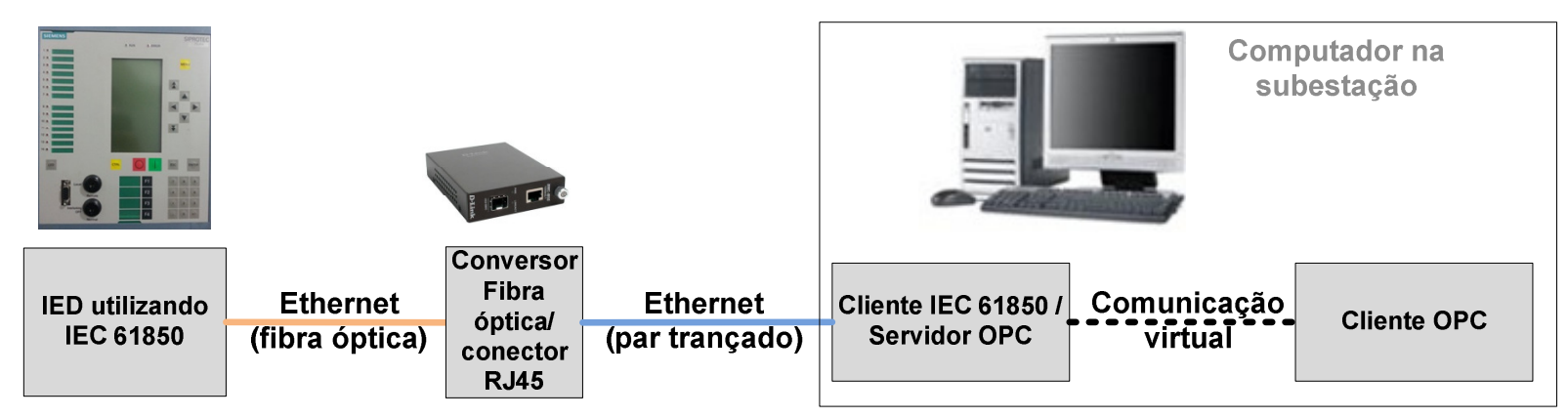

Figura 1 - Arquitetura para sistema de aquisição de dados

A norma IEC 61850 tem sido aceita como padrão mundial para comunicação entre dispositivos em subestações de energia. Ela permite interoperabilidade na integração entre equipamentos de diferentes fabricantes e independe da função que cada dispositivo exerce, seja proteção, controle, medição e/ou automação (SCHWEITZER ENGINEERING LABORATORIES, 2010).

Frequentemente, tem-se o cliente OPC no mesmo computador que o servidor OPC, havendo então apenas comunicação virtual entre eles. A comunicação entre os IEDs e o 
cliente OPC se dá através de um software funcionando como um gateway para tradução de protocolos que contém um cliente IEC 61850 e um servidor OPC. A comunicação entre os IEDs e o gateway comumente utiliza rede ethernet operando sobre TCP/IP. O meio físico na conexão dos relés de proteção digitais pode ser de fibra óptica, o que garante grande velocidade e capacidade na transmissão de dados, além de imunidade eletromagnética e baixas perdas (baixa atenuação do sinal) nas aplicações que a necessitem. Já para o computador na subestação, utilizam-se cabos de par trançado, já que costumam utilizar computadores industriais que utilizam padrão de conector RJ-45 para rede ethernet. Dessa forma, a utilização de um conversor entre rede de fibra óptica e rede de par trançado se faz necessária.

\subsubsection{Primeira etapa: IEC 61850: report control blocks}

Para essa primeira etapa da comunicação, o IED funciona como um servidor IEC 61850, enquanto que no gateway temos um cliente IEC 61850. Isso é realizado através dos chamados reports, que são normatizados pela IEC 61850, sendo mensagens de dados enviados pelo servidor IEC 61850 sem a necessidade de envio de pergunta (polling). O envio desses dados acontece por meio dos chamados report control blocks (RCB). Os RCBs controlam os reportes espontâneos de eventos. O cliente pode modificá-los através de atributos configurados em arquivos SCL (Substation Configuration Language), que contém a descrição do servidor para controle do envio de mensagens. Há dois tipos de RCB, sendo eles:

- Buffered report control blocks: Os eventos são reportados imediatamente. Caso haja perda de comunicação ou problemas relacionados ao controle no fluxo de transporte de dados, os dados a serem reportados são armazenados em um buffer até que o sistema de comunicação volte ao seu funcionamento normal, garantindo a não perda de dados;

- Unbuffered report control blocks: Os eventos são reportados imediatamente mas, se houver problemas no sistema de comunicação ou o fluxo de transporte de dados não for rápido o suficiente, pode haver perda de dados.

Os reportes são enviados quando há algum evento que foi configurado como trigger (disparo). Esses eventos são descritos por conjuntos de dados denominados data sets. Um data set é um conjunto de objetos e atributos de dados que são agrupados por um propósito dado pelo cliente. No caso de $R C B s$, definem o conjunto de dados a serem reportados quando 
ocorrer algum evento configurado para disparar o reporte. As condições de disparo que podem ser escolhidas são: mudança de valor de uma instância de dado; mudança da qualidade do valor de uma instância de dado; atualização da data de uma instância de dado; e integridade do RCB (IEC, 2010b). A figura 2 apresenta um exemplo de buffered report control block em uma arquitetura cliente-servidor. O cliente pode configurar os atributos do buffered $R C B$, como por exemplo os data sets e o tempo que o buffer espera para inserir os dados armazenados em um único reporte (em "BufTm”). Essas configurações são realizadas através do comando SetBRCBValues. Softwares que funcionem como gateway entre o IED com 61850 e um cliente 61850 costumam trazer uma interface amigável para configuração dos RCBs. No servidor são também armazenadas informações da estampa de tempo da geração do reporte, nome do Data Set que foi monitorado e reportado, entre outros, os quais podem ser recuperados pelo cliente através de um comando GetBRCBValues. O detalhamento completo do funcionamento dos $R C B s$ é dado em IEC(2010b).

Vale a observação de que existem também os chamados GOOSE control blocks. No entanto, mensagens GOOSE são utilizadas para envio com alta velocidade de pequenos pacotes de informações entre equipamentos na subestação. Dessa forma, costumam ser utilizadas em aplicações de tempo crítico, como lógicas de intertravamento e envios de Trip. A arquitetura usada já não é mais a cliente-servidor, e sim publisher-subscriber, na qual um equipamento publisher envia mensagens multicast para equipamentos subscribers que assinarem o recebimento dessas mensagens (IEC, 2010b). Além disso, como esse tipo de mensagem é utilizado em funções de alta prioridade em relés de proteção, não se costuma recomendar a configuração de GOOSE control blocks em sistemas não prioritários.

Finalmente, entre esta e a próxima etapa, o gateway traduz os objetos IEC $61850 \mathrm{em}$ itens OPC para o servidor OPC. 


\section{Client}

\section{Server}

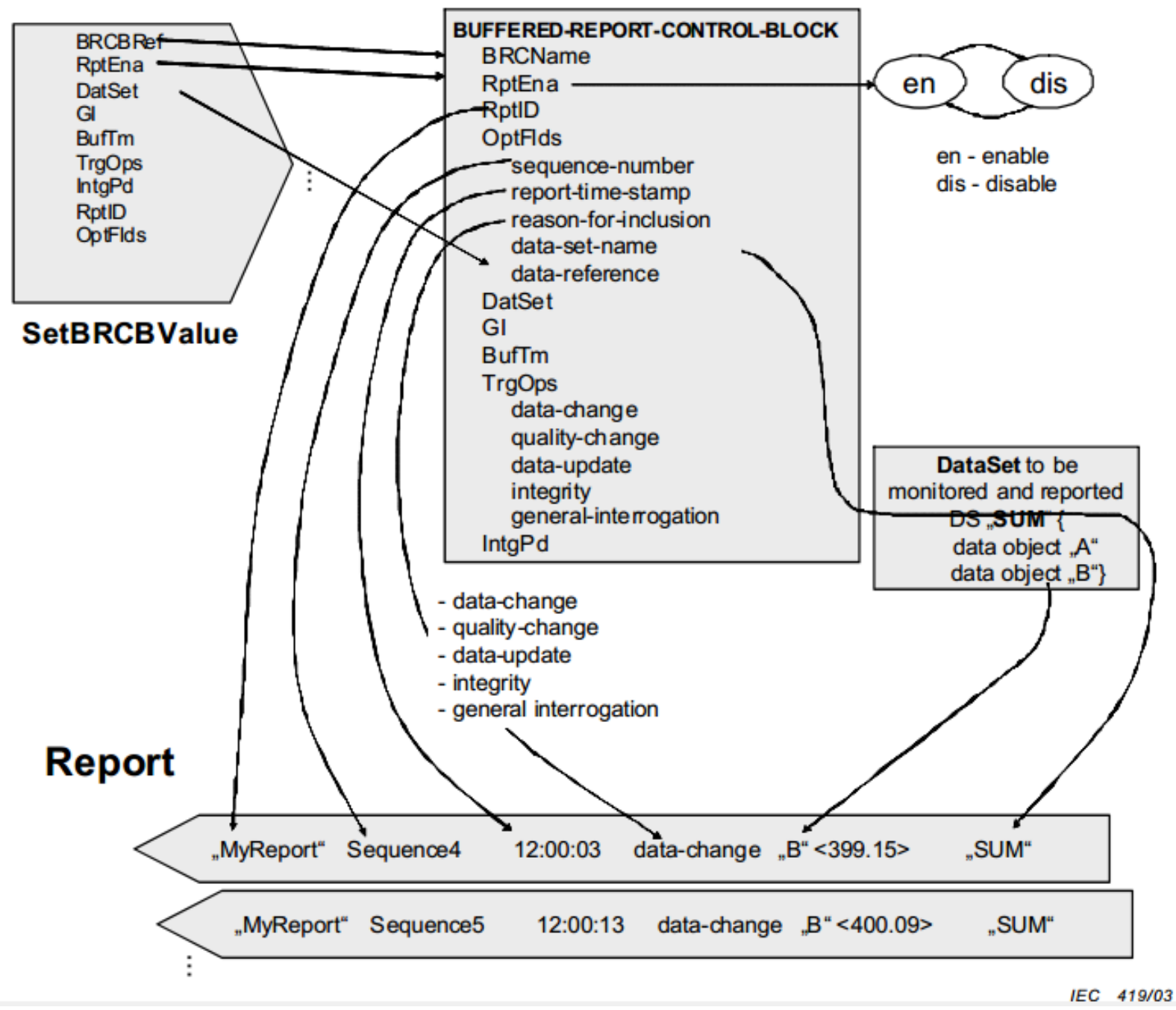

Figura 2 - Exemplo de buffered report control block em uma arquitetura cliente-servidor (fonte: "IEC 61850: International Standard - Communication Networks and Systems for Power Utility Automation, part 7-2,” 2010).

\subsubsection{Segunda etapa: callback entre servidor OPC e cliente OPC}

A segunda etapa da comunicação é constituída pelo servidor OPC e pelo cliente OPC. O cliente faz uma chamada ao servidor e, ao receber o retorno da chamada (callback), processa os dados. O retorno é feito pelo servidor no momento que lhe for conveniente. Em computação, um dos usos diz respeito ao gerenciamento de eventos, ou seja, quando ocorrer algum evento, o callback é realizado. Para isso, são criados grupos de dados, os quais serão repassados ao cliente quando ocorrer algum evento. Alguns desses dados são configurados como trigger, formando o que o servidor considera um evento. É possível notar a similaridade de funcionamento em relação aos report control blocks, detalhados no item anterior. 


\subsection{Proteção em subestações de distribuição}

\subsubsection{Introdução}

A proteção de sistemas elétricos de potência costuma ser vista com dois grandes objetivos:

- Garantir a segurança dos equipamentos e instalações do sistema elétrico, evitando os elevados custos da reposição desses materiais;

- Garantir a maior continuidade possível no fornecimento de energia elétrica, promovendo o rápido restabelecimento de energia quando necessário e o menor número de interrupções possíveis. Dessa forma, evitam-se danos aos consumidores com uma melhor qualidade de serviço.

No entanto, a esta visão é geralmente atribuída um sentido técnico. Atualmente uma outra visão tem ganhado bastante influência nesta área de estudo. Além de evitar custos levando em considerações os dois objetivos acima considerados, foi observado que um alto desempenho do sistema elétrico gera um valor agregado real para as companhias de energia elétrica (RUSH, 2011).

O custo de instalações elétricas de potência é bastante elevado. Se por um lado deve-se garantir confiabilidade e segurança no fornecimento de energia, por outro há o interesse de promover economia nos gastos associados ao funcionamento do sistema elétrico. Isso é feito primeiramente no dimensionamento das instalações, procurando um equilíbrio entre ambos os pontos. Para otimizar o retorno sobre o investimento, é importante maximizar a disponibilidade do sistema, levando em conta as restrições associadas à confiabilidade e segurança. A utilização de funções avançadas de qualidade de serviço e monitoramento das instalações elétricas permite o controle da proteção de forma a otimizar a disponibilidade do sistema elétrico.

\subsubsection{Proteção de sobrecorrente}

A proteção de sobrecorrente atua quando a corrente no circuito protegido ultrapassa um valor limite ajustado. Há dois tipos básicos de relés de sobrecorrente, os instantâneos e os temporizados. 


\subsubsection{Relés de sobrecorrente instantâneos}

Os relés instantâneos (código ANSI 50) atuam de imediato (sem atrasado intencional alocado) assim que é detectada uma corrente acima do valor ajustado. Esse tipo é geralmente utilizado para valores muito altos de corrente, quando não é tolerada por nenhum intervalo de tempo a permanência da corrente, a qual pode ser altamente prejudicial aos equipamentos e oferecer perigo às pessoas.

\subsubsection{Relés de sobrecorrente temporizados}

Os relés temporizados (código ANSI 51) são caracterizados por curvas tempo versus corrente. Atualmente, fabricam-se praticamente apenas relés digitais, nos quais são implementadas diversas funções de proteção e é possível alterar os parâmetros facilmente por meio de softwares. $\mathrm{O}$ atraso na atuação pode ser dado por tempo definido, de forma que apenas coordene com outros dispositivos de proteção com menos tempo de atuação. Além disso, pode também ser dado por equações que fazem a curva tempo versus corrente ter característica inversa. A norma IEC 60255 utiliza a seguinte equação geral:

$$
T=K_{1} \frac{M T}{\left[\left(\frac{I}{I_{p}}\right)^{K_{2}}-1\right]}
$$

onde:

T é o tempo de atuação do relé;

MT é o multiplicador de tempo relacionado à posição da curva do relé;

I é a corrente de curto-circuito referida ao secundário do TC;

$I_{p} \quad$ é a corrente pré-ajustada de pickup no secundário do TC;

$K_{1}$ e $K_{2} \quad$ são constantes relacionadas à característica inversa da curva utilizada.

A figura 3 mostra em um gráfico as curvas genéricas de atuação de um relé de sobrecorrente que segue a equação acima. O eixo das abscissas é dado pela corrente, enquanto que o eixo das ordenadas é dado pelo tempo de atuação do relé. 


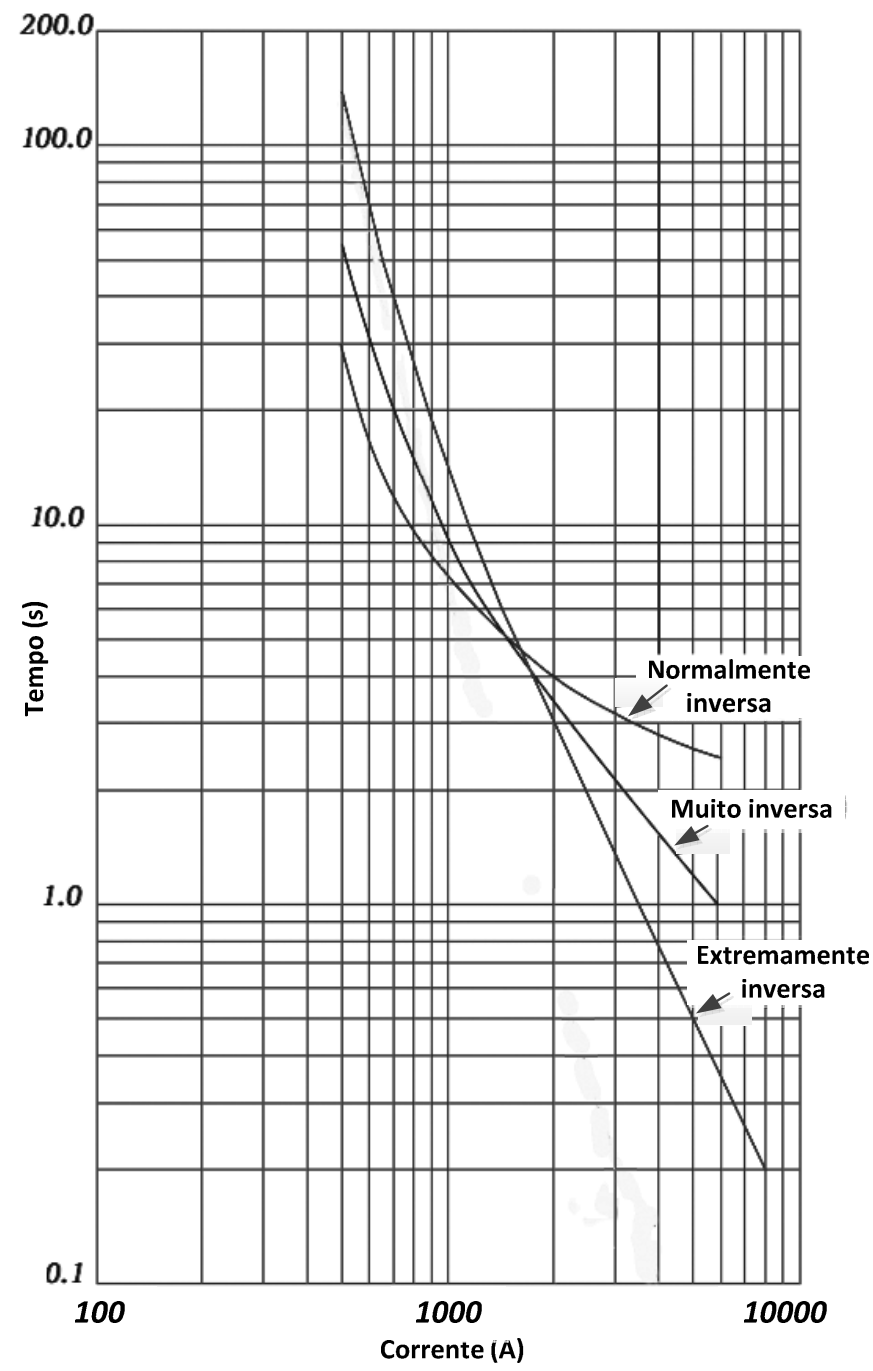

Figura 3 - Curvas características genéricas de um relé de sobrecorrente temporizado.

\subsubsection{Relé de religamento}

O relé de religamento (código ANSI 79) tem a função de comandar de maneira automática o religamento do disjuntor (código ANSI 52) após este ser operado pelo relé de sobrecorrente (códigos ANSI 50 e 51). Pode realizar um número de operações de religamento variando de um a quatro. Quando o relé de sobrecorrente atua causando a abertura do disjuntor, o relé de religamento é acionado iniciando o processo de religamento do disjuntor. É utilizado normalmente em linhas aéreas com a finalidade de evitar desligamentos prolongados causados por faltas temporárias. O esquema de proteção pode ser visualizado na figura 4. 


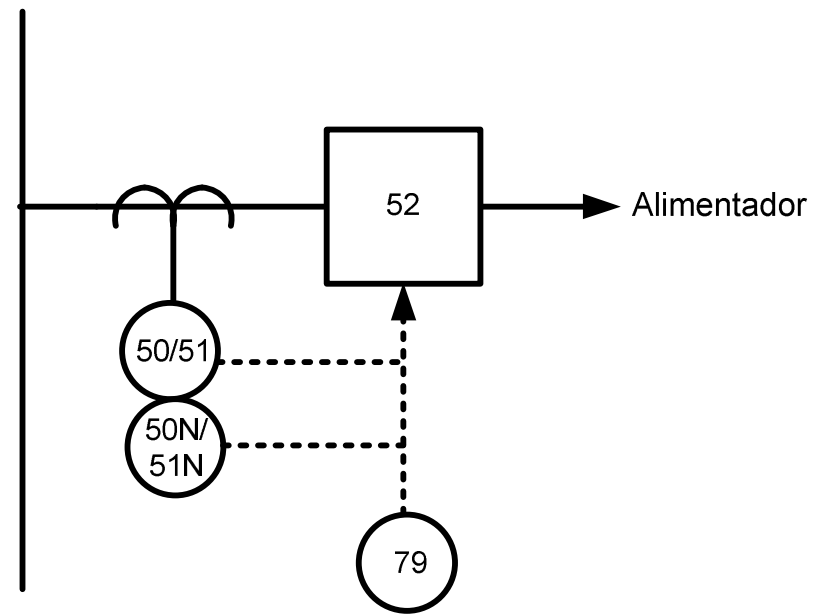

Figura 4 - Esquema de proteção do relé de religamento.

Caso o defeito seja temporário e extinto antes da última operação no ciclo programado, o religamento não fica bloqueado e o disjuntor fecha, restabelecendo o circuito. Esses relés são ajustados geralmente para um a três religamentos, devendo ser observadas as restrições operativas dos disjuntores. Se todos os religamentos forem utilizados e a falta ainda persistir, o disjuntor é aberto novamente e o religamento é bloqueado.

Para a proteção de tronco de alimentadores utilizando relés eletromecânicos geralmente utiliza-se o esquema com dois ou três relés de sobrecorrente de fase e um de neutro em conjunto com um relé de religamento. Nos relés digitais as funções de proteção e de religamento são incorporadas em um mesmo relé.

Há diferentes esquemas quanto à sequência de operações dos relés de sobrecorrente com o relé de religamento. O primeiro é mais comum entre as empresas que seguem padrões norte-americanos, e segue a filosofia chamada fuse saving. Nesta filosofia, o relé de sobrecorrente instantâneo é ajustado em valor relativamente baixo de maneira a atuar rapidamente antes de ocorrer a queima do fusível numa falta temporária em um ramal de alimentador de distribuição. Após a primeira operação, o relé de sobrecorrente instantâneo é bloqueado e, na sequência, os relés de sobrecorrente temporizados se encarregam de operar caso o defeito permaneça, mas o fusível é dimensionado de maneira a atuar antes da operação do relé temporizado. $\mathrm{O}$ ciclo completo de operação para o caso de um defeito permanente no tronco do alimentador é ilustrado na figura 5. 


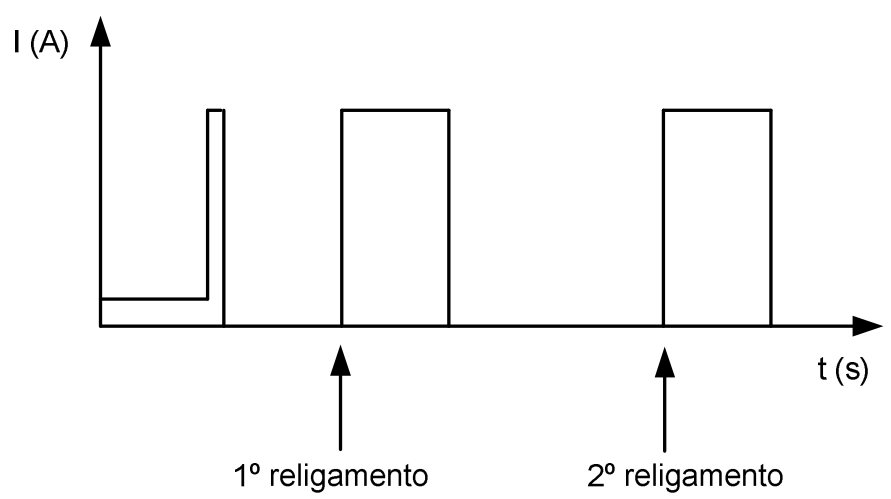

Figura 5 - Ciclo de operações de um relé de religamento de três operações com filosofia fuse saving.

No outro esquema de sequência de operações de relés de sobrecorrente com o relé de religamento não há bloqueio do relé de sobrecorrente instantâneo. Assim, no caso de um defeito permanente, as atuações dos relés de sobrecorrente se dão apenas com as unidades instantâneas (vide figura 6) ou apenas com as unidades temporizadas (vide figura 7), dependendo dos valores de ajustes e dos níveis das correntes de curto-circuito (supondo que os níveis das correntes se mantenham os mesmos durante a sequência).

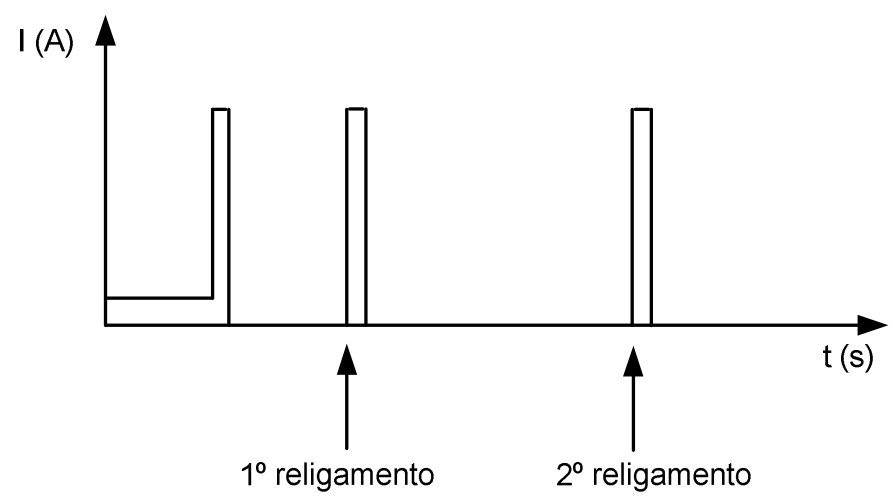

Figura 6 - Ciclo de operações de um relé de religamento de três operações sem filosofia fuse saving e em conjunto com apenas unidades instantâneas de sobrecorrente.

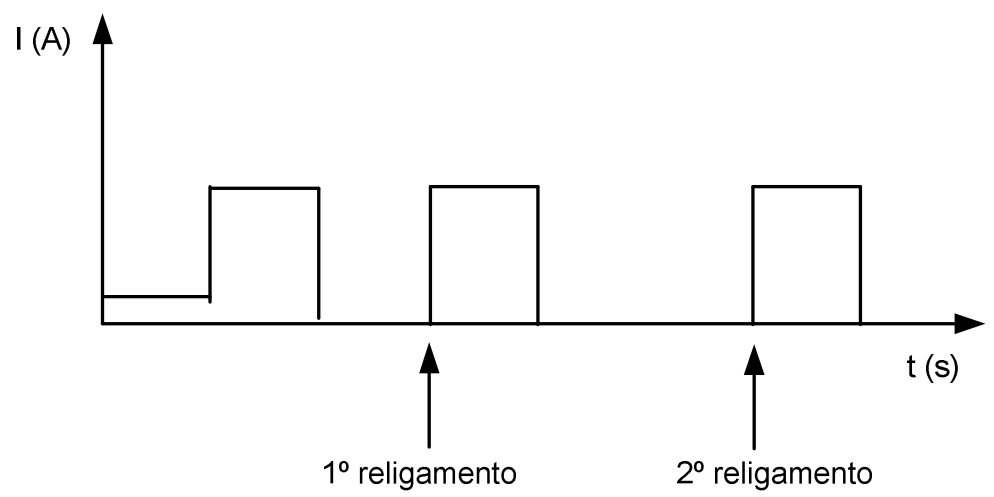

Figura 7 - Ciclo de operações de um relé de religamento de três operações sem filosofia fuse saving e em conjunto com apenas unidades temporizadas de sobrecorrente. 


\subsubsection{Proteção diferencial}

Para a proteção diferencial (código ANSI 87), o circuito protegido se localiza entre os transformadores de corrente (TC) de entrada e os de saída. Partindo do princípio de que o elemento protegido deve conduzir a mesma corrente nos dois lados, a proteção atua quando a diferença entre a corrente de entrada e a corrente de saída ultrapassa um valor limite ajustado, não importando a direção. Há dois tipos básicos de relés diferenciais. A figura 8 mostra o esquema unifilar geral para o relé diferencial amperimétrico. Tendo o TC1 e o TC2 a mesma relação real de transformação, seus circuitos secundários podem ser conectados para formar um circuito fechado com um elemento de medição M. Este elemento de medição costuma ser um relé de sobrecorrente instantâneo. Se o módulo da soma das correntes $I_{1}$ e $I_{2}$ (que em condições operacionais normais tem mesma intensidade e sentidos opostos) for maior que zero e a ponto de sensibilizar o relé, a proteção atua, conforme a seguinte equação, onde $I_{d i f}$ é chamada de corrente diferencial (SIEMENS, 2008):

$$
I_{d i f}=\left|I_{1}+I_{2}\right|>0
$$

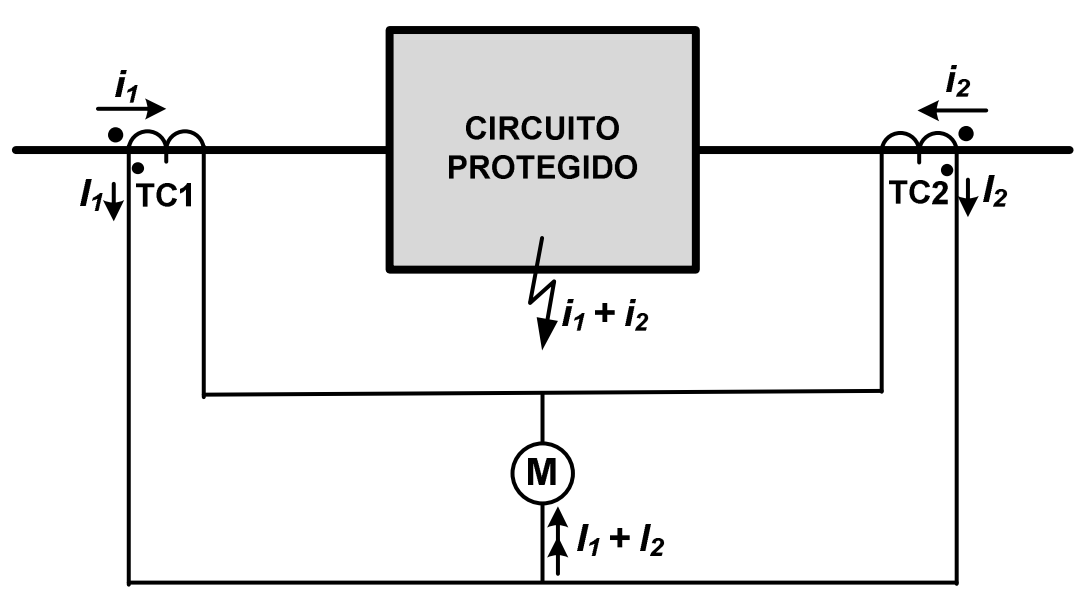

Figura 8 - Esquema unifilar de proteção diferencial.

O outro tipo de relé é o diferencial percentual, cujo esquema unifilar está apresentado na figura 9. Quando ocorre uma falta externa à zona do elemento protegido, uma alta corrente pode resultar em saturações diferentes nos TCs de entrada e saída, o que pode causar um fluxo de corrente no elemento de medição $M$. Se esta corrente for suficientemente alta para sensibilizá-lo, ocorre atuação indevida. Esse esquema de restrição de corrente visa evitar atuações indevidas devido a diferenças de saturação entre os TCs. Isso se torna mais 
importante ainda no caso de proteção diferencial de transformadores de potência (código ANSI 87T), em que os TCs têm relações de transformação diferentes no primário e no secundário do transformador de potência para que o circuito secundário possa ser acoplado. Nesse caso, os TCs têm curvas de saturação mais distantes entre si, o que favorece ainda mais condições diferentes de saturação. As equações a seguir calculam a corrente diferencial e a corrente de restrição.

$$
\begin{gathered}
I_{\text {dif }}=\left|I_{1}+I_{2}\right| \\
I_{\text {res }}=\left|I_{1}\right|+\left|I_{2}\right|
\end{gathered}
$$

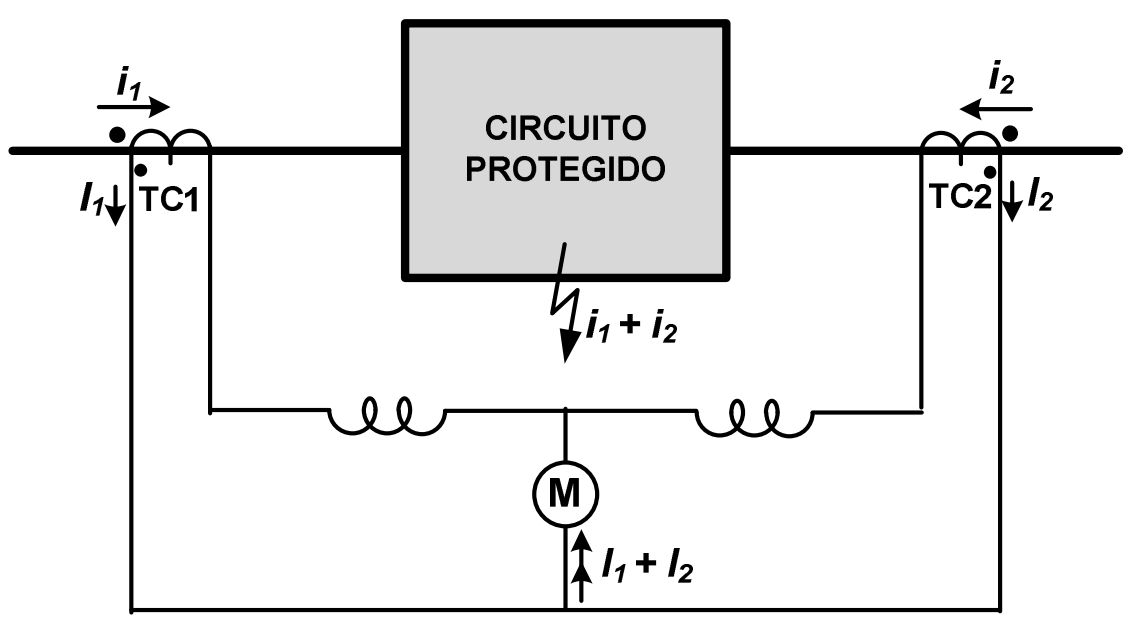

Figura 9 - Esquema unifilar de proteção diferencial com bobinas de restrição.

A figura 10 mostra a característica da proteção do relé diferencial. O eixo das abscissas é dado pela corrente de restrição, enquanto que o eixo das ordenadas é dado pela corrente diferencial. Uma reta ajustável divide o plano em duas regiões, uma de atuação e outra de não atuação. Os relés digitais modernos geralmente permitem o ajuste de mais de uma reta, de forma a flexibilizar e otimizar a proteção diferencial, assim como evitar atuações indevidas, de acordo com diversas condições do sistema elétrico. 


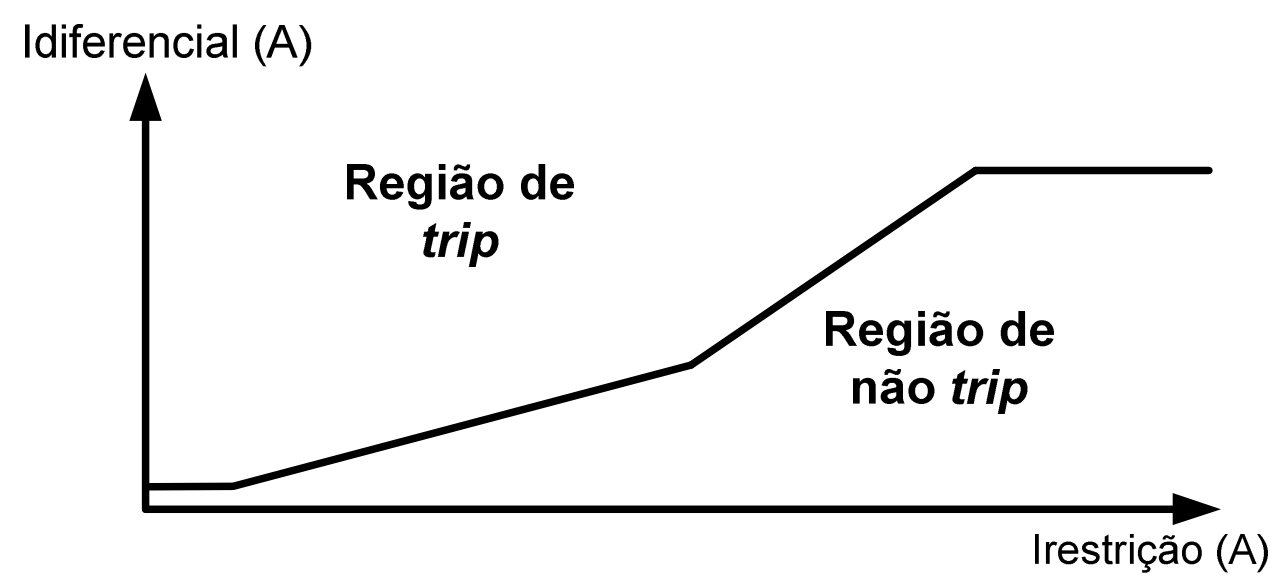

Figura 10 - Característica de operação do relé diferencial.

\subsubsection{Proteção de bloqueio}

Os relés de bloqueio recebem sinais de outros relés de proteção, em geral os de sobrecorrente (inclusive o relé diferencial, que utiliza um relé de sobrecorrente instantâneo em conjunto). São responsáveis por abrir disjuntores e bloquear o religamento em condições de falta. O disjuntor só poderá então ser fechado novamente se o relé de bloqueio for liberado por um operador autorizado.

\subsubsection{Discordância de polos em disjuntores}

O tamanho dos componentes e o espaçamento entre as fases nos disjuntores de alta tensão e, muitas vezes, em disjuntores de média tensão, faz com que sejam usados mecanismos de operação independentes para cada fase do disjuntor. Uma discordância de polos pode ocorrer sempre que uma ou duas das fases na abertura ou fechamento de disjuntores Tripolares demorem mais que o tempo estabelecido para tal. Pode ocorrer também no caso de uma ou duas fases não abrirem/fecharem. Dessa forma, a divergência entre os tempos de abertura nas três fases pode ocasionar uma discordância de polos no disjuntor.

\subsubsection{Curto-circuito}

A seguir serão apresentadas as condições de curtos-circuitos em termos das componentes de fase e em termos das componentes simétricas. Para os itens a seguir, será considerado que as tensões das fontes equivalentes das fases A, B e C são equilibradas. Além 
disso, será utilizada a seguinte notação, onde as grandezas são vistas no ponto da falta, quando aplicável:

- $Z_{F}$ : impedância de falta;

- $Z_{A}$ : impedância equivalente da fase A;

- $Z_{B}$ : impedância equivalente da fase $\mathrm{B}$;

- $Z_{C}$ : impedância equivalente da fase $C$;

- $Z_{0}$ : impedância equivalente de sequência zero;

- $Z_{1}$ : impedância equivalente de sequência positiva;

- $Z_{2}$ : impedância equivalente de sequência negativa;

- $E$ : tensão equivalente;

- $v_{0}$ : tensão equivalente de sequência zero;

- $v_{1}$ : tensão equivalente de sequência positiva;

- $v_{2}$ : tensão equivalente de sequência negativa;

- $I_{A}$ : corrente equivalente de sequência de fase A;

- $I_{B}$ : corrente equivalente de sequência de fase B;

- $I_{C}$ : corrente equivalente de sequência de fase $\mathrm{C}$;

- $I_{0}$ : corrente equivalente de sequência zero;

- $I_{1}$ : corrente equivalente de sequência positiva;

- $I_{2}$ : corrente equivalente de sequência negativa;

- $I_{C C}$ : corrente de curto-circuito;

A impedância de falta $Z_{F}$ é proveniente de arcos elétricos gerados durante a falta entre fases ou entre fases e terra e resistência de terra, quando esta está envolvida.

Por fim, será considerado o operador $\propto$, como segue:

$$
\propto=1 \underline{120^{\circ}}=-\frac{1}{2}+j \frac{\sqrt{3}}{2}
$$




\subsubsection{Curto-circuito trifásico}

Considerando $Z_{F}$ igual nas três fases e que as tensões nas três fontes equivalentes são equilibradas, o curto-circuito trifásico é equilibrado, podendo ser representado apenas pelo diagrama de sequência positiva (OLIVEIRA, SCHMIDT, et al., 2000), conforme figura 11.
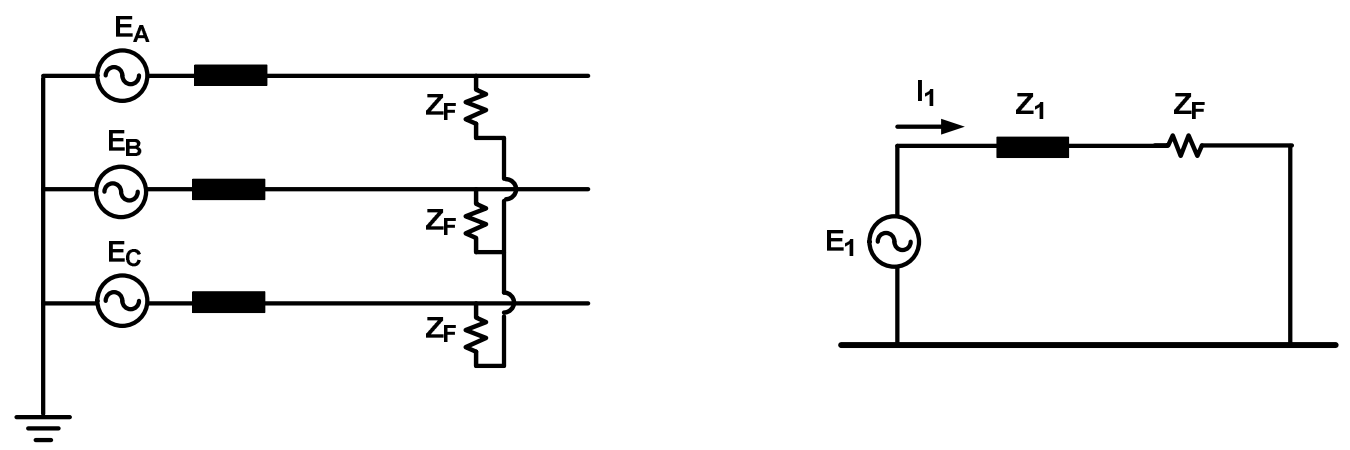

Figura 11 - Circuito trifásico em componentes de fase (a) e componentes simétricas (b).

Nessa situação temos:

$$
\begin{gathered}
I_{A}+I_{B}+I_{C}=0 \\
I_{A}=\propto^{2} I_{B}=\propto I_{C} \\
I_{C C}=I_{A}=I_{1}
\end{gathered}
$$

Do diagrama sequencial, temos que:

$$
I_{1}=\frac{E}{Z_{1}+Z_{F}}
$$

Assim:

$$
I_{C C}=\frac{E}{Z_{1}+Z_{F}}
$$

\subsubsection{Curto-circuito dupla-fase}

Como o curto-circuito não envolve a terra, não há caminho para a corrente $I_{o}$, não havendo portanto componente de sequência zero. A figura 12 mostra um curto-circuito duplafase envolvendo as fases $\mathrm{B}$ e C. 

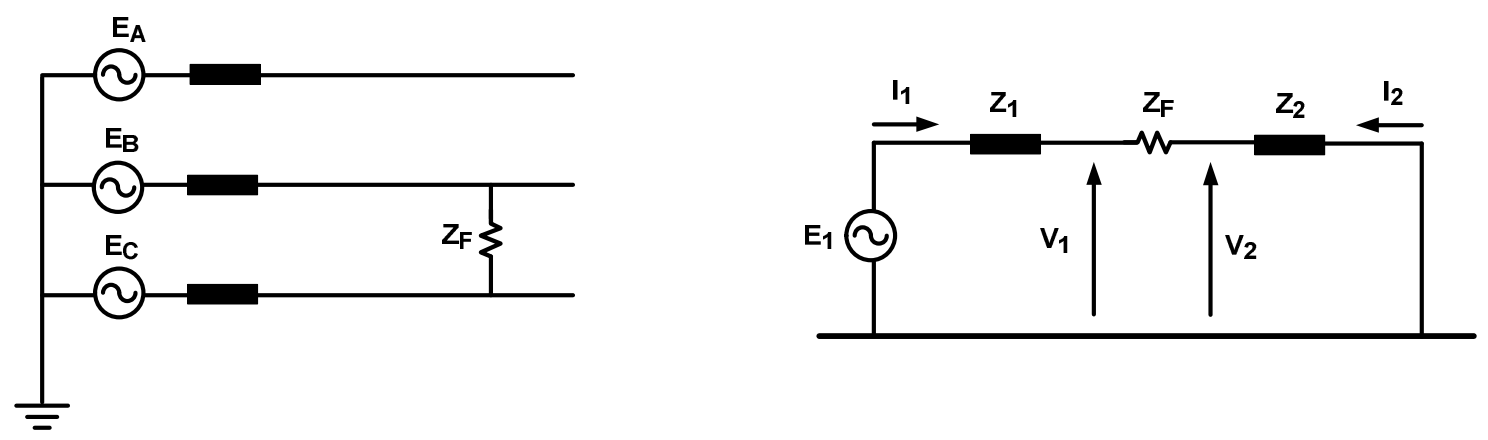

Figura 12 - Circuito dupla-fase em componentes de fase (a) e componentes simétricas (b).

Nessa situação temos:

$$
\begin{gathered}
I_{A}=0 \\
I_{B}=-I_{C} \\
I_{C C}=I_{B}=\propto^{2} I_{1}+\propto I_{2}
\end{gathered}
$$

Do diagrama sequencial, temos que:

$$
I_{1}=-I_{2}=\frac{E}{Z_{1}+Z_{2}+Z_{F}}
$$

Assim, considerando $Z_{1}=Z_{2}$ :

$$
I_{C C}=-j \sqrt{3} \frac{E}{2 Z_{1}+Z_{F}}
$$

\subsubsection{Curto-circuito dupla-fase-terra}

No curto-circuito dupla-fase-terra, há a presença das componentes de sequência zero, positiva e negativa, conforme figura 13 .
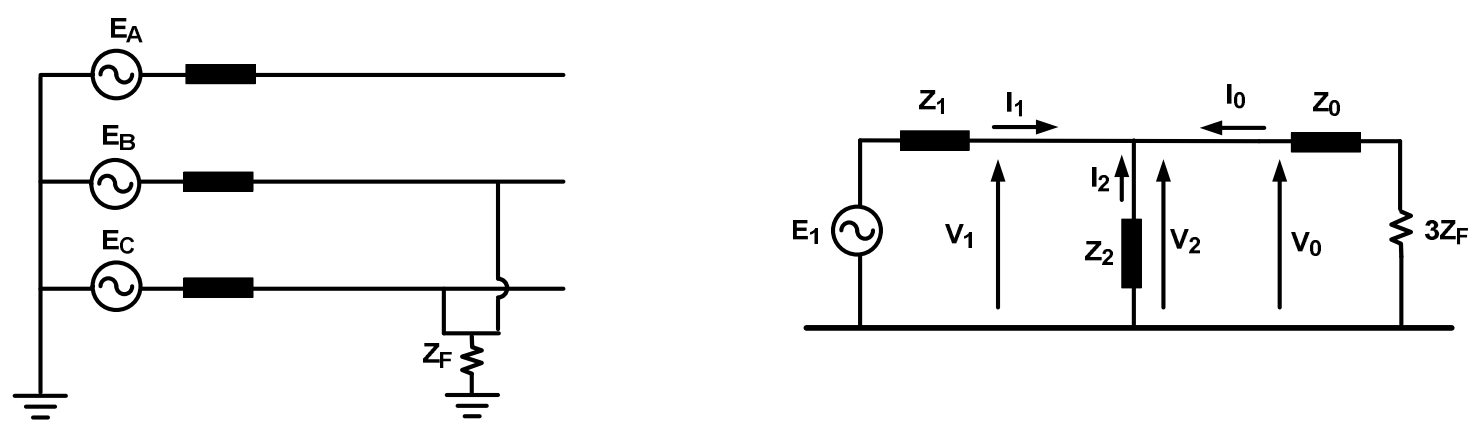

Figura 13 - Circuito dupla-fase-terra em componentes de fase (a) e componentes simétricas (b). 
Nesta situação temos:

$$
I_{C C}=I_{B}+I_{C}
$$

Do diagrama sequencial, temos que:

$$
\begin{gathered}
I_{1}=\frac{E}{Z_{1}+Z_{2} / /\left(Z_{0}+3 Z_{F}\right)}=\frac{E}{Z_{1}+\frac{Z_{2}\left(Z_{0}+3 Z_{F}\right)}{Z_{2}+\left(Z_{0}+3 Z_{F}\right)}} \\
I_{1}=\frac{E\left(Z_{2}+Z_{0}+3 Z_{F}\right)}{Z_{1} Z_{2}+Z_{1}\left(Z_{0}+3 Z_{F}\right)+Z_{2}\left(Z_{0}+3 Z_{F}\right)}
\end{gathered}
$$

Para simplificar a notação, será considerado o seguinte:

$$
Z_{D}=Z_{1} Z_{2}+Z_{1}\left(Z_{0}+3 Z_{F}\right)+Z_{2}\left(Z_{0}+3 Z_{F}\right)
$$

Dessa forma, $I_{1}$ resulta:

$$
I_{1}=\frac{E\left(Z_{2}+Z_{0}+3 Z_{F}\right)}{Z_{D}}
$$

De (19), temos que:

$$
E=\frac{I_{1} * Z_{D}}{\left(Z_{2}+Z_{0}+3 Z_{F}\right)}
$$

Além disso:

$$
\begin{gathered}
v_{2}=E-Z_{1} I_{1} \\
-Z_{2} I_{2}=E-Z_{1} I_{1} \\
-I_{2}=\frac{E-Z_{1} I_{1}}{Z_{2}} \\
I_{2}=-\frac{E\left(Z_{0}+3 Z_{F}\right)}{Z_{D}}
\end{gathered}
$$

Utilizando raciocínio análogo, temos:

$$
I_{0}=-\frac{E Z_{2}}{Z_{D}}
$$

Passando as componentes simétricas para as componentes de fase, temos: 


$$
\begin{gathered}
I_{A}=0 \\
I_{B}=\frac{-3 E Z_{2}-j \sqrt{3} E Z_{2}-2 j \sqrt{3} E\left(Z_{0}+Z_{F}\right)}{2 Z_{D}} \\
I_{C}=\frac{-3 E Z_{2}+j \sqrt{3} E Z_{2}+2 j \sqrt{3} E\left(Z_{0}+Z_{F}\right)}{2 Z_{D}}
\end{gathered}
$$

A corrente de curto-circuito resulta:

$$
I_{C C}=I_{B}+I_{C}=-\frac{3 E Z_{2}}{Z_{D}}
$$

Considerando $Z_{1}=Z_{2}$, temos

$$
I_{C C}=-\frac{3 E Z_{1}}{Z_{D}}
$$

\subsubsection{Curto-circuito fase-terra}

O curto-circuito fase-terra contém as componentes de sequência zero, positiva e negativa, sendo representada segundo a figura 14 .
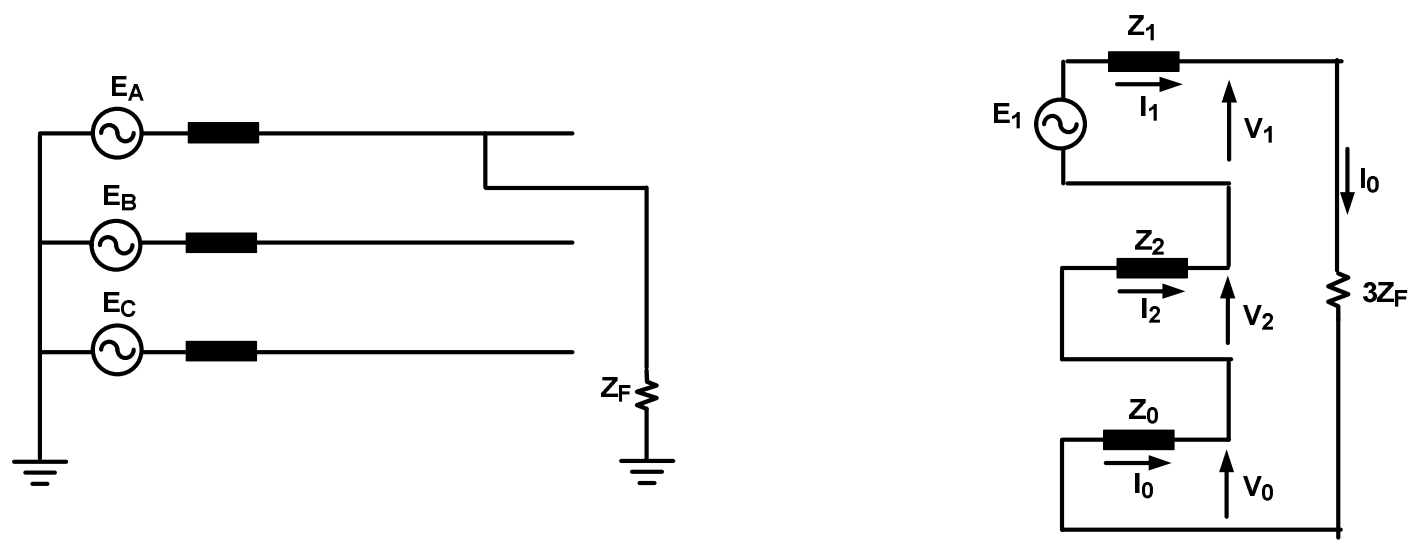

Figura 14 - Circuito fase-terra em componentes de fase (a) e componentes simétricas (b).

Nessa situação, temos:

$$
\begin{gathered}
I_{B}=I_{C}=0 \\
I_{C C}=I_{A}=I_{0}+I_{1}+I_{2}
\end{gathered}
$$

Do diagrama sequencial, temos que: 


$$
I_{0}=I_{1}=I_{2}=\frac{E}{Z_{0}+3 Z_{F}+Z_{1}+Z_{2}}
$$

Considerando $Z_{1}=Z_{2}$, de (28) e (29) temos:

$$
I_{C C}=\frac{3 E}{2 Z_{1}+Z_{0}+3 Z_{F}}
$$

\subsection{Inteligência artificial}

A inteligência artificial é um ramo da ciência da computação que procura dar capacidades a máquinas e softwares para resolver problemas para os quais normalmente os seres humanos são mais capacitados. No entanto, os estudos na área vão além desse conceito, procurando métodos que expandam a capacidade mental do ser humano, incluindo raciocínio, compreensão, reconhecimento, entre outras características. A forma como um método funciona não é necessariamente uma imitação de como um ser humano realiza suas tarefas, mas procura entregar resultados similares ou melhores que seres humanos, promovendo maior eficiência na resolução de problemas (HOPGOOD, 2011).

\subsubsection{Aspectos gerais}

Realizar a análise de uma quantidade muito grande de dados e levar em conta a enorme quantidade de combinações que podem formar cenários diferentes é uma tarefa muitas vezes inviável para ser processada por meio de algoritmos convencionais (por exemplo, algoritmos procedurais) e, se ainda assim for possível, muito demorada. Para isso, técnicas de inteligência artificial podem ser utilizadas.

A inteligência artificial provê métodos capazes de fornecer resultados similares aos apresentados por seres humanos, procurando, no entanto, ser mais rápida e eficiente. Um especialista humano em certa área não necessita analisar todas as combinações possíveis de situações para prover um diagnóstico final sobre um evento. O humano sabe inferir a partir de apenas alguns dados quais são os casos mais prováveis, excluindo a maior parte das combinações. Dessa forma, apenas tais casos serão analisados.

Para isso, diversas técnicas de inteligência artificial existem para que a eficiência e confiabilidade aumentem. Primeiramente, sistemas computacionais não estão sujeitos a erros 
humanos, resultantes, por exemplo, de cansaço ou estresse, que podem diminuir a capacidade de sucesso de raciocínio. Além disso, seres humanos estão sempre mais sujeitos a cometerem erros de inferência conforme a situação. Algoritmos computacionais são consistentes e não estão sujeitos a prover análises diferentes (e errôneas). Por outro lado, é um humano que programa tais algoritmos, ou seja, a confiabilidade do sistema inteligente só será garantida se não houver erros humanos na própria programação. Um segundo fator importante na escolha do uso de técnicas de inteligência artificial é a eficiência em termos de custo. A não necessidade de investir homens-hora para a análise de cada evento resulta em uma grande economia financeira para uma empresa. O custo provém apenas do investimento realizado para a implementação do sistema inteligente e, após, para as manutenções/atualizações que sejam necessárias conforme o tempo passa e mudanças ocorrem. Essa eficiência também vem de um terceiro fator vantajoso, que é a eficiência em relação ao tempo. Algoritmos inteligentes são capazes de realizar o mesmo trabalho de um humano em um tempo extremamente menor, o que é decorrente da capacidade atual de processamento computacional.

\subsubsection{Sistemas especialistas baseados em regras de produção}

Sistemas especialistas formam um ramo da inteligência artificial que procura apresentar desempenho comparável ao de seres humanos na execução de tarefas através de sistemas computacionais aliados aos conhecimentos de especialistas humanos. Outros ramos da inteligência artificial costumam lidar com aspectos mais genéricos de pensamentos gerados por um computador. Já sistemas especialistas são aplicações mais focadas em problemas específicos, com conhecimentos especializados, utilizando uma base de conhecimento composta por fatos, regras e modelos (REFERENCE FOR BUSINESS) em conjunto com um mecanismo de inferência.

\subsubsection{Benefícios}

Sistemas especialistas são vantajosos quando se deve lidar com uma complexa e grande quantidade de dados, sem fazer com que o tempo dedicado para o processamento seja alto, o que aumenta a produtividade. As principais características ainda serão descritas no item 3.3.2.3. 
A principal qualidade de sistemas especialistas é a possibilidade de registrar conhecimentos que apenas especialistas em determinada área teriam. Isso faz com que não haja necessidade de contratar especialistas humanos para cada evento que será analisado. Mesmo na presença de especialistas humanos, o sistema serve como auxiliador e encaminhador de decisões. Além disso, comparando-se com humanos, caracteriza-se pela durabilidade do conhecimento, não havendo esquecimentos ou necessidade de prática para evitar isso.

Um dos aspectos vantajosos comentados anteriormente foi a eficiência em relação a custos quando se utilizam ferramentas inteligentes. Neste aspecto, o sistema especialista se torna uma das ferramentas mais poderosas, pois sua manutenção/atualização é muito mais simples. Isso decorre da possibilidade de adicionar regras em sua base de conhecimento sem a necessidade de se preocupar com as demais regras do sistema, isto é, não são necessárias alterações nas regras já estabelecidas para que atualizações sejam implementadas levando em conta, por exemplo, novos dados que podem ser analisados ou novos casos que podem acontecer. Isso decorre da seguinte característica: um sistema especialista é formado por uma base de conhecimentos (regras e fatos) e um motor de inferência que toma decisões sobre quais regras aplicar e como aplicá-las a partir dos fatos existentes. No entanto, estas duas partes estão desvinculadas, ou seja, a adição ou remoção de regras e fatos não altera a forma como o motor funciona.

Um benefício adicional é a possibilidade de utilização de sistemas especialistas para treinar novos funcionários a partir de simulações de diferentes situações e posterior tomada de decisões.

\subsubsection{Pontos negativos}

Assim como qualquer sistema e qualquer algoritmo, sistemas especialistas também possuem algumas desvantagens. Se por um lado possui a capacidade de substituir especialistas humanos, por outro lado depende de humanos para que sejam programados. Um sistema mal projetado pode resultar em análises errôneas. Ademais, o conhecimento sempre será limitado àquilo que foi programado, ou seja, ao contrário de humanos, tem um limite de capacidade de raciocínio, o que dificulta lidar com situações novas.

Outro ponto de dificuldade é quando se deve lidar com problemas ambíguos, nos quais uma decisão de qual caminho tomar não é tão óbvia. A maioria dos sistemas especialistas não consegue lidar com essas situações, dependendo muito da experiência do programador para 
organizar estratégias que eliminem essas ambiguidades. Além disso, no caso de decisões erradas, sistemas especialistas não possuem uma capacidade natural de aprendizado, isto é, dependem de intervenção humana para aprender com os erros.

\subsubsection{Conceitos e características}

Sistemas especialistas são sistemas computacionais que desempenham as funções do raciocínio empregado por especialistas humanos na resolução de problemas complexos e que exigem perícia humana através de conhecimentos e procedimentos inferenciais. Segundo Farreny (1985), para que um sistema seja considerado especialista, deve apresentar três características básicas:

- Linguagem de representação dos conhecimentos;

- Base de conhecimentos;

- Motor de inferência

Serão descritos a seguir os componentes acima citados e suas funções:

\subsection{Linguagem de representação dos conhecimentos}

Uma linguagem de representação é necessária para a formalização dos conhecimentos. Dessa forma, os mecanismos de manipulação e as estruturas sintáticas são formalmente descritas. Dois aspectos envolvem a linguagem de representação dos conhecimentos.

O primeiro aspecto é a utilização de uma linguagem formal de programação. Linguagens de lógica costumam ser as bases de linguagens de programação para a construção de sistemas especialistas baseados em regras. Algumas linguagens possíveis são PROLOG, LISP, CLIPS, JESS, entre outras.

O segundo aspecto relaciona-se com a forma como o conhecimento é representado. As linguagens de programação costumam deixar flexíveis ao programador formalizar a maneira como o conhecimento será descrito. Isso leva em conta a sintaxe de representação do conhecimento, ou seja, como os fatos são escritos, e também a forma como as regras são implementadas. A representação do conhecimento deve ser formulada de maneira que seja de fácil compreensão ao ser humano, tornando possível e facilitando a interpretação. 


\subsection{Base de conhecimentos}

Responsável por manter todos os conhecimentos do sistema especialista, a base de conhecimentos deve ser robusta, de forma a processar suas funções sem o conhecimento explícito de todas as combinações de situações possíveis. Além disso, uma boa implementação constrói um sistema generalizável, de forma que se adapte a diversas situações e interpretações.

- Fatos

São representações de conhecimento fixo que utilizam os dados de entrada e conhecimentos gerados durante o processamento do sistema especialista;

- Regras de produção

As regras de produção representam conhecimento de forma modular, ou seja, representam uma fração de conhecimento independente das outras frações. Além disso, são (e devem ser) compreensíveis com facilidade, de forma a se tornarem fáceis de modificar. Uma implementação ideal deve tornar fácil a manutenção de regras, assim como a exclusão e adição, sem que influencie o resto do sistema.

Regras de produção são regras causais que apresentam forma "condição-ação", ou, similarmente, forma "if-then". Se as condições de uma regra estiverem satisfeitas no estado corrente do mundo, ou seja, se o estado em que o sistema se encontra naquele instante tornar tais condições verdadeiras, a produção é desencadeada, sendo então as ações executadas. Isso pode ser enxergado também da seguinte forma: estando as premissas de uma regra satisfeitas, a regra é disparada, produzindo resultados e conclusões (intermediárias ou finais). Esses resultados e conclusões se dão na forma de fatos, os quais serão utilizados para determinar o novo estado atual do mundo, de forma a desencadear o disparo de outras regras ou chegar a uma conclusão final.

Sistemas especialistas baseados em regras de produção utilizam cadeias de lógicas do tipo condição-ação. Dessa forma, conforme regras são disparadas, o mundo corrente é alterado, satisfazendo outras regras, sucedendo dessa maneira em uma cadeia de produção. Tais sistemas são capazes de resolver problemas complexos utilizando regras relativamente simples, fazendo a combinação dos resultados e regras de maneira apropriada a partir de mecanismos de inferência. 
- Memória de Trabalho

A memória do trabalho é o conhecimento adquirido durante o processamento do sistema especialista e tem caráter temporário e dinâmico. Representa o estado do problema em dado instante do processamento, permitindo a comunicação entre regras junto ao motor de inferência.

\subsection{Motor de inferência de regras de produção}

Também chamado de máquina de inferência, é a parte responsável por substituir o papel do raciocínio de um especialista, determinando como serão processadas as informações contidas nos fatos e regras de produção. O motor de inferência determina quais regras apresentam maior relevância para serem processadas de acordo com o estado da memória de trabalho, escolhendo quais serão disparadas e em qual ordem.

Por causa do motor de inferência, sistemas especialistas apresentam maior eficiência de processamento e facilidade de manutenção. Não é necessária a criação de uma regra para cada combinação diferente entre os fatos de entrada, pois o sistema especialista tem capacidade de inferir resultados não explícitos.

Há dois métodos de raciocínio que podem ser utilizados. O primeiro é chamado encadeamento progressivo, que é dirigido por dados. Desde o estado inicial do sistema com os dados de entrada, novos fatos são originados formando estados intermediários através das regras. O motor de inferência seleciona as regras que tenham como premissas os fatos presentes no estado corrente do sistema. O processo continua até que se chegue a uma conclusão final. É também chamado de data-driven inference, partindo dos dados até uma conclusão. O segundo método de raciocínio é chamado encadeamento regressivo, que é dirigido por metas. O processamento começa com uma meta e o motor de inferência seleciona as regras que casam com a meta em alguma extensão. Dessa forma, novas metas são traçadas, e outras regras são disparadas até que se tenha alcançado a meta inicial. É também chamado de goal-directed inference, partindo das metas até que se chegue aos dados que as tornem verdadeiras e alcancem a meta principal. Diferentes ferramentas de programação para sistemas especialistas costumam focar em um dos tipos de encadeamento. Contudo, a forma como as regras são implementadas permitem simular o outro tipo de encadeamento. 


\subsection{Encadeamento progressivo}

No encadeamento progressivo, para se chegar a uma conclusão, o motor de inferência segue um ciclo de execução conforme os três passos a seguir:

1. Unificação: Compara os fatos existentes na memória de trabalho com as premissas das regras para obter uma lista de quais regras são aplicáveis. O conjunto de regras aplicáveis gera o chamado "conjunto de conflito", devendo-se decidir a ordem de prioridade de aplicação das regras e se elas serão realmente aplicadas;

2. Resolução de conflitos: Havendo mais de uma regra no conjunto, a próxima regra a ser aplicada é escolhida a partir de mecanismos de resolução de conflitos (Clips Reference Manual: Basic Programming Guide, 2008), que utilizam critérios como: prioridade atribuída manualmente, prioridade atribuída estatisticamente, complexidade e simplicidade das regras, características dos dados contidos nas regras, ou, se nenhum mecanismo for capaz de selecionar uma única regra, segue-se ao sorteio;

3. Disparo de regras: A regra com maior prioridade de aplicação no conjunto de conflito é aplicada.

Este ciclo de inferência é repetido até que o conjunto de conflito fique vazio, quando a execução do sistema especialista é terminada.

Um sistema especialista sem máquina de inferência normalmente verificaria as condições de todas as regras em um loop contínuo até que não houvesse mais regras disparáveis, não provendo nenhum ganho na eficiência em relação às linguagens procedurais. O algoritmo de Rete (SOUZA, 2005) faz uso de duas características que tornam o processamento muito mais eficiente, sendo elas:

\section{Similaridade estrutural}

Grupos de padrões similares costumam aparecer nas premissas de regras diferentes. Assim, o algoritmo memoriza as regras que apresentem padrões similares, agrupando-os de forma que tais padrões não tenham que ser verificados em cada uma das regras novamente, ou seja, são verificados apenas uma vez para todas as regras que os utilizem. Isso é feito construindo-se uma rede de nós chamada rede de dependência, onde cada nó (exceto nas raízes) corresponde a um padrão. Regras com padrões em comum partirão desse mesmo nó, podendo seguir para ramos diferentes a partir daí. 
Para exemplificar, considere as seguintes regras:

\begin{tabular}{|l|l|}
\hline \multicolumn{2}{|l|}{ Regra 1 } \\
\hline Premissas & \begin{tabular}{l} 
1. \\
2. Fato A \\
2. Fato B \\
\hline $\begin{array}{l}\text { Ações / } \\
\text { Conclusões }\end{array}$
\end{tabular} \\
\hline
\end{tabular}

\begin{tabular}{|c|c|}
\hline \multicolumn{2}{|l|}{ Regra 2} \\
\hline Premissas & $\begin{array}{l}\text { 1. Fato A } \\
\text { 2. Fato B } \\
\text { 3. Fato C }\end{array}$ \\
\hline $\begin{array}{l}\text { Ações / } \\
\text { Conclusões }\end{array}$ & Gera Fato R2 \\
\hline
\end{tabular}

Um sistema especialista que não use a similaridade estrutural a seu favor constrói uma rede de nós sem dependência entre regras. Isso acaba resultando em uma rede com mais nós, o que não traz eficiência no processamento. A figura 15 mostra a rede construída a partir das regras 1 e 2 acima descritas. É possível notar que a rede possui um total de 10 nós. Por outro lado, um sistema especialista que aproveite a similaridade estrutural para criar dependência entre regras faz com que a eficiência seja aumentada, diminuindo a quantidade de nós. Isso é feito a partir da junção em um mesmo nó de padrões similares. Esse nó de junção é então compartilhado por duas ou mais regras. A figura 16 mostra as mesmas duas regras acima em uma rede de nós otimizada pela junção de padrões similares em um mesmo nó.

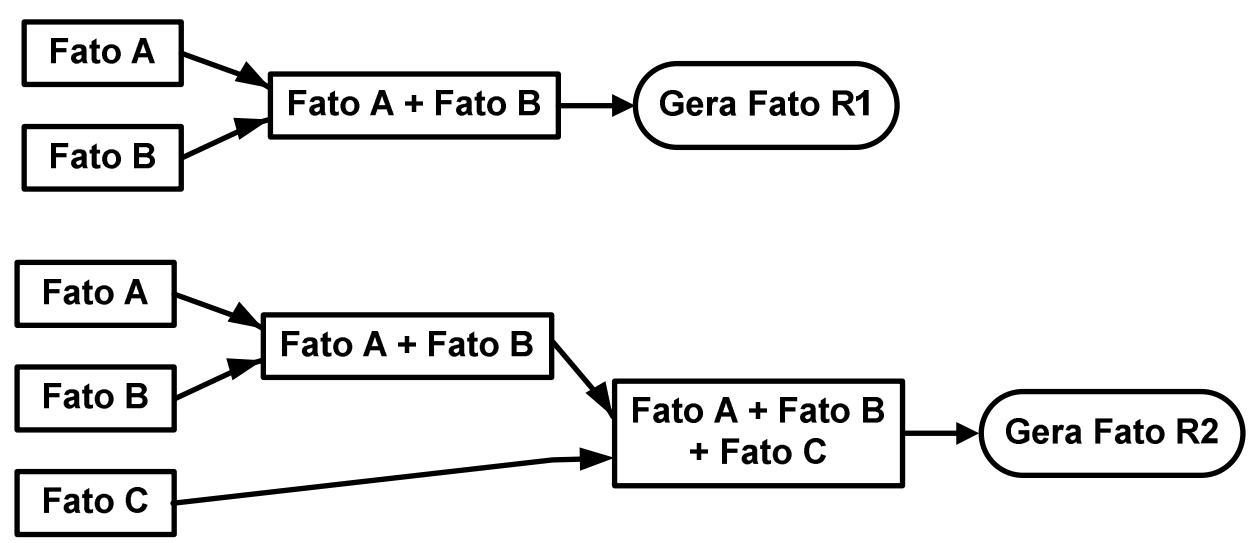

Figura 15 - Rede de nós sem proveito da similaridade estrutural. 


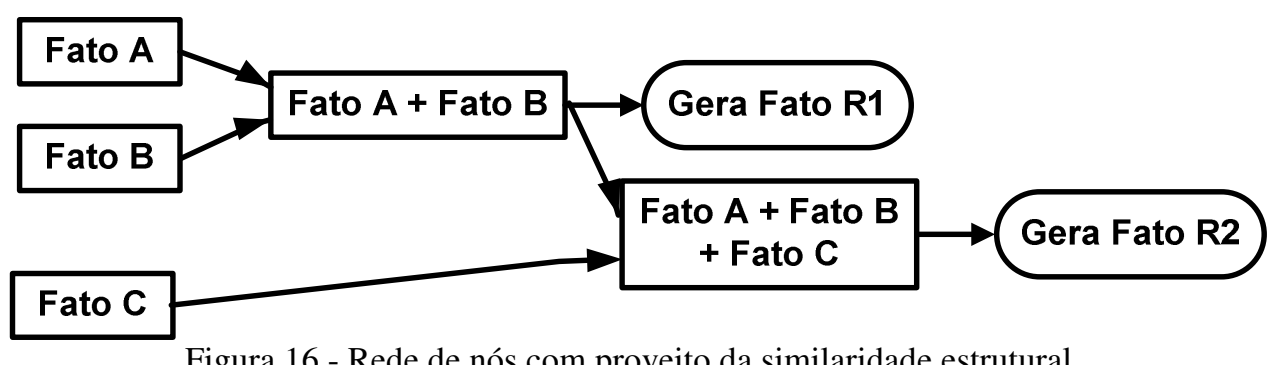

Figura 16 - Rede de nós com proveito da similaridade estrutural.

\section{Redundância temporal}

Entre um ciclo de inferência e outro costuma haver poucas mudanças no conjunto dos fatos presentes na memória de trabalho, ou seja, grande parte dos fatos contidos na memória de trabalho continua intacta. Isso acontece porque a aplicação de uma regra adicionará e/ou apagará apenas os fatos que estiverem determinados para sofrer tais ações nesta única regra. Todos os fatos não relacionados às ações dessa regra permanecerão iguais. Dessa forma, memorizando os resultados da unificação do ciclo de inferência anterior, não é necessário fazer nova unificação para as regras cujas premissas dependam de fatos que não foram alterados no último ciclo. Deve-se apenas refazer a unificação para os fatos e regras que dependam das mudanças ocorridas entre o estado anterior e o estado atual da memória de trabalho. No armazenamento do estado anterior tem-se a chamada unificação parcial, na qual parte dos padrões de uma regra foi satisfeita no estado anterior, devendo o próximo ciclo de inferência apenas se atentar às alterações ocorridas para verificar se haverá mudança para unificação completa.

A utilização da redundância temporal aumenta bastante a eficiência no processamento, já que não é necessário comparar todos os fatos com todos os padrões. Porém, há um uso mais intensivo de memória para guardar o estado anterior do sistema, que é o que torna possível utilizar as unificações parciais para evitar as comparações desnecessárias. No entanto, primeiramente, isso não configura nenhum problema para sistemas especialistas que utilizem ordem de dezenas ou mesmo centenas de regras. Segundo, o bom proveito da similaridade estrutural evita a duplicidade entre regras, utilizando padrões similares conjuntamente e aumentando a eficiência do sistema especialista. 


\subsection{Encadeamento regressivo}

No encadeamento regressivo, o motor de inferência segue um ciclo de execução conforme especificado a seguir, tendo uma variável-objetivo como meta inicial a ser alcançada. Dessa forma, para realizar a análise, o sistema especialista parte de uma hipótese, devendo então verificar se há condições suficientes para esta hipótese (a variável-objetivo) ser considerada verdadeira. Esta hipótese a ser provada no encadeamento regressivo corresponderia à conclusão obtida por um encadeamento progressivo.

O ciclo de inferência do encadeamento regressivo é composto pela chamada "unificação", como segue:

1. Procura a variável-objetivo no lado das ações das regras (lado do "então"). Dessa forma, forma-se uma lista com todas as regras que tem o poder de alterar o valor verdade dessa variável. Chamando essa lista de lista-objetivo, segue-se para:

2. Se a lista-objetivo estiver vazia, o sistema especialista é finalizado. Se não, a primeira regra da lista é selecionada e todas as premissas dessa regra são analisadas, podendo haver três situações. A primeira ocorre quando todas as premissas forem consideradas verdadeiras de acordo com os fatos presentes na memória de trabalho, condição em que a meta é considerada alcançada, ou seja, a hipótese foi provada. Dessa forma, a regra é disparada e é analisado se há mais objetivos na lista-objetivo. A segunda situação ocorre quando alguma das premissas for falsa, condição em que a regra é descartada e segue-se para a próxima regra da lista-objetivo. A terceira situação ocorre quando alguma premissa não tiver seu valor conhecido. Neste caso, essa variável é considerada o novo objetivo, repetindo o ciclo de inferência (unificação).

Percebe-se que no caso do encadeamento regressivo, não há necessidade de resolução de conflitos, pois estes não acontecem. Para provar uma hipótese (ou alcançar uma meta), deve-se provar que as premissas de qualquer regra que tornem essa hipótese verdadeira sejam também verdadeiras. Consequentemente, não importa a ordem com a qual as regras são analisadas, desde que uma delas torne a hipótese verdadeira. No caso de ser provada que a meta principal foi alcançada a partir de uma regra, o motor de inferência poderá finalizar o processamento do sistema especialista ou continuar seguindo na lista-objetivo para encontrar se há outras regras que também provam a hipótese. Isso dependerá de como o motor de inferência foi implementado. A escolha para a procura continuar mesmo após alcançado o objetivo se dá quando se quer uma lista de todas as condições que estão satisfeitas para tal. Se 
o objetivo é apenas provar a hipótese não importando todas as possibilidades que a tornaram verdadeira, então o processamento pode ser finalizado antes de analisar toda a lista-objetivo. 


\section{SISTEMA PROPOSTO}

\subsection{Sistema de automação}

Este capítulo descreve o sistema proposto que automatiza a análise dos eventos ocorridos na subestação de energia. O sistema é todo instalado em um computador industrial na própria subestação de energia. Dessa forma, a eficiência é aumentada, pois não é necessário enviar uma grande quantidade de dados provenientes dos relés e equipamentos da subestação para o Centro de Operação do Sistema (COS). Todo o sistema roda na própria subestação e apenas os resultados são enviados para uma interface Web para visualização pelo operador do sistema.

O sistema foi dividido em quatro subsistemas, sendo eles: aquisição, armazenamento, pré-tratamento e processamento de dados. Caso haja necessidade de atualização de software ou atualização da base de dados, um subsistema não interfere no outro, ou seja, não há necessidade de alteração de todo o sistema. Esses subsistemas serão descritos a seguir, assim como será mostrada a integração entre eles.

O fluxo de dados do sistema pode ser visualizado na figura 17.

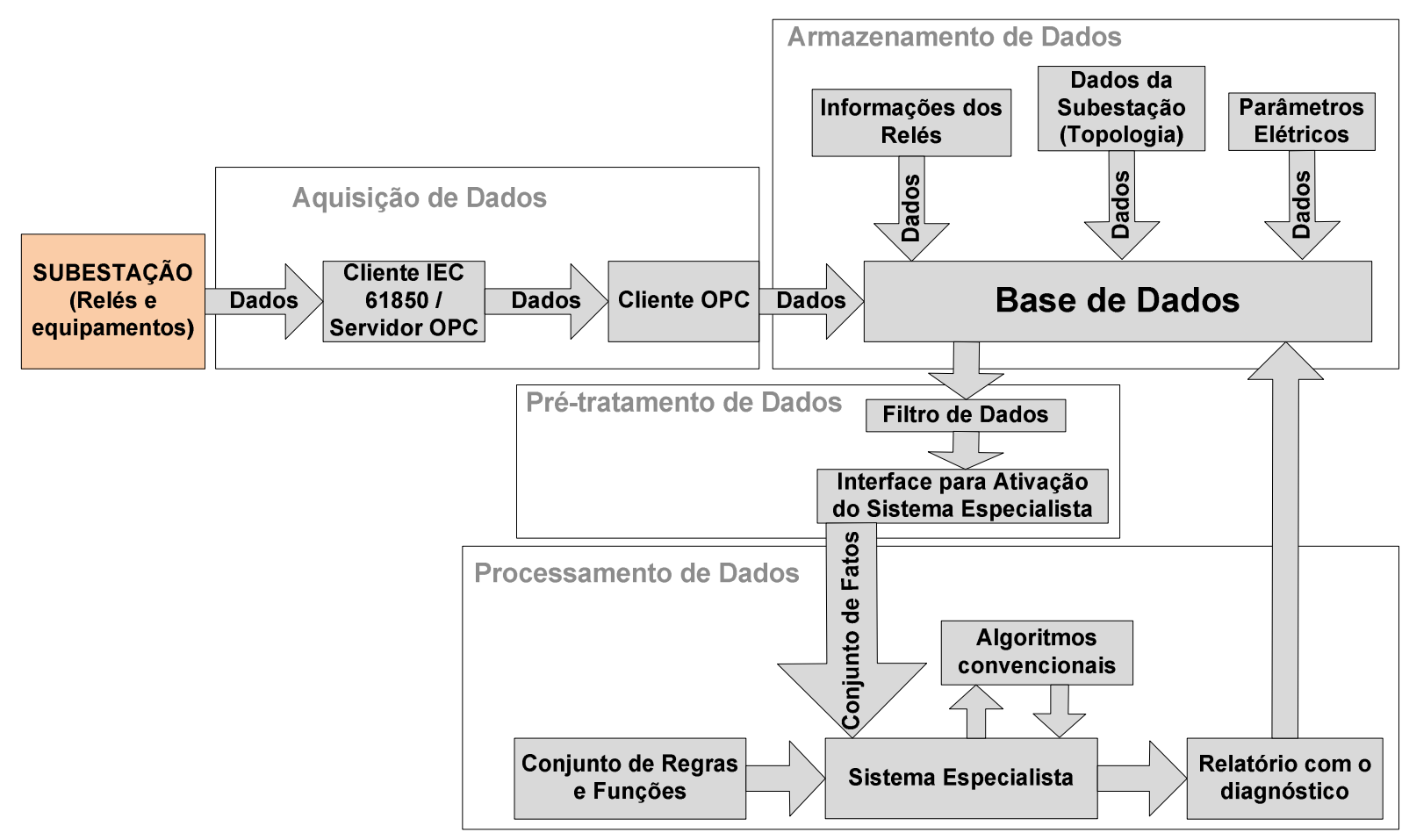

Figura 17 - Fluxo de dados do sistema de automação. 
O sistema de automação foi dividido em quatro subsistemas, sendo eles:

- Subsistema de Aquisição de Dados;

- Subsistema de Armazenamento de Dados;

- Subsistema de Pré-Tratamento de Dados;

- Subsistema de Processamento de Dados.

\subsubsection{Subsistema de aquisição de dados}

O sistema proposto considerou a utilização da norma IEC 61850 para comunicação de dados nos relés digitais de proteção, que representam a tendência corrente para subestações novas e modernizadas. Para a aquisição de dados nos relés, um gateway com cliente IEC 61850 e servidor OPC é utilizado através de conexão Ethernet sobre TCP/IP. Os reportes espontâneos através dos report control blocks e dos dados configurados como trigger nos data sets enviam os dados do relé digital IEC 61850 para o cliente IEC 61850, os quais são traduzidos para itens OPC. Em seguida, o servidor OPC é responsável por efetuar um callback para o cliente OPC, repassando-lhe os dados recebidos do relé, os quais serão armazenados no banco de dados, pré-processados e formatados para entrada no sistema especialista.

Foram inseridos alguns atrasos propositais (de até 500ms) para a recuperação de dados nos IEDs de forma que o conjunto completo de dados atualizados seja colocado em um único reporte de evento de proteção. Dessa forma, é possível garantir que o sistema de proteção tenha operado completamente até a abertura do disjuntor, fornecendo então todos os dados necessários atualizados para o diagnóstico do evento.

\subsubsection{Subsistema de armazenamento de dados}

Os dados aquisitados dos relés de proteção são salvos em um banco de dados relacional. Tais dados incluem aqueles coletados através da IEC 61850 (vide apêndice A) e também arquivos de oscilografia. Além disso, o banco de dados guarda informações sobre o sistema de proteção da subestação. A primeira informação importante é a identificação da subestação, pois, sendo possível o sistema ser instalado em várias subestações de uma companhia de distribuição de energia, uma base de dados única conterá as informações e 
relatórios relativos a todas as subestações para que possam ser acessadas e geridas pela equipe de operação.

Além disso, outros dados ficam armazenados que contêm informações necessárias para as etapas seguintes do sistema, entre eles:

- Topologia da subestação no esquema pai-filho englobando as linhas de transmissão, os disjuntores, as barras, os transformadores e os alimentadores de distribuição;

- Parâmetros elétricos da rede elétrica, tais como: potência dos transformadores, tensões e correntes nominais na rede e nos equipamentos elétricos, e impedâncias das linhas de transmissão e alimentadores de distribuição;

- Dados de equipamentos:

○ Relação de transformação dos transformadores de corrente (TC) e dos transformadores de potencial (TP);

- Tempos máximos admitidos para a abertura dos disjuntores (proveniente do manual ou de testes de disjuntores);

- Tempos máximos admitidos para não configurar discordância de polos nos disjuntores (proveniente do manual ou de testes de disjuntores);

- Erros admitidos para as estampas de tempo das variáveis digitais nos relés de proteção (por exemplo, estampas de tempo do Trip e da partida de funções de proteção);

○ Tolerância para valores aquisitados de variáveis analógicas, como correntes e tensões (relacionados às precisões dos TCs e TPs);

Ao final do processamento do sistema de análise da proteção, o relatório gerado em arquivo texto (XML) também é armazenado no banco de dados em um campo no formato de texto, para depois ser acessado por uma aplicação Web que resgatará os dados nos campos do XML e os disponibilizará em uma interface Web. 


\subsubsection{Subsistema de pré-tratamento de dados}

A primeira função do subsistema de pré-tratamento de dados é selecionar e colocar os dados provenientes das variáveis nos relés no formato de entrada de dados para o software utilizado na etapa seguinte, que utiliza algoritmos convencionais e um sistema especialista.

Além disso, quando necessários, arquivos de oscilografia podem ser utilizados para aperfeiçoar a análise de eventos de proteção. Tais arquivos contêm os estados digitais de algumas variáveis (por exemplo, Trip e partida de funções de proteção) e também valores analógicos discretizados de tensões e correntes nas três fases. Foram utilizados arquivos no formato padrão COMTRADE (IEEE, 2013), os quais são gerados quando da atuação da proteção, registrando dados desde alguns ciclos antes até alguns ciclos depois do evento. Os dados da oscilografia são analisados de forma a resgatar os instantes de abertura dos disjuntores e de cada um de seus três polos. Além disso, é realizada a análise discreta de Fourier das formas de onda, determinando-se os valores das magnitudes e fases das correntes e tensões antes e após o Trip da função de proteção. Os subitens a seguir descrevem como foi feito o pré-tratamento de dados.

\subsubsection{Variáveis digitais}

Quando a oscilografia contiver o estado de variáveis digitais, é possível detectar se a variável mudou de estado ou não. Além disso, é possível recuperar a estampa de tempo no momento de mudança de valor da variável analisando sequencialmente as amostras da oscilografia. No exemplo da figura 18, é possível detectar que houve atuação da função 51 da proteção de sobrecorrente, e que esta ocorreu no instante $0.033 \mathrm{~s}$, que é o instante em que o valor da amostra alterou do valor 0 para o valor 1 . Esta primeira amostra de valor 1 terá a estampa de tempo associada que se quer recuperar. 


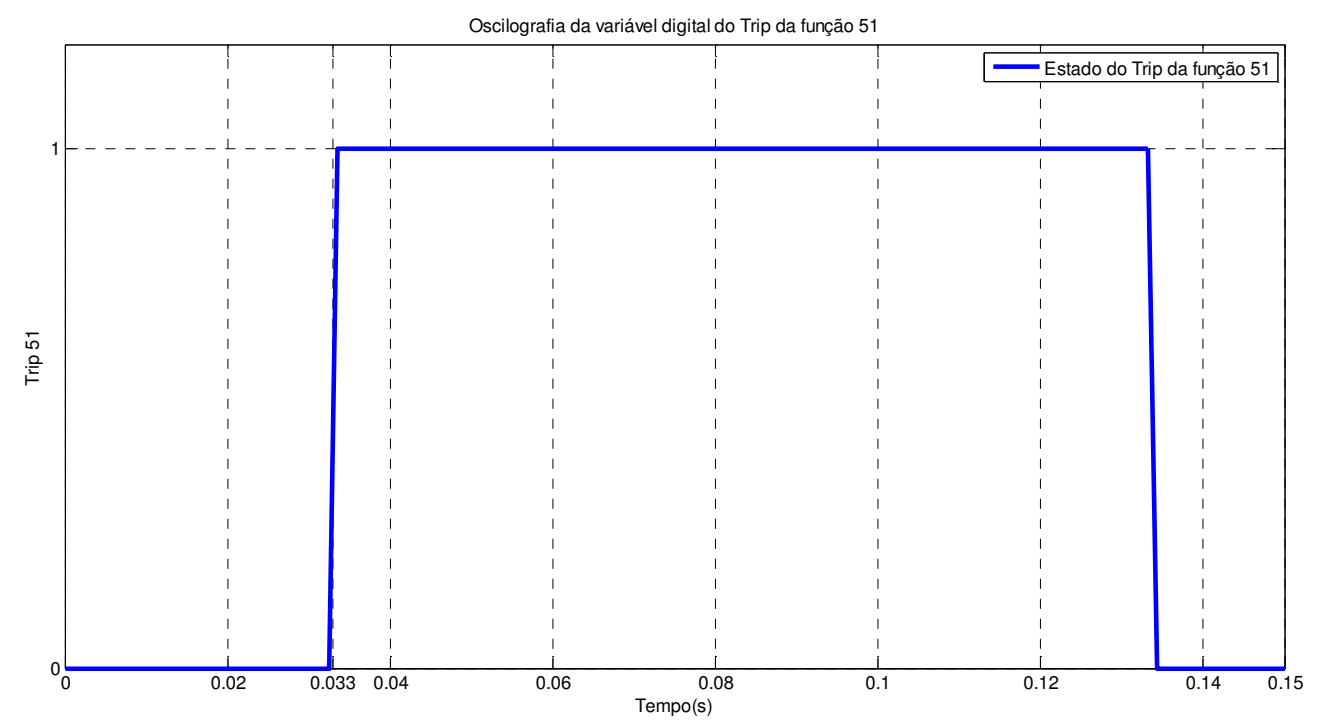

Figura 18 - Oscilografia da variável digital do Trip da função 51.

\subsubsection{Instante de abertura do disjuntor}

É possível verificar o instante de abertura do disjuntor através da oscilografia das correntes. Isso pode ser feito para cada umas das três fases do sistema, o que resultará nos instantes de abertura de cada um dos polos do disjuntor. Para isso, deve-se detectar o instante em que a corrente vai a zero. Umas das formas de implementar isso é, a partir da verificação sequencial das amostras da corrente em cada fase, verificar o instante em que uma amostra tem valor nulo e, a partir daí, permanecer por mais algumas amostras seguidas neste valor, por exemplo, por cinco amostras. Dessa forma, evita-se recuperar uma estampa de tempo errada da passagem instantânea da corrente por zero. Deve-se lembrar que, tratando-se de valores provenientes de instrumentos de medição (TCs), uma faixa de tolerância deve ser considerada para o valor da corrente, a qual pode ser estimada por meio de dados reais de oscilografias. Assim, o valor nulo da corrente deve ser considerado em uma faixa, como a seguir:

$$
0-\text { Tol } \leq \text { Valor nulo de corrente } \leq 0+\text { Tol }
$$

onde:

Tol Tolerância para erros de medição de valor nulo de corrente 
É considerada uma tolerância específica para o valor nulo da corrente porque em outros valores de corrente a tolerância depende da precisão do TC, a qual terá um erro que, por sua vez, depende do valor absoluto não nulo medido da corrente.

No exemplo da figura 19 , ocorreu um curto-circuito monofásico no instante $0.03 \mathrm{~s}$. No instante $0.0815 \mathrm{~s}$, o polo B do disjuntor abre. No instante $0.0857 \mathrm{~s}$, o polo $\mathrm{C}$ do disjuntor abre. Finalmente, no instante $0.0867 \mathrm{~s}$, o polo A do disjuntor abre.

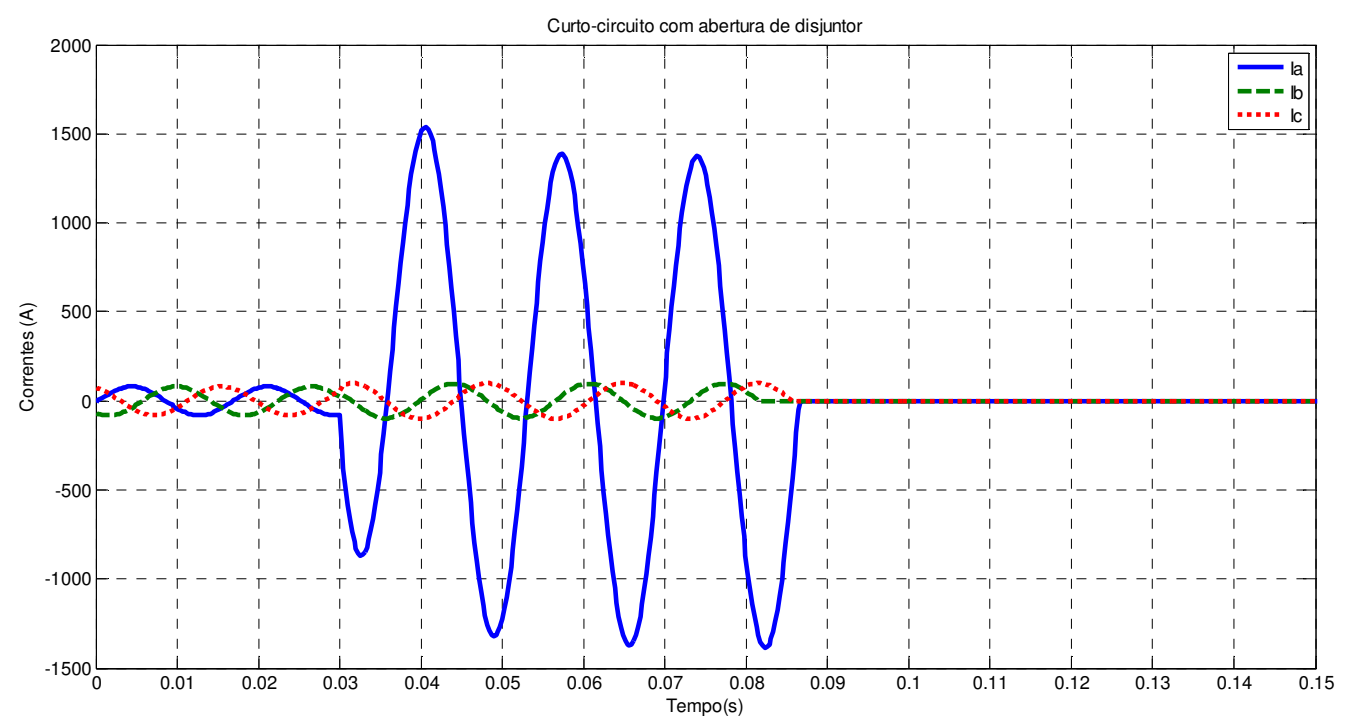

Figura 19 - Curto-circuito seguido de abertura do disjuntor.

\subsubsection{Variáveis analógicas discretizadas}

Muitos relés digitais modernos disponibilizam os valores das magnitudes e das fases de variáveis analógicas, tanto em relação a correntes de medição em regime permanente normal, quanto em relação a correntes de curto-circuito. Porém, ainda é comum encontrar relés que não disponibilizem tais informações, ainda mais levando em conta a não obrigatoriedade segundo a IEC 61850. Nos casos em que não houver esses dados, é possível calculá-los se houver arquivos de oscilografia para recuperação de variáveis analógicas discretizadas.

Para recuperar os valores dos fasores, aplica-se a transformada discreta de Fourier de forma a recuperar a magnitude e o ângulo de fase das componentes contínua, fundamental e harmônicas do sinal analógico discretizado. O método é aplicado a uma janela de um ciclo completo nas regiões de pré-falta, durante falta e pós-falta. 


\subsubsection{Subsistema de processamento de dados}

Este subsistema é responsável por processar todos os dados e realizar a análise dos eventos de proteção. O diagnóstico é realizado por um sistema especialista baseado em regras de produção, o qual é responsável por validar conclusões a partir de uma base de conhecimentos tal qual um perito no assunto tem para analisar o problema.

Vale observar que a viabilização da implementação através de um sistema especialista se deu principalmente pela grande quantidade de dados de entrada a serem processados (vide item 4.1.2, principalmente em relação à quantidade de dados coletados via IEC 61850). Além disso, algoritmos procedurais são utilizados em conjunto com o sistema especialista para cálculos como o tipo de curto-circuito, o que é viabilizado através do software CLIPS, que é uma linguagem híbrida. O CLIPS realiza o raciocínio e inferências através do algoritmo de Rete, o qual foi detalhado no item 3.3.2.3.3.1 - encadeamento progressivo.

O detalhamento dessa etapa será dado no item 4.2 - Sistema especialista: análise de eventos.

\subsubsection{Interface Web: visualização do diagnóstico}

O relatório do sistema especialista é gerado em formato XML para que facilite a leitura do arquivo para disponibilização em uma interface Web. O quadro 1 mostra a estrutura do arquivo com as tags utilizadas.

Os campos do arquivo são descritos a seguir:

- sistemaespecialista: tag principal;

- relatório: contém todas as informações do relatório;

- SESigla: contém a sigla da subestação, o que é útil para o caso de o sistema ser aplicado em mais de uma subestação;

- IED: identifica o IED que reportou o evento de proteção ocorrido;

- DataEvento: identifica a data do evento com precisão de milissegundos;

- Evento: identifica qual evento ocorreu, ou seja, qual dos módulos de análise do sistema especialista é responsável pela geração do relatório, conforme item 4.2.3 - Módulos de diagnóstico;

- DescEvento: contém o diagnóstico feito pelo sistema especialista. 
Quadro 1 - Estrutura XML do arquivo gerado pelo sistema especialista.

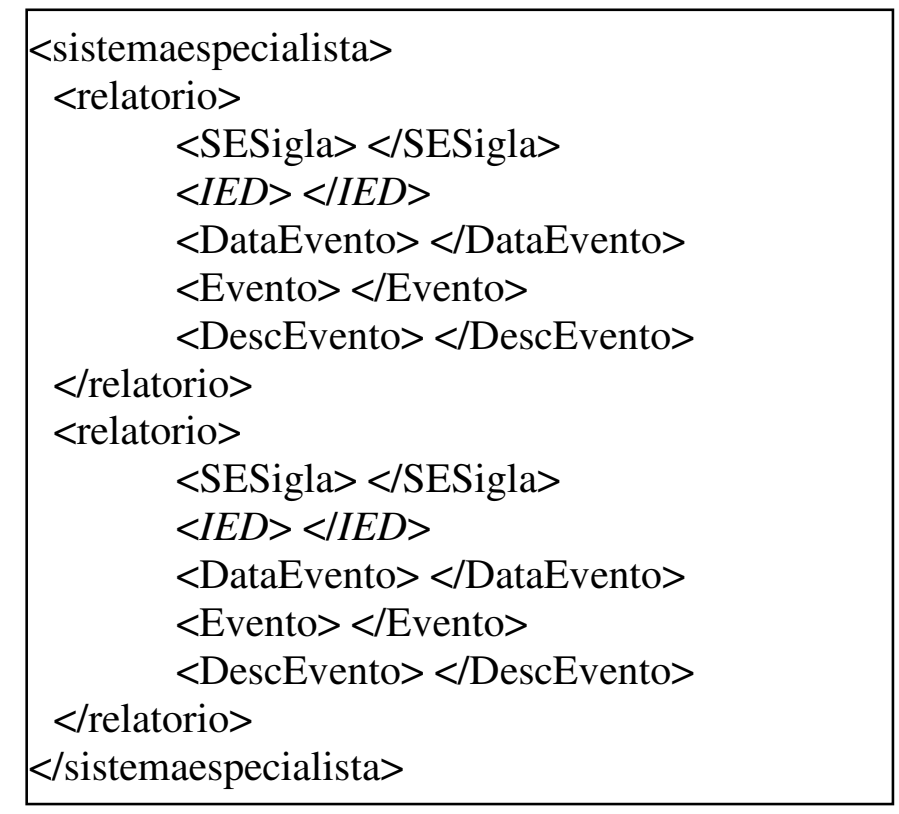

Nota-se que é possível haver mais de um relatório em um mesmo arquivo. Isso acontece em eventos de proteção em que mais de um módulo de análise do sistema especialista é ativado. Um exemplo é quando ocorre um curto-circuito em que houve Trip da função de sobrecorrente. Neste caso, haverá um relatório com o diagnóstico da proteção de sobrecorrente, outro relatório com o diagnóstico do curto-circuito, e ainda outro com o diagnóstico do disjuntor.

A tela da interface criada para visualização da lista de relatórios gerados pelo sistema especialista pode ser visualizada na figura 20. Para uma subestação, é possível filtrar os relatórios gerados pelo nome do relé que reportou o evento de proteção ocorrido, pela identificação do evento e, além disso, selecionar uma data inicial e uma data final. Após clicar no botão "D”, abre-se uma nova tela conforma a figura 21 , na qual é possível visualizar o relatório gerado. 


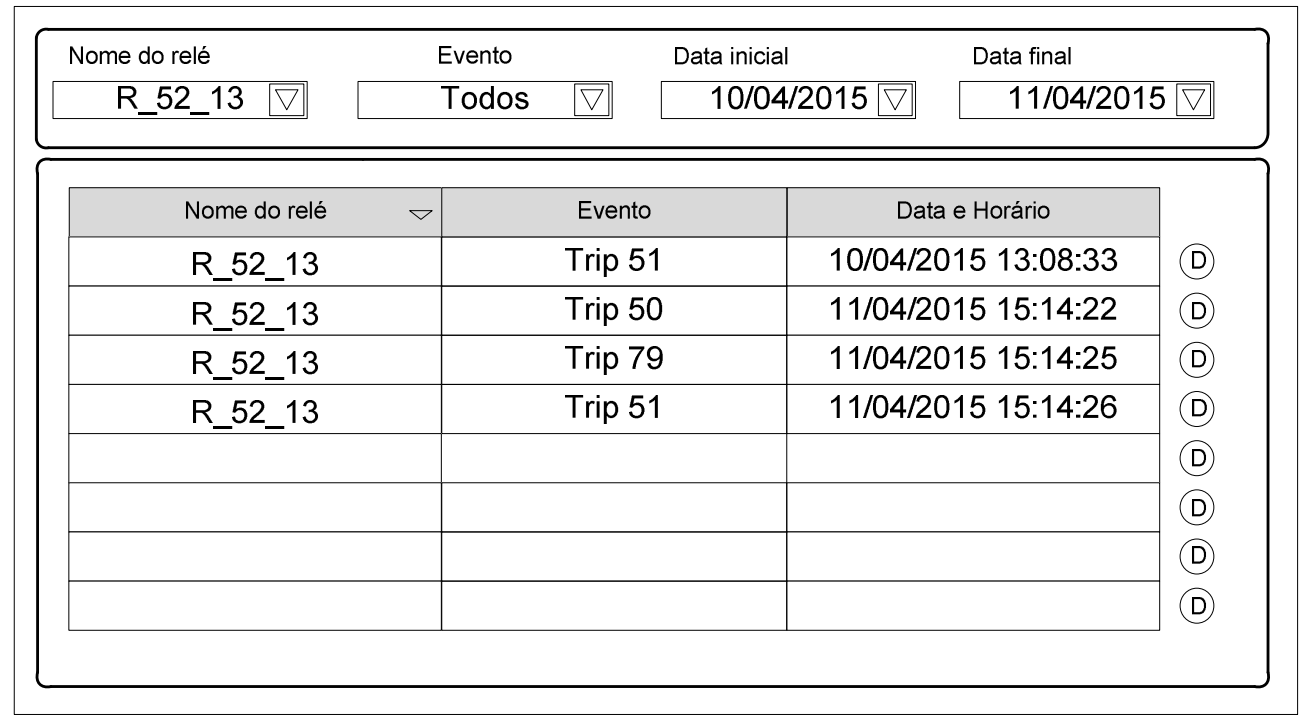

Figura 20 - Interface Web com a relação dos relatórios gerados pelo sistema especialista.

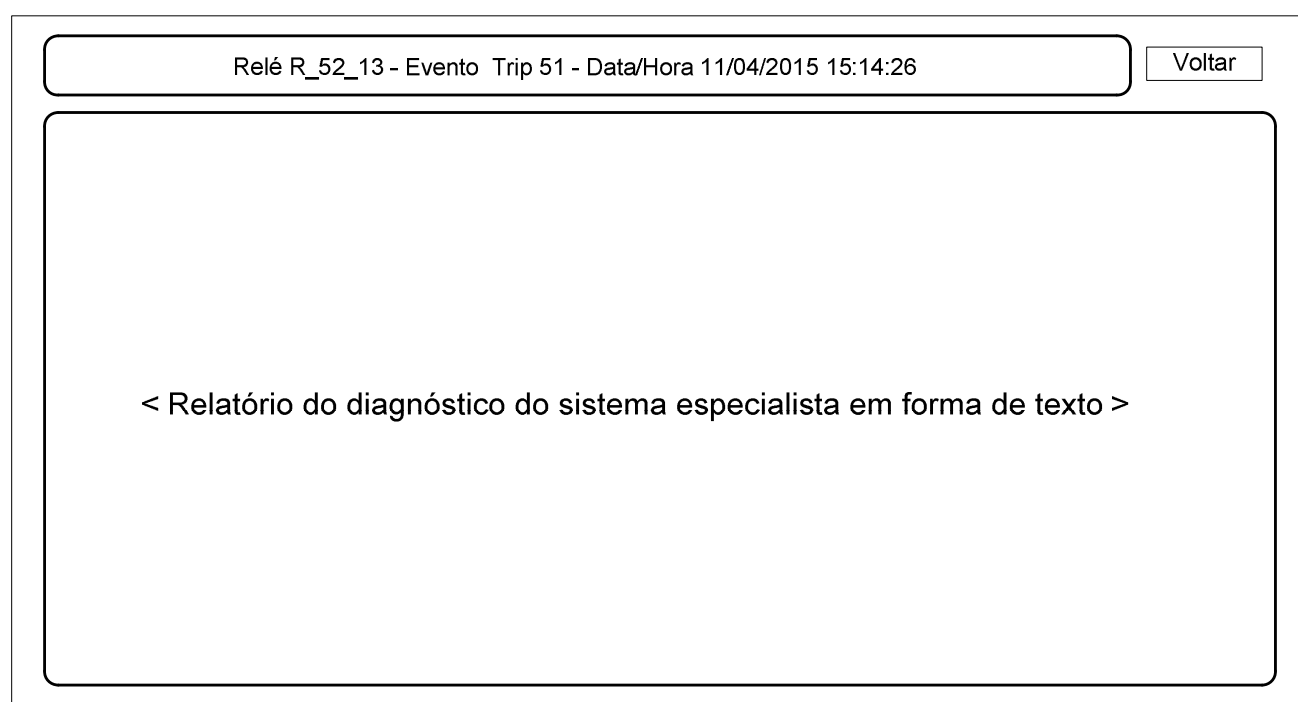

Figura 21 - Interface Web para a visualização do relatório gerado pelo sistema especialista.

\subsection{Sistema especialista: análise de eventos}

O sistema especialista é formado por uma base de conhecimentos que utiliza diferentes métodos de raciocínio, técnicas de inferência e módulos de agrupamento de conhecimento. Uma vez implementada, a base de conhecimentos é gravada em arquivos do CLIPS com extensão ".clp”, possibilitando atualizações a partir da adição/remoção de regras e formatos de entrada de fatos nesses arquivos. 


\subsubsection{Métodos de raciocínio}

Foram utilizados dois métodos de raciocínio - processamento básico de alarmes e raciocínio baseado em modelos - que visam aumentar a eficiência do programa e entregar resultados mais completos.

\subsubsection{Processamento Básico de Alarmes}

É responsável pela análise mais superficial no problema do diagnóstico. Sendo assim, consiste em proceder com verificações mais gerais, entre elas: identificar qual relé atuou; o estado das variáveis digitais de Trip e partida das funções de proteção, das variáveis digitais de abertura do disjuntor e dos alarmes do relé; e as magnitudes das variáveis analógicas que sejam importantes para a análise do evento ocorrido, fornecendo então um primeiro grupo de resultados para identificar tal evento. Além disso, para facilitar uma consulta ágil, são fornecidas informações do relé que atuou, como os parâmetros ajustados para as funções de proteção, as correntes no momento da falta e mensagens acerca do estado dos alarmes no relé, quando aplicáveis.

\subsubsection{Raciocínio Baseado em Modelos (RBM)}

O raciocínio baseado em modelos é um método de inferência no qual um modelo é construído para representar o funcionamento daquilo que se quer analisar, seja um equipamento ou um sistema. Dessa forma, a máquina de inferência será responsável por parear dados do equipamento ou sistema real com o modelo de forma a concluir o funcionamento esperado ou não.

No caso do problema de análise da proteção, no RBM (MCARTHUR, MCDONALD, et al., 1996) é construído um modelo com detalhamento e complexidade suficientes para descrever o comportamento esperado dos relés e disjuntores frente a diversas condições de defeitos. Partindo dessas informações, prossegue-se para uma comparação com todos os comportamentos reais, obtidos via IEC 61850 e arquivos de oscilografia. Se os resultados do modelo e os resultados reais condisserem, tem-se então a validação dos resultados, confirmando o que aconteceu neste evento na subestação. Por outro lado, se houver discrepância, serão analisados a causa e os efeitos acerca deste evento. 


\subsubsection{Técnicas de inferência}

Foram utilizadas duas técnicas de inferência - regras distintas para diferentes informações de entrada e regras distintas para um mesmo diagnóstico final - que procuram promover e possibilitar o fornecimento de resultados mesmo na ausência de alguma informação de entrada.

A ausência de algumas informações pode ocorrer por diversos motivos, como por exemplo:

- Falhas no sistema de comunicação entre o relé e o servidor OPC. Neste caso, procura-se diminuir as chances de perda de dados utilizando-se os buffered report control blocks. Dessa forma, em caso de perda de comunicação, os dados são armazenados em um buffer até que o sistema de comunicação volte a operar normalmente;

- Defeitos em equipamentos de medição;

- Indisponibilidade de algumas informações nos relés utilizados. Uma das causas para isso é o fato de a norma IEC 61850 não tornar obrigatória a disponibilização de muitos dados que poderiam ser úteis em um sistema de análise do sistema de proteção. Um exemplo disso é a não obrigatoriedade de disponibilização das correntes de curto-circuito. Nesse caso, fica a cargo dos fabricantes de relés fornecerem esses dados ou não. Outro fator que influi na indisponibilidade de informações nos relés é, ainda decorrente da não obrigatoriedade de disponibilização de alguns dados segundo a norma IEC 61850, o fato de relés utilizados em sistemas de distribuição muitas vezes não terem tantas funcionalidades quanto relés utilizados em sistemas de transmissão de energia, os quais, por outro lado, costumam ter custo maior. Tais fatos também fazem com que diferentes fabricantes disponibilizem diferentes informações, o que gera a necessidade de flexibilizar o sistema especialista de modo a lidar com essas variações.

\subsubsection{Regras distintas para diferentes informações de entrada}

As informações de entrada podem não ser sempre as mesmas em todas as situações em que o sistema especialista é ativado. Uma forma de contornar essa situação é através da implementação de regras que analisem uma situação de formas diferentes. 
Supondo que a análise em questão seja o tipo de curto-circuito, podemos construir dois caminhos que cheguem a alguma conclusão:

$1^{\circ}$. Um conjunto de regras que utilizem os valores das correntes nas três fases, o que permite uma análise completa partindo da teoria de circuitos trifásicos para determinar o tipo de curto-circuito que ocorreu;

$2^{\circ}$. Um conjunto de regras que considere a ausência de informação da corrente em uma das fases, mas que trabalhe em conjunto com outras regras responsáveis pela verificação das variáveis indicadoras de Trip por fase e Trip por terra. Dessa forma, procura-se preencher um vazio de informação com algum dado que, de alguma maneira, forneça conhecimento necessário para completar a análise. Por exemplo, a verificação de altas correntes nas fases A e B de um alimentador poderiam ser complementadas com a informação de que não houve Trip nem na fase individual $\mathrm{C}$ e nem por terra, concluindo que a falta foi bifásica e fornecendo os valores das correntes;

É importante implementar mecanismos que visem evitar o envio de mensagens com diagnósticos iguais caso mais de um caminho de regras seja ativado, o que é feito a partir de agrupamentos de regras que façam um mesmo tipo de análise de tal forma que apenas uma mensagem seja exibida.

\subsubsection{Regras distintas para um mesmo diagnóstico final}

Outra forma de lidar com a possibilidade de as informações de entrada variarem é a utilização de caminhos que partam de uma hipótese e procurem as informações que satisfaçam tal hipótese, ou seja, a filosofia do encadeamento regressivo é aplicada.

Supondo que a hipótese seja "falha no disjuntor", primeiramente uma regra ditará as condições que, sendo uma delas satisfeita, é provado que a hipótese está correta. Se todas as condições forem falsas, então a hipótese é refutada. Se não houver condições satisfeitas, mas houver alguma condição cujo valor-verdade é desconhecido, então se procura avaliar o valorverdade dessa condição a partir de outras regras na base de regras do sistema especialista. Se for concluído que seu valor é verdadeiro, então a hipótese de falha no disjuntor continua sendo correta.

Dessa forma, é possível concluir uma falha no disjuntor a partir de diferentes premissas que resultem nisso, como por exemplo: 
$1^{\circ}$. Indicações de falhas em mensagens de alarmes captados via IEC 61850;

$2^{\circ}$. Verificação dos tempos de abertura/fechamento esperados e reais.

A diferença entre este método e o anterior é que o primeiro foca nas informações de entrada para produzir um diagnóstico final a partir de caminhos distintos de regras. Contrariamente, o segundo método foca no diagnóstico final, procurando se há informações de entrada que satisfaçam tal hipótese.

\subsubsection{Módulos de diagnóstico}

Uma vantagem de sistemas especialistas é a modularidade, a qual permite o processamento apenas da parte que interessa para o evento em análise. Esta característica permite aumentar a eficiência e rapidez do processamento. O sistema de análise da proteção foi dividido em sete módulos. Todos os módulos utilizam o método do processamento básico de alarmes de forma similar, o qual constitui uma análise mais superficial do evento ocorrido. Porém, o método do raciocínio baseado em modelos difere bastante entre os módulos, já que é responsável por uma análise mais profunda do evento, dependendo das particularidades de cada um. Os módulos, que são apresentados na figura 22, serão detalhados nos subitens a seguir, cada um com o detalhamento do RBM correspondente, com exceção do módulo principal, que não possui RBM, já que não é responsável por uma análise específica dos componentes analisados do sistema de proteção.

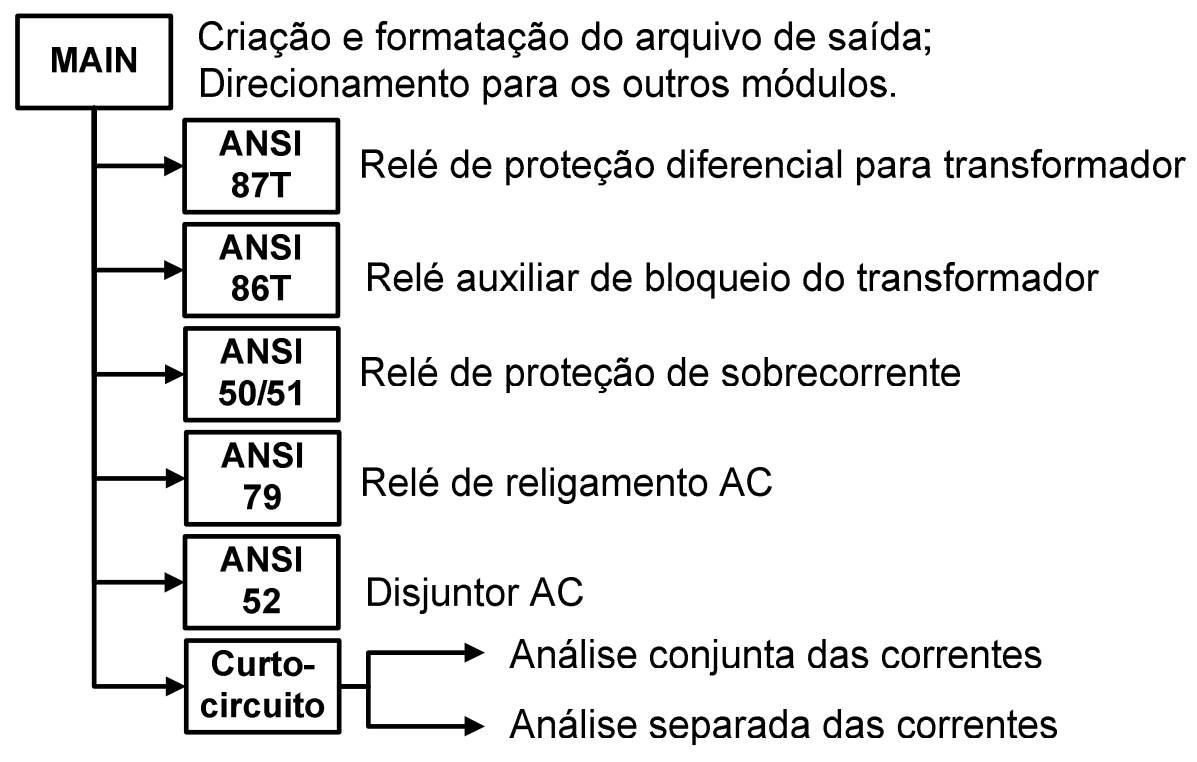

Figura 22 - Módulos de diagnóstico do sistema especialista. 


\subsubsection{Módulo geral}

A primeira função do módulo geral é criar e formatar o arquivo no qual o relatório com o diagnóstico será escrito.

A segunda função é, a partir das variáveis digitais de atuação da proteção ou disjuntores do evento que ocorreu, direcionar para um dos seis módulos específicos, nos quais as análises particulares e que estejam relacionadas a este evento serão realizadas.

\subsubsection{Módulo de análise da proteção de sobrecorrente}

Este módulo fornece o diagnóstico das funções de proteção de sobrecorrente (ANSIs $50,51,50 \mathrm{~N}, 51 \mathrm{~N}$ e $51 \mathrm{GS})$.

Para o RBM, o modelo resgata todos os valores de ajustes dos parâmetros dos relés, sendo eles: corrente de partida; tipo de curva (IEC, IEEE, IAC, US, I2T, RI, FLEX ou tempo definido); característica da curva de atuação (normal inversa, moderadamente inversa, muito inversa, extremamente inversa, tempo curto-inversa e tempo longo-inversa) de acordo com a curva utilizada; e configurações de atrasos intencionais. Com os valores das correntes de curto-circuito e os ajustes do relé, é possível calcular o tempo de atuação esperado para o terra e cada fase do relé. A seguir, é calculado o tempo de atuação real, ou seja, o comportamento real do relé neste quesito. Isso é feito subtraindo-se as etiquetas de tempo das variáveis digitais do Trip e da partida da função de proteção obtidas via IEC 61850 ou utilizando os tempos obtidos através da análise da oscilografia.

É interessante também analisar a consistência dos valores dos estados das variáveis entre si. Por exemplo, se o Trip estiver ativado e a partida não estiver, evidencia-se uma atuação indevida. Além disso, o modelo construído deve esperar que as correntes de falta estejam acima da corrente de partida e que a proteção não esteja bloqueada por qualquer motivo para que haja Trip. Finalmente, deve-se lidar com possíveis variações nos tempos esperados de atuação, já que o IED tem precisão limitada. O mesmo vale quando se está considerando variáveis analógicas, como correntes, já que instrumentos de medição também têm precisão limitada, havendo necessidade de se levar em conta erros admitidos de acordo com o equipamento de medição utilizado.

A figura 23 mostra a visão geral do modelo para RBM utilizado para a previsão do comportamento da proteção de sobrecorrente temporizada na fase A. Neste caso, apenas para exemplificação e visualização, a curva de atuação utilizada é a IEC. Além disso, no caso em 
que são utilizados relés em concordância com a IEC 61850, a variável que indica que a proteção está em pleno funcionamento deve estar ativa.

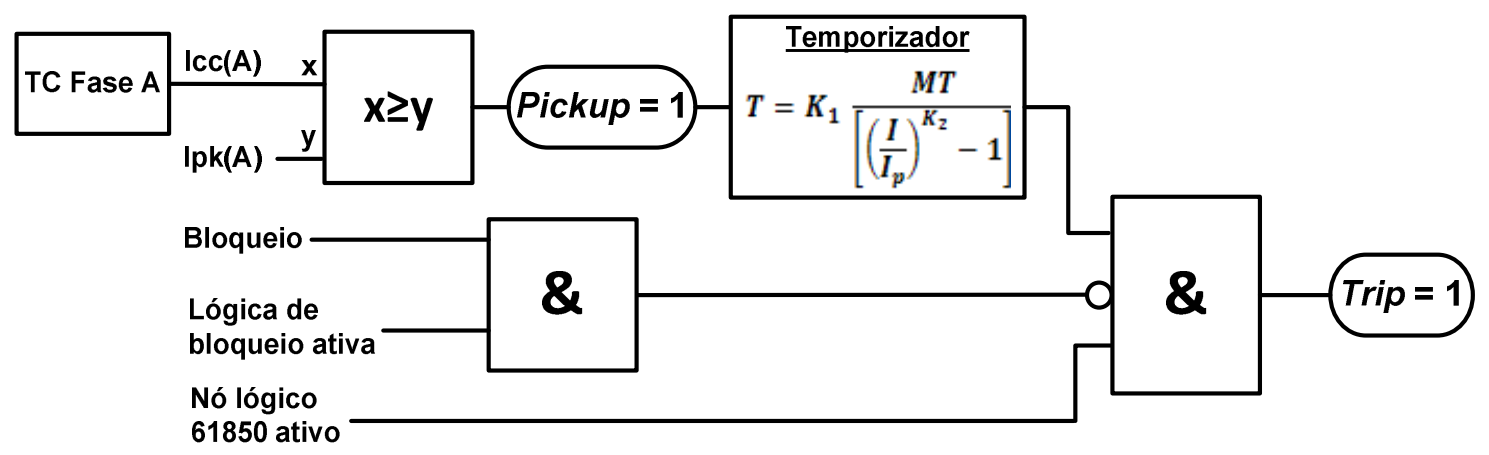

Figura 23 - Modelo RBM de proteção de sobrecorrente temporizada na fase A.

Em todos os módulos relativos a funções de proteção há um breve diagnóstico do estado do disjuntor, verificando se houve abertura, se houve falha ou se está em algum estado inválido. Além disso, é verificado se houve abertura do disjuntor principal ou do disjuntor de retaguarda. Se houve atuação da retaguarda, há indício de possível falha no disjuntor principal, no envio de sinal de abertura ao disjuntor principal, ou de parametrização errada/desatualizada da proteção no relé na zona primária de proteção. Entretanto, foi desenvolvido um módulo separado que realiza uma análise mais profunda do disjuntor.

\subsubsection{Módulo de análise da proteção diferencial em transformadores}

Para o modelo da proteção diferencial, consideraram-se os parâmetros da proteção 87T para o relé Siemens 7UT6135. A curva de atuação da proteção é dada pela corrente diferencial em relação à corrente de restrição, sendo dividida em quatro regiões. Para formar essas regiões, são considerados os seguintes parâmetros ajustáveis:

- Idif: valor da reta da primeira região: corrente diferencial de partida para baixas correntes;

- Slope 1: inclinação da reta da segunda região;

- BPl (Base Point 1): intersecção da extensão da reta da segunda região com o eixo das abscissas;

- Slope 2: inclinação da reta da terceira região;

- BP2 (Base Point 2)): intersecção da extensão da reta da terceira região com o eixo das abscissas; 
- Idiff: valor da reta da quarta região: corrente diferencial de partida para altas correntes;

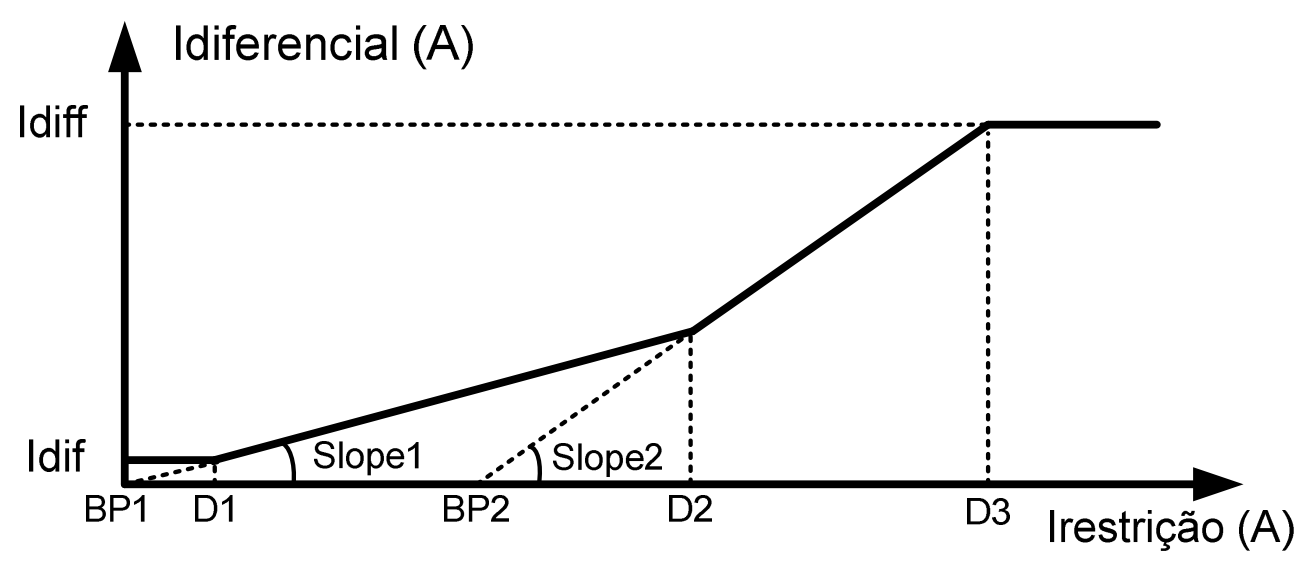

Figura 24 - Gráfico da curva de atuação da proteção diferencial.

Primeiramente, determinam-se os pontos D1, D2 e D3 para que a análise seja feita por regiões com facilidade, sendo elas 0-D1, D1-D2, D2-D3 e D3- $\infty$. Para relés que não usam esse mesmo padrão de configuração, há duas possibilidades. A primeira é estabelecer uma regra ou conjunto de regras que coloque os dados da curva no mesmo formato por regiões. A vantagem dessa opção é que não é necessário alterar a base de regras já existente do sistema especialista, bastando adicionar novas regras. A outra possibilidade é proceder com a formatação dos dados na etapa de pré-tratamento de dados do sistema de análise da proteção. Essa opção também tem a vantagem de não necessidade de alteração da base de regras já existente no sistema especialista. Porém, tem a desvantagem da necessidade de alteração na programação da etapa de pré-tratamento de dados.

A figura 25 mostra a visão geral do modelo para RBM construído para a proteção diferencial referente à fase A. A partir das correntes medidas nos TCs de entrada e saída (que limitam a zona de proteção diferencial), derivam-se a corrente diferencial e a corrente de restrição, que são analisadas segundo a curva de atuação da figura 24.

Há alguns fatores que podem acarretar no bloqueio da proteção diferencial, ou seja, mesmo na condição que configuraria Trip segundo a curva, não há atuação da proteção. $\mathrm{O}$ primeiro modo de bloqueio é por restrição harmônica, o qual visa evitar Trip indevido decorrente de harmônicos gerados por manobras de reatores ou por sobre-excitação ou conexão de transformadores e que envolvam a fase no transformador na qual o bloqueio está ativo. Outro modo é o bloqueio cruzado, que é o mesmo proveniente da restrição harmônica, 
porém decorrente de harmônicos em outra fase (B ou C no caso da figura 25). Há ainda o modo de bloqueio por estabilização add-on, que visa evitar Trip indevido decorrente de saturações diferentes entre os TCs quando da ocorrência de faltas externas à zona de proteção, as quais gerariam correntes com valores diferentes nos TCs de entrada e saída, principalmente quando os TCs são de diferentes modelos (o que é comum, pois um está no lado da alta tensão e o outro está no lado da baixa tensão). Estes bloqueios, porém, só serão efetivos se não houver Trip rápido causado por alta corrente na zona de proteção diferencial, pois correntes extremamente altas poderiam danificar rapidamente o transformador.

Finalmente, o envio de sinal para abertura dos disjuntores é dado através do relé de bloqueio 86T, o qual não permitirá fechamento automático dos disjuntores.

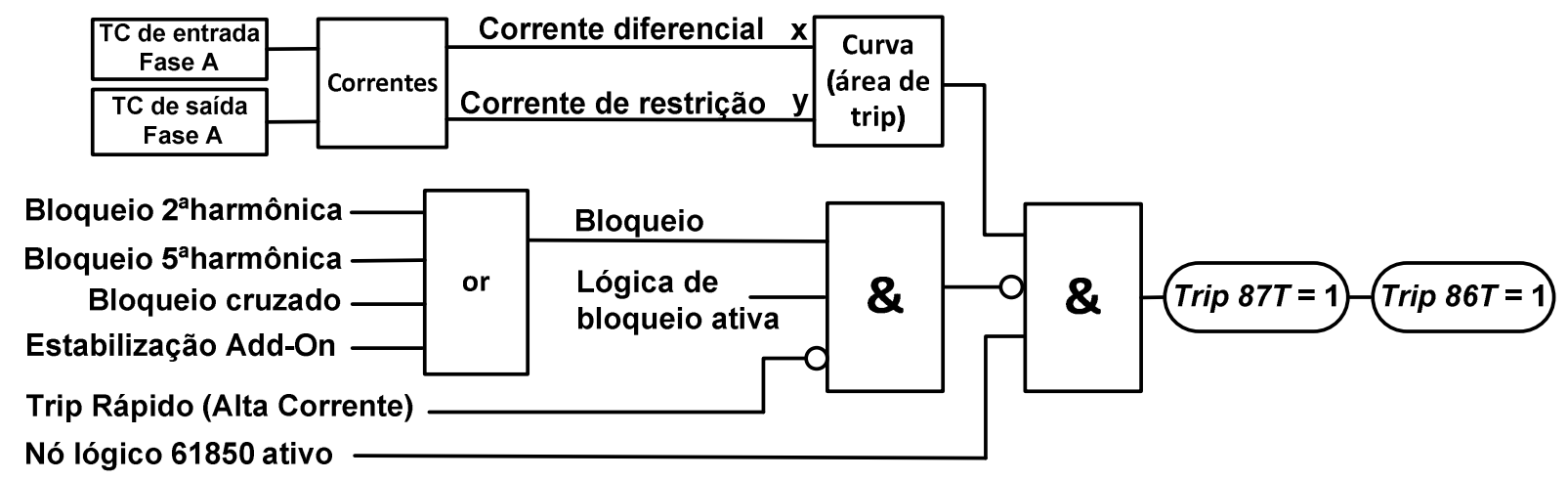

Figura 25 - Modelo RBM de proteção diferencial na fase A.

Para o módulo de análise da proteção diferencial em transformadores, serão mostradas as regras implementadas baseadas no modelo para RBM, para que o leitor possa entender a forma como a base de regras é construída. É possível implementar as regras em um sistema especialista de inúmeras formas a partir de um modelo. A seguir será mostrada a forma como foi implementada neste trabalho. Algumas regras são explicadas detalhadamente para melhor entendimento do funcionamento isolado e conjunto das regras. O raciocínio é aplicado de forma análoga para as demais regras.

Toda regra terá um ou mais fatos nas premissas. Para que a regra seja executada, todos esses fatos devem estar presentes na memória de trabalho do estado corrente do sistema especialista. Após a execução da regra, um ou mais novos fatos são gerados. 


\begin{tabular}{|c|c|}
\hline Premissas & $\begin{array}{l}\text { 1. Trip 87T; } \\
\text { 2. Corrente diferencial e corrente de restrição na área de Trip da curva; } \\
\text { 3. Não há bloqueio final do } 87 \mathrm{~T} \text {; } \\
\text { 4. Nó lógico } 61850 \text { ativo. }\end{array}$ \\
\hline $\begin{array}{l}\text { Ações / } \\
\text { Conclusões }\end{array}$ & Atuação correta da proteção diferencial 87T. \\
\hline
\end{tabular}

Na regra 1, para que seja concluído que a proteção diferencial 87T atuou corretamente, quatro fatos devem estar presentes no conjunto de fatos na memória de trabalho.

1. Para que exista o fato indicando que houve Trip da função 87T, uma das regras $5,6,7$ ou 8 deve ter sido executada;

2. Para que exista o fato indicando que as correntes estão na área de Trip da curva, uma das regras 10, 12, 14 ou 16 deve ter sido executada;

3. Para que exista o fato indicando que não houve bloqueio final da função 87 , uma das regras 25,26 ou 27 deve ter sido executada;

4. Deve haver fato indicando que o nó lógico 61850 está ativo (proveniente diretamente do IED).

\begin{tabular}{|c|c|}
\hline Premissas & $\begin{array}{l}\text { 1. Trip 87T; } \\
\text { 2. Corrente diferencial e corrente de restrição fora da área de Trip da } \\
\text { curva; }\end{array}$ \\
\hline $\begin{array}{l}\text { Ações / } \\
\text { Conclusões }\end{array}$ & * Atuação incorreta da proteção diferencial 87T. \\
\hline
\end{tabular}

Para a regra 2, temos:

1. Para que exista o fato indicando que o fato indicando que houve Trip da função $87 \mathrm{~T}$, uma das regras $5,6,7$ ou 8 deve ter sido executada;

2. Para que exista o fato indicando que as correntes estão na área de Trip da curva, uma das regras $11,13,15$ ou 17 deve ter sido executada.

Cada uma das regras do sistema especialista gera uma impressão no relatório indicando a análise que ocorreu, quando necessário. Por exemplo, na regra 2 tem-se a 
impressão no relatório de uma frase indicando que houve Trip indevido da função 87T de proteção diferencial do transformador, já que a corrente diferencial e a corrente de restrição resultaram em um ponto fora da área de Trip na curva de atuação.

Qualquer uma das regras 2, 3 ou 4 resulta na conclusão de atuação incorreta da proteção diferencial, que é a conclusão contrária à regra 1. Regras que indicam situações contrárias a outras tornam o diagnóstico mais rico em informações fornecidas.

Os raciocínios acima desenvolvidos sobre o funcionamento das regras são análogos para as demais regras do sistema especialista.

\begin{tabular}{|l|l|}
\hline Regra 3 : Atuação incorreta do 87T por bloqueio \\
\hline Premissas & $\begin{array}{l}\text { 1. Trip 87T; } \\
\text { 2. }\end{array}$ \\
\hline $\begin{array}{l}\text { Açóes / bloqueio final do 87T; } \\
\text { Conclusões }\end{array}$ & Atuação incorreta da proteção diferencial 87T. \\
\hline
\end{tabular}

\begin{tabular}{|l|l|}
\hline Regra 4 : Atuação incorreta do 87T por nó 61850 inativo \\
\hline Premissas & $\begin{array}{l}\text { 1. Trip 87T; } \\
\text { 2. Nó lógico } 61850 \text { não ativo. }\end{array}$ \\
\hline $\begin{array}{l}\text { Ações / } \\
\text { Conclusões }\end{array}$ & \\
\hline
\end{tabular}

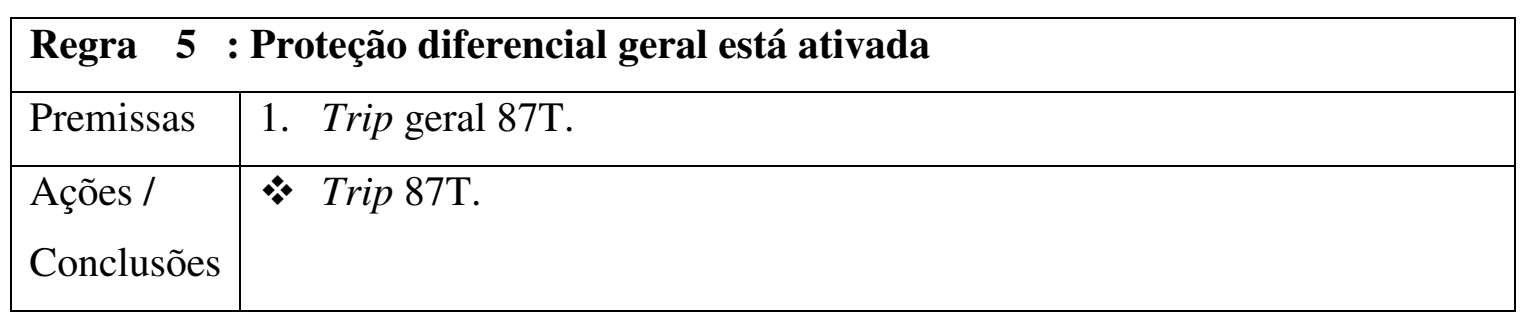

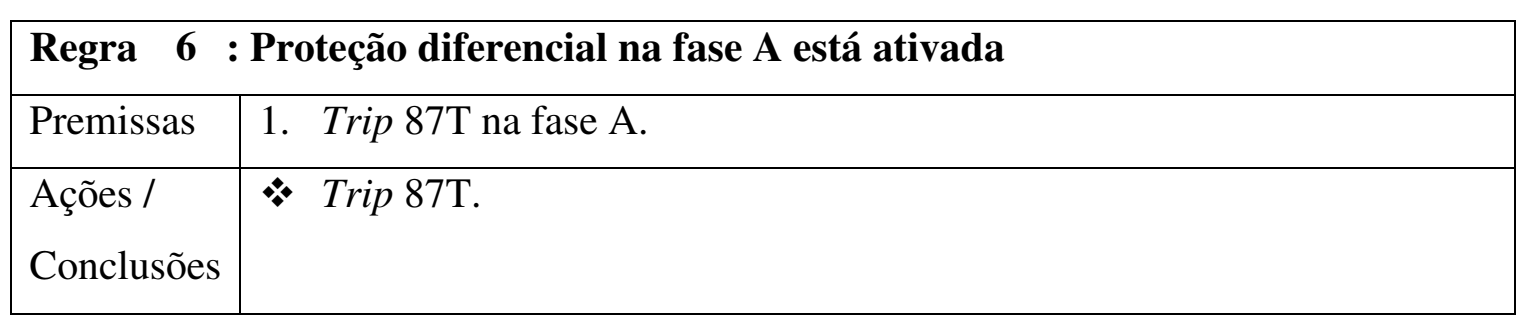




\begin{tabular}{|l|l|}
\hline Regra $\mathbf{7}$ : Proteção diferencial na fase B está ativada \\
\hline Premissas & 1. Trip 87T na fase B. \\
\hline Ações / & Trip 87T. \\
Conclusões & \\
\hline
\end{tabular}

\begin{tabular}{|c|c|}
\hline Premissas & 1. Trip 87T na fase $\mathrm{C}$. \\
\hline $\begin{array}{l}\text { Ações / } \\
\text { Conclusões }\end{array}$ & * Trip 87T. \\
\hline
\end{tabular}

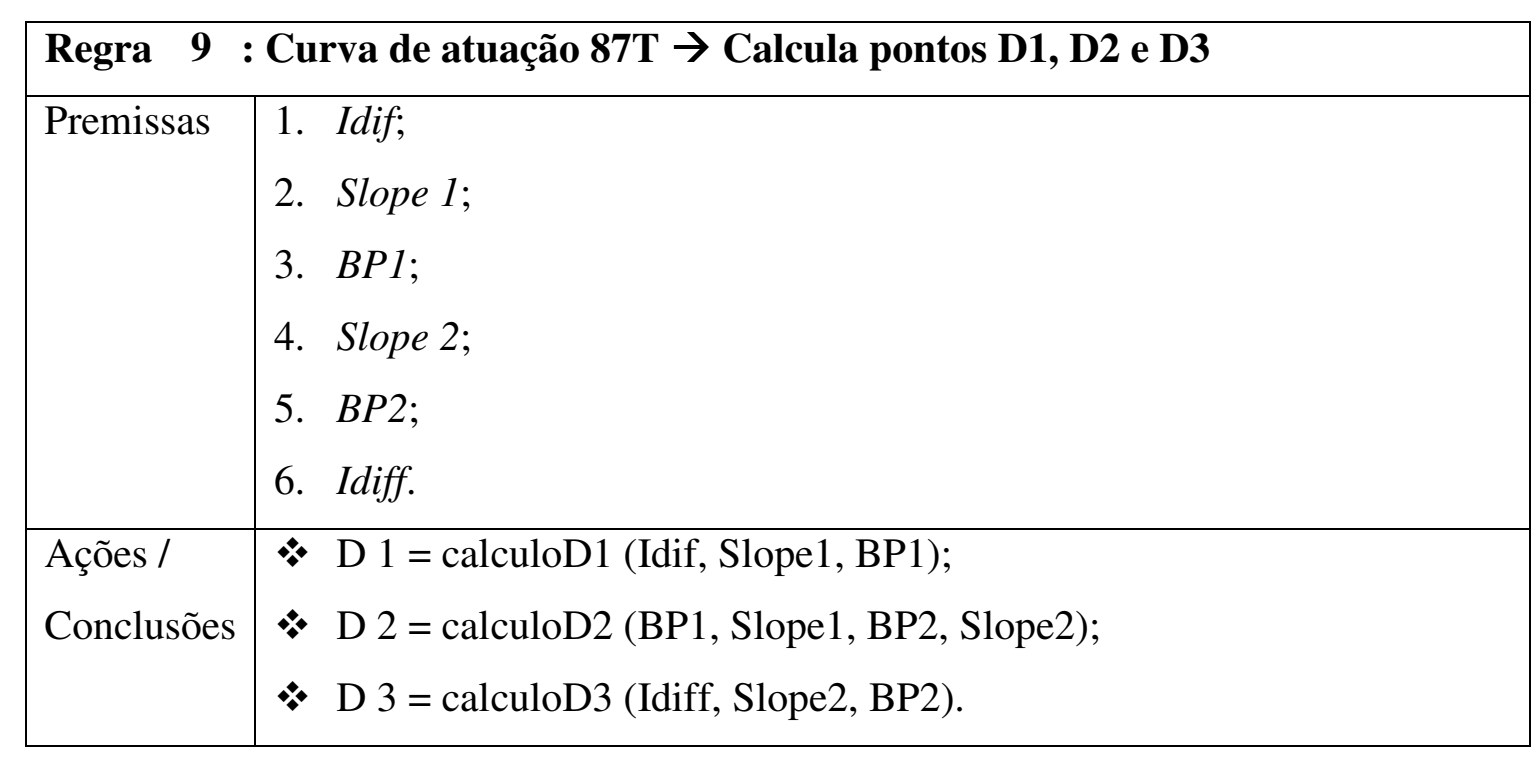

A regra 9 insere fatos com os valores calculados dos parâmetros D1, D2 e D3 a partir dos parâmetros de configuração da curva de atuação da proteção diferencial. Esses cálculos são feitos chamando as funções calculoD1, calculoD2 e calculoD3, implementadas com linguagem procedural.

calculoD1 (Idif, Slope1, BP1): função procedural para cálculo de D1

\begin{tabular}{|l|l|}
\hline Retorna D1 & D1 $=\frac{\text { Idif }}{\text { Slope } 1}+B P 1$ \\
\hline
\end{tabular}

calculoD2 (BP1, Slope1, BP2, Slope2): função procedural para cálculo de D2

\begin{tabular}{l|l} 
Retorna D2 & D2 $=\frac{(B P 1 * \text { Slope } 1)-(\text { BP } 2 * \text { Slope } 2)}{\text { Slope } 1-\text { Slope } 2}$
\end{tabular} 


\begin{tabular}{|l|l|}
\hline \multicolumn{2}{|c|}{ calculoD3 (Idiff, Slope2, BP2): função procedural para cálculo de D3 } \\
\hline Retorna D3 & D3 $=\frac{\text { Idiff }}{\text { Slope } 2}+B P 2$ \\
\hline
\end{tabular}

\begin{tabular}{|c|c|}
\hline \multicolumn{2}{|c|}{$\begin{aligned} \text { Regra } 10 & : \text { Curva de atuação 87T } \rightarrow \text { Análise intervalo 0-D1 } \rightarrow \text { Dentro da área } \\
& \text { de Trip }\end{aligned}$} \\
\hline Premissas & $\begin{array}{l}\text { 1. D1; } \\
\text { 2. Corrente de restrição; } \\
\text { 3. Teste: Corrente de restrição } \leq \mathrm{D} 1 ; \\
\text { 4. Corrente diferencial; } \\
\text { 5. Idif; } \\
\text { 6. Teste: Corrente diferencial } \geq \text { Idif. }\end{array}$ \\
\hline $\begin{array}{l}\text { Ações / } \\
\text { Conclusões }\end{array}$ & * Corrente diferencial e corrente de restrição na área de Trip da curva. \\
\hline
\end{tabular}

A regra 10 efetua um teste na região 0-D1 da curva de atuação da proteção diferencial para verificar que está na região Trip. A regra 11 a seguir verifica que não está na região de Trip.

\begin{tabular}{|c|c|}
\hline \multicolumn{2}{|c|}{$\begin{array}{l}\text { Regra } 11: \text { Curva de atuação 87T } \rightarrow \text { Análise intervalo 0-D1 } \rightarrow \text { Fora da área de } \\
\text { Trip }\end{array}$} \\
\hline Premissas & $\begin{array}{l}\text { 1. D1; } \\
\text { 2. Corrente de restrição; } \\
\text { 3. Teste: Corrente de restrição } \leq \text { D1; } \\
\text { 4. Corrente diferencial; } \\
\text { 5. Idif; } \\
\text { 6. Teste: Corrente diferencial < Idif. }\end{array}$ \\
\hline $\begin{array}{l}\text { Ações / } \\
\text { Conclusões }\end{array}$ & $\begin{array}{l}\text { Corrente diferencial e corrente de restrição fora da área de Trip da } \\
\text { curva. }\end{array}$ \\
\hline
\end{tabular}




\begin{tabular}{|c|c|}
\hline \multicolumn{2}{|c|}{$\begin{array}{l}\text { Regra } 12: \text { Curva de atuação 87T } \rightarrow \text { Análise intervalo D1-D2 } \rightarrow \text { Dentro da } \\
\text { área de Trip }\end{array}$} \\
\hline Premissas & $\begin{array}{l}\text { 1. D1; } \\
\text { 2. D2; } \\
\text { 3. Corrente de restrição; } \\
\text { 4. Teste: Corrente de restrição > D1; } \\
\text { 5. Teste: Corrente de restrição } \leq \mathrm{D} 2 ; \\
\text { 6. Corrente diferencial; } \\
\text { 7. Slope1; } \\
\text { 8. BP1; } \\
\text { 9. Teste: Corrente diferencial } \geq \text { Slope1 * (Corrente de restrição - BP1). }\end{array}$ \\
\hline $\begin{array}{l}\text { Ações / } \\
\text { Conclusões }\end{array}$ & * Corrente diferencial e corrente de restrição na área de Trip da curva. \\
\hline
\end{tabular}

\begin{tabular}{|c|c|}
\hline \multicolumn{2}{|c|}{$\begin{array}{c}\text { Regra } 13: \text { Curva de atuação 87T } \rightarrow \text { Análise intervalo D1-D2 } \rightarrow \text { Fora da área } \\
\text { de Trip }\end{array}$} \\
\hline Premissas & $\begin{array}{l}\text { 1. D1; } \\
\text { 2. D2; } \\
\text { 3. Corrente de restrição; } \\
\text { 4. Teste: Corrente de restrição > D1; } \\
\text { 5. Teste: Corrente de restrição } \leq \mathrm{D} 2 ; \\
\text { 6. Corrente diferencial; } \\
\text { 7. Slope1; } \\
\text { 8. BP1; } \\
\text { 9. Teste: Corrente diferencial < Slope1 * (Corrente de restrição - BP1). }\end{array}$ \\
\hline $\begin{array}{l}\text { Ações / } \\
\text { Conclusões }\end{array}$ & $\begin{array}{l}\text { * Corrente diferencial e corrente de restrição fora da área de Trip da } \\
\text { curva. }\end{array}$ \\
\hline
\end{tabular}




\begin{tabular}{|c|c|}
\hline Regra 14 & $\begin{array}{l}\text { Curva de atuação 87T } \rightarrow \text { Análise intervalo D2-D3 } \rightarrow \text { Dentro da } \\
\text { área de Trip }\end{array}$ \\
\hline Premissas & $\begin{array}{l}\text { 1. D2; } \\
\text { 2. D3; } \\
\text { 3. Corrente de restrição; } \\
\text { 4. Teste: Corrente de restrição > D2; } \\
\text { 5. Teste: Corrente de restrição } \leq \mathrm{D} 3 ; \\
\text { 6. Corrente diferencial; } \\
\text { 7. Slope2; } \\
\text { 8. BP2; } \\
\text { 9. Teste: Corrente diferencial } \geq \text { Slope2 } * \text { (Corrente de restrição - BP2). }\end{array}$ \\
\hline $\begin{array}{l}\text { Ações / } \\
\text { Conclusões }\end{array}$ & * Corrente diferencial e corrente de restrição na área de Trip da curva. \\
\hline
\end{tabular}

\begin{tabular}{|c|c|}
\hline \multicolumn{2}{|c|}{$\begin{array}{c}\text { Regra } 15 \text { : Curva de atuação 87T } \rightarrow \text { Análise intervalo D2-D3 } \rightarrow \text { Fora da área } \\
\text { de Trip }\end{array}$} \\
\hline Premissas & $\begin{array}{l}\text { 1. D2; } \\
\text { 2. D3; } \\
\text { 3. Corrente de restrição; } \\
\text { 4. Teste: Corrente de restrição > D2; } \\
\text { 5. Teste: Corrente de restrição } \leq \mathrm{D} 3 ; \\
\text { 6. Corrente diferencial; } \\
\text { 7. Slope2; } \\
\text { 8. BP2; } \\
\text { 9. Teste: Corrente diferencial < Slope2 * (Corrente de restrição - BP2). }\end{array}$ \\
\hline $\begin{array}{l}\text { Ações / } \\
\text { Conclusões }\end{array}$ & $\begin{array}{l}\text { * Corrente diferencial e corrente de restrição fora da área de Trip da } \\
\text { curva. }\end{array}$ \\
\hline
\end{tabular}




\begin{tabular}{|l|l|}
\hline Regra 16 : Curva de atuação 87T $\rightarrow$ Análise intervalo D3- $\infty \rightarrow$ Dentro da área \\
de Trip
\end{tabular}

\begin{tabular}{|l|l|}
\hline Regra 17 : Curva de atuação 87T $\rightarrow$ Análise intervalo D3- $\infty \rightarrow$ Fora da área \\
de Trip
\end{tabular}

\begin{tabular}{|l|l|}
\hline Regra 18 : Cálculo da corrente diferencial \\
\hline Premissas & $\begin{array}{l}\text { 1. Ainda não há corrente diferencial no conjunto de fatos; } \\
\text { 2. Corrente TC de entrada; } \\
\text { 3. Corrente TC de saída; }\end{array}$ \\
\hline $\begin{array}{l}\text { Ações / } \\
\text { Conclusões }\end{array}$ & $\begin{array}{l}\text { I Corrente diferencial = } \\
\text { ICorrente TC de entrada + Corrente TC de saída I }\end{array}$ \\
\hline
\end{tabular}

A regra 18 utiliza as correntes nos TCs de entrada e de saída do transformador para calcular a corrente diferencial. Esta regra só é ativada caso o IED não disponibilize diretamente o valor da corrente diferencial. 


\begin{tabular}{|l|l|}
\hline Regra 19 : Cálculo da corrente de restrição \\
\hline Premissas & $\begin{array}{l}\text { 1. Ainda não há corrente de restrição no conjunto de fatos; } \\
\text { 2. Corrente TC de entrada; } \\
\text { 3. Corrente TC de saída; }\end{array}$ \\
\hline $\begin{array}{l}\text { Ações / } \\
\text { Conclusões }\end{array}$ & $\begin{array}{l}\text { I Corrente de restrição }= \\
\text { I Corrente TC de entrada I + I Corrente TC saída I }\end{array}$ \\
\hline
\end{tabular}

\begin{tabular}{|l|l|}
\hline Regra 20 & : Há bloqueio da proteção diferencial \\
\hline Premissas & 1. Bloqueio; \\
& $\begin{array}{l}\text { 2. Lógica de bloqueio ativa; } \\
\text { 3. Não há Trip rápido (alta corrente) }\end{array}$ \\
\hline $\begin{array}{l}\text { Ações / } \\
\text { Conclusões }\end{array}$ & Há bloqueio final do 87T. \\
\hline
\end{tabular}

\begin{tabular}{|l|l|}
\hline Regra 21 & $:$ Bloqueio $2^{\mathbf{0}}$ harmônica \\
\hline Premissas & $1 . \quad$ Bloqueio $2^{\mathbf{a}}$ harmônica. \\
\hline $\begin{array}{l}\text { Ações / } \\
\text { Conclusões }\end{array}$ & \multirow{2}{}{ Bloqueio. } \\
\hline
\end{tabular}

\begin{tabular}{|c|c|}
\hline Regra 22 & : Bloqueio $5^{\circ}$ harmônica \\
\hline Premissas & 1. Bloqueio $5^{\mathrm{a}}$ harmônica. \\
\hline $\begin{array}{l}\text { Ações / } \\
\text { Conclusões }\end{array}$ & Bloqueio. \\
\hline
\end{tabular}

\begin{tabular}{|c|c|}
\hline $\begin{array}{ll}\text { Regra } 23 \\
\end{array}$ & : Bloqueio cruzado \\
\hline Premissas & 1. Bloqueio cruzado. \\
\hline $\begin{array}{l}\text { Ações / } \\
\text { Conclusões }\end{array}$ & * Bloqueio. \\
\hline
\end{tabular}

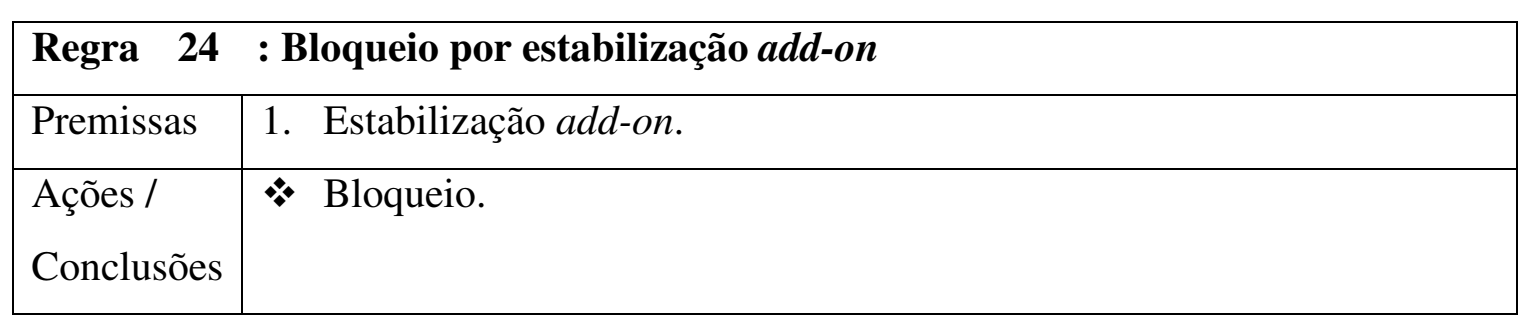




\begin{tabular}{|c|c|}
\hline Regra 25 & : Não há bloqueio \\
\hline Premissas & $\begin{array}{l}\text { 1. Não há bloqueio } 2^{a} \text { harmônica; } \\
\text { 2. Não há bloqueio } 5^{\mathrm{a}} \text { harmônica; } \\
\text { 3. Não há bloqueio cruzado; } \\
\text { 4. Não há estabilização add-on. }\end{array}$ \\
\hline $\begin{array}{l}\text { Ações / } \\
\text { Conclusões }\end{array}$ & * Não há bloqueio final do 87T. \\
\hline
\end{tabular}

\begin{tabular}{|l|l|}
\hline Regra 26 & : Não há bloqueio \\
\hline Premissas & 1. Lógica de bloqueio não ativa. \\
\hline $\begin{array}{l}\text { Ações / } \\
\text { Conclusões }\end{array}$ & \\
\hline
\end{tabular}

\begin{tabular}{|l|l|}
\hline Regra 27 & : Não há bloqueio \\
\hline Premissas & 1. Trip rápido (alta corrente). \\
\hline $\begin{array}{l}\text { Ações / } \\
\text { Conclusões }\end{array}$ & \\
\hline
\end{tabular}

\subsubsection{Módulo de análise do religamento}

Primeiramente verifica-se o valor das variáveis indicadoras de estado da função de religamento. Em seguida, a análise é feita em relação aos parâmetros da função, sendo eles a quantidade e os tempos de religamento.

A IEC 61850 não torna obrigatória a disponibilização da variável que conta a quantidade de religamentos nem normatiza uma variável que informe os tempos reais de religamento (IEC, 2010d). Havendo variável disponível via IEC 61850 que disponibilize informação de qual foi a tentativa de religamento, a análise se torna mais simples, bastando verificar se os tempos estão dentro de uma faixa aceitável em relação aos ajustes. Os tempos são calculados a partir das estampas de tempo das variáveis digitais de Trip do religamento e da última abertura anterior do disjuntor. No caso de não haver informações em relação ao número da tentativa de religamento, o sistema especialista efetua o mesmo cálculo dos tempos de religamento anterior, mas deduz qual foi o número sequencial da tentativa comparando os tempos reais e os tempos parametrizados. 


\subsubsection{Módulo de análise do relé auxiliar de bloqueio para transformadores}

O relé auxiliar de bloqueio 86T é usado conjuntamente com a proteção diferencial nos transformadores para promover a abertura dos disjuntores sem permitir que estes sejam fechados automaticamente por outros comandos. Este módulo consiste basicamente da análise de consistência entre os valores das variáveis indicadoras dos estados de ativação da função de proteção diferencial, da função de ativação do bloqueio e das variáveis indicadoras dos estados dos disjuntores conectados ao relé de bloqueio.

\subsubsection{Módulo de análise de disjuntores}

A figura 26 mostra a visão geral do modelo para RBM utilizado para diagnóstico do disjuntor. Primeiramente, para que haja o funcionamento correto do disjuntor, três condições devem ser satisfeitas. A primeira é ter ocorrido o Trip de alguma função de proteção que envie sinal para abertura desse disjuntor; A segunda é a chave 43 Local/Remota estar na posição remota, o que indica que permite comandos remotos ao disjuntor. Para a terceira condição ser satisfeita, assim como nas funções de proteção, o nó lógico da IEC 61850 relativo ao objeto que comanda o disjuntor deve estar ativo para que haja funcionamento normal dos comandos ao disjuntor. Estando essas três condições satisfeitas, é enviado um sinal de abertura ao disjuntor. Um atraso de tempo relativo ao mecanismo de abertura do disjuntor deve ser considerado, o qual pode ser obtido no manual do disjuntor (o tempo máximo admitido) ou a partir dos resultados de testes de abertura do disjuntor. Por último, deve ser feita uma verificação de discordância de polos. É admitido um tempo máximo de diferença entre a abertura dos três polos do disjuntor. Se tal valor não for respeitado, ocorre uma situação de discordância de polos. Além disso, se não houver abertura de um ou dois polos apenas, a discordância também é verificada. A não abertura dos três polos é considerada falha completa do disjuntor. Se tudo tiver ocorrido com sucesso, o disjuntor é considerado aberto com sucesso $(\mathrm{CB}=1$, que significa Circuit Breaker - disjuntor - aberto).

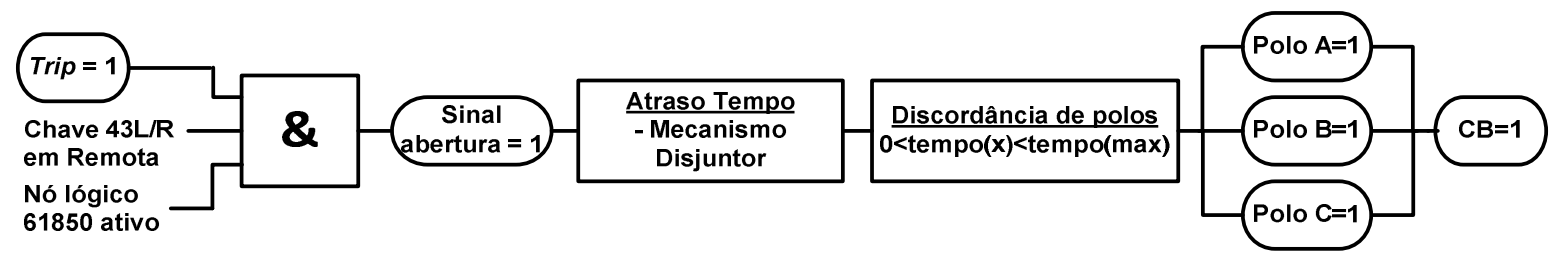

Figura 26 - Modelo RBM da abertura do disjuntor. 


\subsubsection{Módulo de análise de curto-circuito}

Para a classificação dos tipos de curto-circuito que podem ter ocorrido, uma série de condições foi estabelecida, utilizando, porém, duas linhas de raciocínio diferentes.

\subsection{Análise conjunta das correntes}

É possível proceder com a classificação do tipo de falta a partir dos valores das correntes em cada fase. No entanto, para que um valor seja considerado igual a outro valor, deve-se considerar uma faixa de tolerância que deverá levar em conta os erros dos instrumentos de medição (TCs e TPs). Dessa forma, por exemplo, $|\mathrm{Ia}|=|\mathrm{Ib}|$ deve ser tratado como $|\mathrm{Ia}|<|I b|+$ Tolerância e $|\mathrm{Ia}|>|I b|-$ Tolerância. Além disso, quando for equacionada comparação do valor de uma corrente com o valor nulo (zero), deve-se na realidade considerar que há uma corrente de carga, ou seja, o valor nulo remete à corrente causada unicamente pelo curto-circuito, e não pela carga.

Nos subitens a seguir, utiliza-se a seguinte notação:

Ia: Corrente de falta na fase $\mathrm{A}$;

$I b$ : Corrente de falta na fase $\mathrm{B}$;

Ic: Corrente de falta na fase $\mathrm{C}$;

- Curto-circuito trifásico

$$
\begin{aligned}
& I a+I b+I c=0 \\
& |I a|=|I b| \\
& |I a|=|I c| \\
& |I b|=|I c| \\
& |I a| \neq 0 \\
& |I b| \neq 0 \\
& |I c| \neq 0
\end{aligned}
$$


- Curto-circuito dupla-fase AB

$$
\begin{aligned}
& I a+I b=0 \\
& |I a| \neq 0 \\
& |I b| \neq 0 \\
& |I c|=0
\end{aligned}
$$

Para curtos-circuitos BC e CA, o equacionamento é análogo.

- Curto-circuito dupla-fase-terra ABG

$$
\begin{aligned}
& I a+I b \neq 0 \\
& |I a| \neq 0 \\
& |I b| \neq 0 \\
& |I c|=0
\end{aligned}
$$

Para curtos-circuitos BCG e CAG, o equacionamento é análogo.

- Curto-circuito fase-terra AG

$$
\begin{aligned}
& |I a| \neq 0 \\
& |I b|=0 \\
& |I c|=0
\end{aligned}
$$

Para curtos-circuitos BG e CG, o equacionamento é análogo.

\subsection{Análise separada das correntes}

Às vezes pode não ser possível efetuar a análise conjunta das correntes, como por exemplo, quando não há os dados das fases das correntes, mas apenas as magnitudes. Na impossibilidade de realizar tal análise, pode-se realizar a análise separada das correntes em cada fase, para posteriormente juntar as informações adquiridas e realizar o diagnóstico. Dessa forma, tendo em mãos os dados das magnitudes das correntes, temos que detectar a presença de correntes de curto-circuito em cada fase e no terra do circuito. Para isso, 
seguimos os seguintes passos, também utilizados em Girgis e Johns (1989) e Dehghani e Nezami (2013):

1. Guardar o maior valor de corrente entre as três fases na variável Imax:

$I \max =\max (I a, I b, I c)$

2. Normalize a corrente em cada fase e a componente de sequência zero (para analisar o terra) em relação a Imax:

$$
\begin{aligned}
& I a_{\text {norm }}=\frac{I a}{I \max } \\
& I b_{\text {norm }}=\frac{I b}{I \max } \\
& I c_{\text {norm }}=\frac{I c}{I \max } \\
& I o_{\text {norm }}=\frac{I o}{I \max }
\end{aligned}
$$

3. Para cada corrente normalizada, compare com limites pré-estabelecidos $K \max$ e $K \min$ (para componentes de fase) e $K \max _{0}$ e $K \min _{0}$ (para a componente de sequencia zero). Se a corrente normalizada for maior que o limite máximo, então a fase (ou terra) é considerada em curto-circuito. Se for menor que o limite mínimo, então é considerada fora de situação de curtocircuito. Tais limites devem ser escolhidos levando-se em conta as correntes de curto-circuito normalmente encontradas, podendo ser verificadas a partir de simulações dos diferentes tipos de curtos-circuitos, para condizer com situações de falta.

Seguindo os passos acima, basta analisar quais fases (mais o terra) estão em curtocircuito e quais não estão para classificar o tipo de curto-circuito, conforme tabela a seguir, na qual o valor 1 indica fase (ou terra) em curto-circuito e o valor 0 indica fora de situação de curto-circuito: 
Tabela 1 - Classificação do tipo de falta.

\begin{tabular}{|l|c|c|c|c|}
\hline Tipo de falta & la & lb & Ic & lo \\
\hline A-G & 1 & 0 & 0 & 1 \\
\hline B-G & 0 & 1 & 0 & 1 \\
\hline C-G & 0 & 0 & 1 & 1 \\
\hline A-B & 1 & 1 & 0 & 0 \\
\hline A-C & 1 & 0 & 1 & 0 \\
\hline B-C & 0 & 1 & 1 & 0 \\
\hline A-B-G & 1 & 1 & 0 & 1 \\
\hline A-C-G & 1 & 0 & 1 & 1 \\
\hline B-C-G & 0 & 1 & 1 & 1 \\
\hline A-B-C & 1 & 1 & 1 & 0 \\
\hline
\end{tabular}

Em algumas situações, pode haver ausência de informação das magnitudes das correntes em uma ou mais fases. Nestes casos, ainda é possível determinar se a fase (ou terra) é considerada em curto-circuito resgatando as informações de variáveis digitais indicadoras de Trip de cada uma das fases e do terra. Como explicado anteriormente, a técnica de inferência de "regras distintas para diferentes informações de entrada" é utilizada para lidar com essa mistura de informações. As informações de Trip também podem ser utilizadas nos casos em que as correntes normalizadas estiverem entre os limites mínimo e máximo estabelecidos (entre $K \min$ e $K \max$ ou entre $K \min _{0}$ e $K \max _{0}$ ), que são situações em que o sistema especialista não tem certeza se a fase (ou terra) está ou não em curto-circuito. 


\section{ESTUDOS DE CASOS}

Foram simulados casos levando em conta a subestação de distribuição na qual o sistema especialista está sendo instalado. A topologia da subestação é apresentada na figura 27.

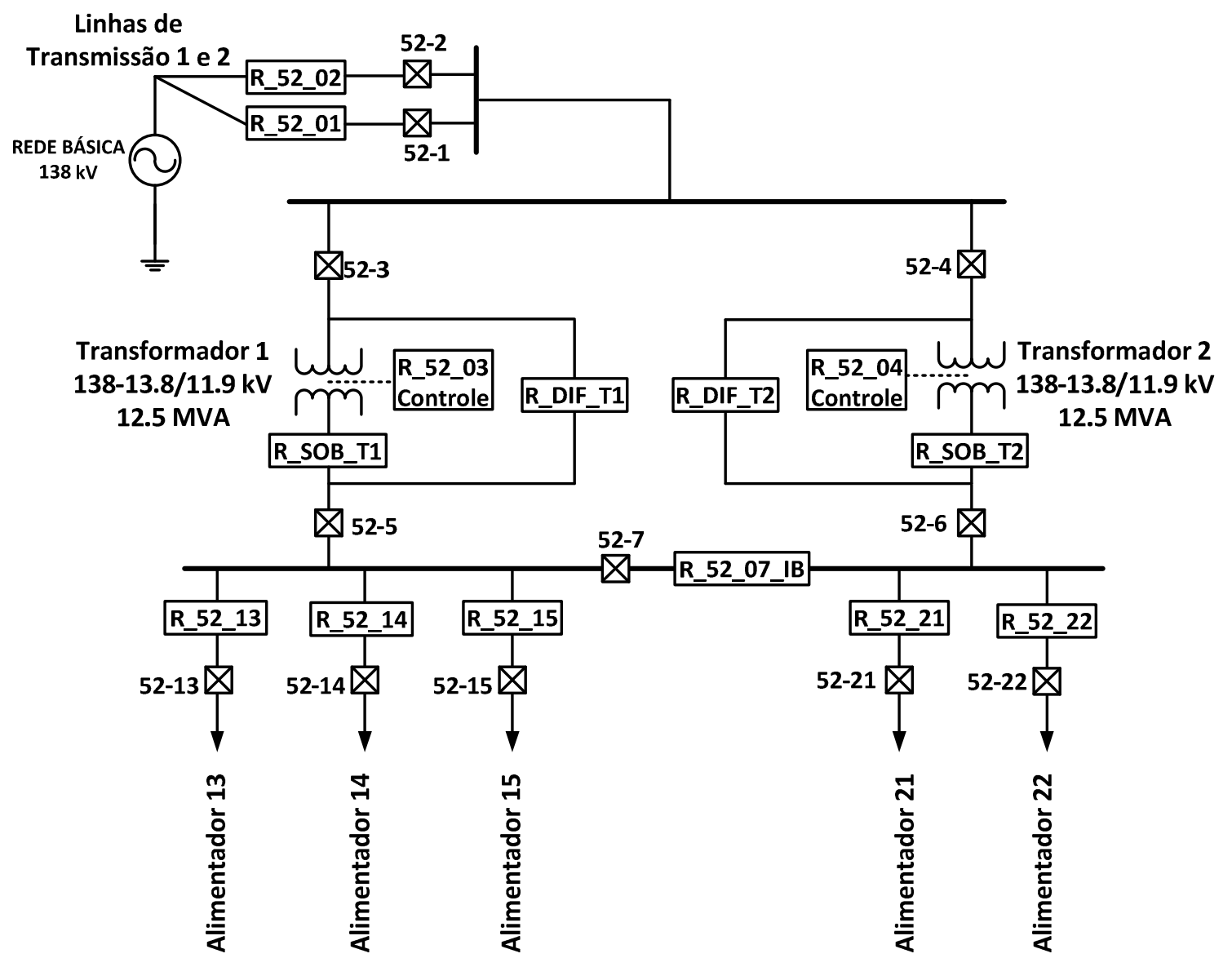

\begin{tabular}{|c|c|c|c|}
\hline Legenda: & & & \\
\hline$\bigotimes$ & Disjuntor & & \\
\hline R_52_01 & Relé de proteção na linha de transmissão 01 & R_SOB_T2 & $\begin{array}{l}\text { Relé de proteção de sobrecorrente no } \\
\text { transformador } 02\end{array}$ \\
\hline R_52_02 & Relé de proteção na linha de transmissão 02 & R_DIF_T2 & Relé de proteção diferencial no \\
\hline R_52_03 & Relé para controle do transformador 01 & & \\
\hline R 5204 & Relé para controle do transformador 02 & R_52_13 & Relé de proteção no alimentador 13 \\
\hline I con T1 & Relé de proteção de sobrecorrente no & R_52_14 & Relé de proteção no alimentador 14 \\
\hline K_SOB_11 & transformador 01 & R_52_15 & Relé de proteção no alimentador 15 \\
\hline R_DIF_T1 & $\begin{array}{l}\text { Relé de proteção diferencial no } \\
\text { transformador } 01\end{array}$ & R_52_21 & Relé de proteção no alimentador 21 \\
\hline R_52_07_IB & $\begin{array}{l}\text { Relé para proteção e controle na barra de } \\
\text { saída da subestação }\end{array}$ & R_52_22 & Relé de proteção no alimentador 22 \\
\hline
\end{tabular}

Figura 27 - Topologia da subestação. 
A arquitetura do sistema de comunicação desta subestação é apresentada na figura 28, sendo que todo o sistema de análise desenvolvido está instalado em um computador na subestação.

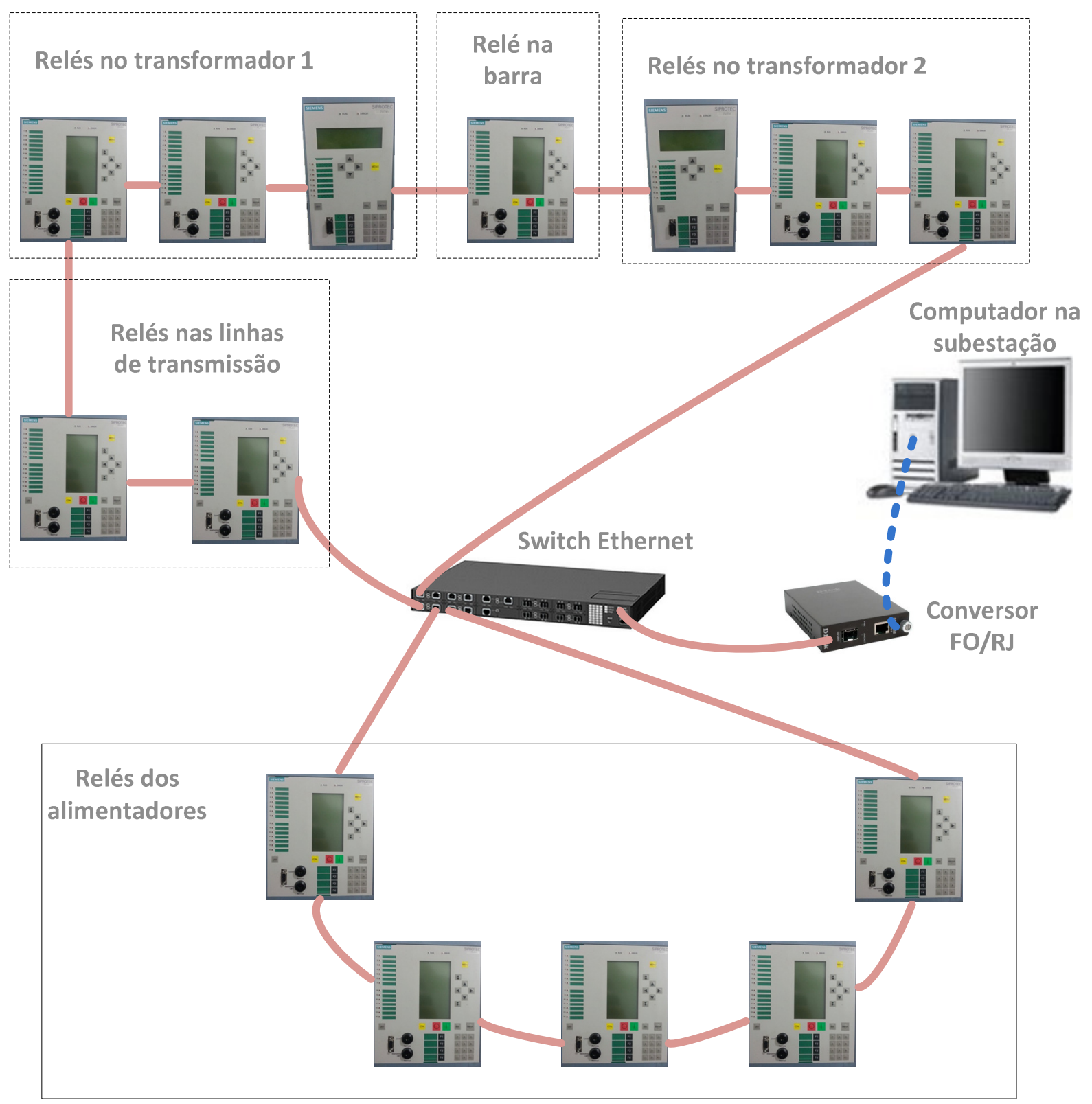

$\begin{array}{ll}\text { Legenda: } & \\ \text { Rede Ethernet com meio físico em fibra óptica } \\ \text { Rede Ethernet com meio físico em par trançado }\end{array}$

Figura 28 - Arquitetura de comunicação da subestação

A seguir, são apresentados os resultados gerados de casos rodados no sistema. 


\subsection{Curto-circuito no alimentador 14 e atuação não ideal da proteção de sobrecorrente e do disjuntor}

Foi aplicado um curto-circuito dupla-fase no alimentador 14. Os valores das correntes de curto-circuito foram simulados e são apresentados a seguir:

Tabela 2 - Valores das correntes para curto-circuito dupla-fase no alimentador 14.

\begin{tabular}{|c|r|c|r|r|r|c|}
\hline \multirow{2}{*}{ Alimentador } & \multicolumn{6}{|c|}{ Correntes (A) } \\
\cline { 2 - 7 } & \multicolumn{2}{|c|}{ la } & \multicolumn{2}{c|}{ lb } & \multicolumn{2}{c|}{ Ic } \\
\cline { 2 - 7 } & módulo & fase & módulo & fase & módulo & fase \\
\hline 14 & 2365.0 & -38.4 & 2365.0 & 141.6 & 0.1 & -163.1 \\
\hline
\end{tabular}

Os relatórios gerados pelos módulos de análise da proteção de sobrecorrente, de curtocircuito e do disjuntor podem ser visualizados no quadro 2. Seguem alguns comentários em relação aos resultados:

Módulo de proteção de sobrecorrente:

- O sistema detectou que a função a ser analisada é a de proteção de sobrecorrente temporizada cujo código ANSI é 51;

- É possível visualizar o ajuste da corrente de pickup para a curva de atuação da função de proteção;

- É mostrado o diagnóstico geral da proteção e também em relação às unidades da função de proteção em cada fase em que houve o curto-circuito junto com as magnitudes das correntes em cada fase;

- O tempo real de atuação do relé foi verificado e também são mostrados os ajustes da curva de atuação da proteção de sobrecorrente;

- O tempo esperado foi calculado e concluiu-se que o relé não atuou em conformidade. $\mathrm{O}$ relé atuou um pouco depois do esperado $(\mathrm{em} \mathrm{t}=0.388 \mathrm{~s}$ frente ao tempo esperado $=0.319 \mathrm{~s}$ ).

Módulo de curto-circuito:

- Foi detectada que houve uma fase bifásica envolvendo as fases A e B;

- São mostradas as correntes de curto-circuito (módulo e fase).

Módulo de disjuntor:

- O disjuntor que deve abrir é o com identificação 52-14;

- Houve abertura do disjuntor, porém demorou mais que o esperado para abrir ( 0.195 s contra 0.1 s esperado), já tendo sido levado em conta o tempo máximo admitido de atraso; 
- Não houve discordância de polos.

Quadro 2 - Relatório emitido pelos módulos de análise da proteção de sobrecorrente, de curto-circuito e do disjuntor para curto-circuito dupla-fase no alimentador 14.

\section{Módulo de proteção de sobrecorrente}

- Relé responsável pela atuação: R_52_14

Diagnóstico da função de sobrecorrente temporizada (ANSI 51)

- $\quad$ Ajuste da corrente de pickup $=249.6[\mathrm{~A}]$

A unidade temporizada do relé de sobrecorrente de fase (ANSI 51) atuou de acordo com o ajuste de pickup.

- A unidade temporizada de sobrecorrente da fase A detectou uma falta corretamente.

Corrente na fase $\mathrm{A}=2365.0$ [A]

- A unidade temporizada de sobrecorrente da fase B detectou uma falta corretamente. Corrente na fase $\mathrm{B}=2365.0[\mathrm{~A}]$

- Atuação do relé da função 51 em $\mathrm{t}=0.388$ segundo(s).

- O tempo de atuação não está em conformidade com o tempo de atuação esperado segundo a curva IEC muito-inversa, com Ipickup = 249.6 [A] e Dial de tempo =0.2. Tempo esperado $=0.319$ segundo(s).

Diagnóstico do disjuntor

- Houve a abertura do disjuntor principal 52-14.

\section{Módulo de curto-circuito}

Diagnóstico do curto-circuito

- Ocorreu uma falta bifásica.

- Fases afetadas: A e B.

- Corrente na fase A:

Módulo = 2365.0 [A]

Fase $=-38.4$ graus.

- Corrente na fase B: Módulo = 2365.0 [A]

Fase $=141.6$ graus.

- Corrente na fase C:

Módulo = $0.1[\mathrm{~A}]$

Fase $=-163.1$ graus.

\section{Módulo de disjuntor}

Diagnóstico completo do disjuntor

- Disjuntor: 52-14.

- Houve a abertura do disjuntor.

- O disjuntor demorou mais que o tempo esperado para abrir. Tempo esperado máximo para abertura $=0.1$ segundo $(\mathrm{s})$.

Tempo de abertura real $=0.195$ segundo(s).

- Não houve discordância de polos. 


\subsection{Curto-circuito em um enrolamento do transformador com atuação da proteção diferencial}

Foi aplicado um curto-circuito monofásico no enrolamento da fase A do transformador 1. O relatório gerado pelo módulo de análise da proteção diferencial pode ser visualizado no quadro 3. Após, seguem alguns comentários em relação aos resultados:

Quadro 3 - Relatório emitido pelo módulo da proteção diferencial e do disjuntor para curtocircuito monofásico no enrolamento da fase A do transformador 1.

Módulo de proteção diferencial

- Relé responsável pela atuação: R_DIF_T1

Diagnóstico da função de proteção diferencial no transformador (ANSI 87T)

- $\quad$ A unidade diferencial $87 \mathrm{~T}$ da fase A detectou uma falta.

Corrente de restrição na fase $\mathrm{A}=20.5432$ [\% da corrente nominal].

Corrente diferencial na fase $\mathrm{A}=116.412$ [\% da corrente nominal].

Para Irestrição na fase A $=20.5432$ [\% da corrente nominal] $=>$ Idiferencial mínimo = 9.0216 [\% da corrente nominal] para relé 87T da fase A operar.

Diagnóstico do Disjuntor

- Houve a abertura do disjuntor principal 52-03.

- Houve a abertura do disjuntor principal 52-05.

Módulo de disjuntor

Diagnóstico completo do disjuntor

- Disjuntor: 52-03.

- Houve a abertura do disjuntor.

- O disjuntor abriu dentro do tempo esperado.

Tempo esperado máximo para abertura $=0.1$ segundo(s).

Tempo de abertura real $=0.088$ segundo(s).

- Não houve discordância de polos.

Diagnóstico completo do disjuntor

- Disjuntor: 52-05.

- Houve a abertura do disjuntor.

- O disjuntor abriu dentro do tempo esperado.

Tempo esperado máximo para abertura $=0.1$ segundo(s).

Tempo de abertura real $=0.085$ segundo(s).

- Não houve discordância de polos. 
Módulo de proteção diferencial:

- O sistema detectou que a função a ser analisada é a de proteção de diferencial para transformadores e potência cujo código ANSI é 87T;

- O sistema concluiu que a fase A detectou uma falta e mostra a corrente diferencial e a corrente de restrição que estão envolvidas nesta fase;

- Como a proteção atuou corretamente, o sistema especialista mostra que para uma corrente de restrição de $20.5 \%$ da corrente nominal, deve-se ter uma corrente diferencial mínima de $9 \%$ da corrente nominal para que aja atuação da proteção diferencial. No caso, a corrente diferencial foi $116.4 \%$ da corrente nominal;

- É mostrado que houve abertura dos disjuntores identificados por 52-03 e 5205, que são os responsáveis por isolar o transformador 1;

Módulo de disjuntor:

- Os disjuntores 52-03 e 52-05 funcionaram da forma esperada: dentro dos tempos esperados e sem discordância de polos.

\subsection{Arquitetura de hardware e software e desempenho do sistema}

Foi utilizado um computador com processador Core i7 $2.93 \mathrm{GHz}, 4 \mathrm{MB}$ de cache, memória RAM de 8GB DDR3 e HD de 1 Terabyte Serial ATA. Além disso, foi utilizado sistema operacional Windows 7 Professional de 64 bits.

Verificou-se que o sistema tem resposta bastante rápida, com tempo total da ordem de poucos segundos, o que é extremamente rápido, visto que o objeto final do sistema é um relatório que deve ser lido por uma pessoa que demorará muito mais tempo para lê-lo.

O sistema especialista tem, individualmente, tempo de processamento instantâneo à percepção humana, demonstrando a eficiência alcançada após o desenvolvimento da base de conhecimentos. 


\section{CONCLUSÕES}

\subsection{Conclusões sobre o sistema desenvolvido}

Foi desenvolvido um sistema automático de análise da proteção para diagnóstico da atuação da proteção em subestações de distribuição de energia, sendo baseado principalmente em um sistema especialista, e que foi instalado na subestação Morungaba II da Companhia Paulista de Força e Luz (CPFL).

O subsistema de aquisição de dados utilizando solução com um gateway com um cliente IEC 61850 e um servidor OPC se mostrou uma opção básica, porém preenchendo com eficiência a função de repasse de dados dos IEDs para o cliente OPC. Além disso, o servidor OPC ainda permite compatibilidade com outros protocolos de comunicação que não o da IEC 61850, como por exemplo, DNP3 e Modbus, permitindo a comunicação também com outros relés e/ou equipamentos de medição. Tal característica aumenta a flexibilidade do sistema, assim como sua compatibilidade com diversos equipamentos utilizados em sistemas elétricos de potência.

O banco de dados relacional permite fácil gerenciamento de todas as informações envolvidas no sistema completo de análise da proteção, tendo sido projetado para comportar que o sistema seja instalado em diversas subestações da companhia de distribuição de energia elétrica, permitindo gerenciamento muito mais completo do sistema de proteção da rede da companhia.

O subsistema de pré-tratamento de dados permite que todos os dados coletados nos relés de proteção sejam devidamente formatados para compatibilizarem com o software utilizado na etapa de processamento de dados. Além disso, analisa arquivos de oscilografia a fim de recuperar informações de magnitudes e fases de variáveis analógicas, como correntes e tensões, os instantes de abertura de disjuntores e de cada um de seus três polos, e também de variáveis digitais, como Trip e partida de funções de proteção.

A etapa de processamento de dados utiliza um sistema especialista implementado no software CLIPS, que é de domínio público e é continuamente atualizado, se mostrando uma ferramenta versátil, sem nenhum custo envolvido, com facilidade de programação e eficiente. O sistema especialista desenvolvido considerou as informações que os equipamentos em redes de distribuição costumam poder fornecer. Tais relés, diferentemente dos relés nas redes de transmissão, podem não fornecer todas as variáveis consideradas importantes ao diagnóstico, 
ou então não disponibilizar informações consideradas opcionais segundo a IEC 61850, sendo necessário obter outras soluções, como a geração e utilização de arquivos de oscilografia ou a implementação de regras que não dependam dessas informações. Utilizando as técnicas de processamento básico de alarmes e o RBM, e também as técnicas de inferência que procuram lidar com possíveis ausências de informações importantes para um diagnóstico completo, é possível gerar um diagnóstico que facilite a decisão do engenheiro de proteção em rever a necessidade de reparametrização do sistema de proteção, visto que a rede de distribuição está mais sujeita a mudanças ao longo do tempo, seja pela adição/remoção de cargas, seja pela inclusão de novas subestações, seja pela conexão/desconexão de geração distribuída, entre outros fatores. Ademais, é possível gerir falhas nos equipamentos, de forma a tomar providências em relação àqueles que apresentem maiores taxas de falhas ou problemas mais graves.

Finalmente, há extrema facilidade para o engenheiro de proteção ou operador do sistema em visualizar os relatórios gerados pelo sistema especialista em uma interface Web em questão de segundos após a ocorrência de um evento de proteção. Tal fato permite uma rápida e eficiente tomada de decisões, o que é muito importante em companhias que possuem muitas subestações a serem gerenciadas e que se preocupam em manter a qualidade no fornecimento de energia elétrica.

\subsection{Desenvolvimentos futuros}

Foi apresentada uma breve revisão da literatura acerca de sistemas de localização de faltas em redes de distribuição no item 2.1.2 deste trabalho. Um sistema automático de localização de faltas para alimentadores de distribuição de média tensão (MT) é um recurso útil que pode possibilitar uma maior agilidade na operação do sistema de distribuição quando da ocorrência de faltas na rede que causam interrupções permanentes no fornecimento de energia, permitindo maior rapidez no conhecimento do problema e também no restabelecimento. Além disso, mesmo nos casos de faltas temporárias, pode-se tirar proveito de informações, pois permite diagnosticar a falta e tomar medidas preventivas evitando muitas vezes que o problema evolua para uma falta permanente. A integração de um sistema desse tipo com o diagnóstico gerado pelo sistema especialista pode ser de grande valia ao sistema completo.

Outra possibilidade é a utilização de relés de diferentes fabricantes de forma a testar a compatibilidade do sistema com quaisquer IEDs. Ressalta-se que o sistema deste trabalho já 
foi implementado levando-se em conta IEDs compatíveis com a norma IEC61850, ou seja, ele já é compatível com outros IEDs que estejam em concordância com a norma, desde que o banco de dados seja corretamente configurado para corresponder aos endereços utilizados para as variáveis em cada relé. De qualquer forma, há ainda a possibilidade de utilização do sistema com relés que não estejam de acordo com a norma IEC 61850, utilizando outros protocolos de comunicação, o que é possível utilizando um servidor OPC compatível com tais protocolos.

O sistema implementado levou em conta as informações normalmente acessíveis em relés digitais em subestações reais. Pode-se, no entanto, implementar regras que analisem um grupo maior e mais completo de dados, de forma a abranger informações que diferentes fabricantes disponibilizam e informações que futuramente podem ser incluídas. Dessa forma, seria possível fornecer um diagnóstico mais detalhado. 


\section{REFERÊNCIAS BIBLIOGRÁFICAS ${ }^{1}$}

CHEN, S. J. et al. Using Multi-vendor IEDs for IEC 61850 Interoperability and HMISCADA Applications. International Symposium on Computer, Consumer and Control (IS3C). Taichung: IEEE. 2012. p. 745-748.

CLIPS Reference Manual: Basic Programming Guide. 1ª ed. [S.1.]: [s.n.], 2008.

CRISPINO, F. et al. Multiplatform and Multi-technology System for Interpretation and Analysis of Protection Tripping in Distribution Substations. IEEE/PES Transmission \& Distribution Latin America. [S.1.]: [s.n.]. 2010.

DAVIDSON, E. M. et al. Automated Analysis of SCADA and DFR data: Post-fault Diagnosis of Power System Disturbances and Condition Assessment of Plant. Power Fourth International Conference on System Control and Management, (Conf. Publ. No. 421). Atlanta: [s.n.]. 2008. p. 1-7.

DAVIDSON, E. M.; MCARTHUR, S. D. J.; MCDONALD, J. R. A toolset for applying model-based reasoning techniques to diagnostics for power systems protection. IEEE Transactions on Power Systems, v. 18, May 2003.

DEHGHANI, F.; NEZAMI, H. A New Fault Location Technique on Radial Distribution Systems Using Aritificial Neural Network. CIRED, 22nd International Conference on Electricity Distribution. Stockholm: [s.n.]. 2013. p. 10-13.

FARRENY, H. Les Systemes Experts: Principles et Exemples. Toulouse: CEPADUESEditions, 1985.

FEIZIFAR, B. et al. Fault location in combined overhead line and underground cable distribution networks using fault transient based mother wavelets. 12th International Conference on Environment and Electrical Engineering (EEEIC). Wroclaw: IEEE. 2013. p. 41-45.

GAO, Z.; CHEN, Q.; SHI, L. Fault Diagnosis of Power System Using Relay Protection Setting Values. 10th IET International Conference on Developments in Power System Protection (DPSP 2010). Managing the Change. [S.1.]: [s.n.]. 2010.

GHADERI, A.; MOHAMMADPOUR, H. A.; GINN, H. Active fault location in distribution network using time-frequency reflectometry. Power and Energy Conference at Illinois (PECI). Champaign: IEEE. 2015. p. 1-7.

GIRGIS, A. A.; JOHNS, M. B. A Hybrid Expert System for Faulted Section Identification, Fault Type Classification, and Selection of Fault Location Algorithms. IEEE Transaction on Power Delivery, v. 4, April 1989.

\footnotetext{
${ }^{1}$ De acordo com a Associação Brasileira de Normas Técnicas. NBR 6023.
} 
HONG, Q.; DYśKO, A.; BOOTH, C. Intelligent System for Detecting 'Hidden' Errors in Protection Settings. 47th International Universities Power Engineering Conference (UPEC). [S.1.]: [s.n.]. 2012.

HOPGOOD, A. A. Intelligent Systems for Engineers and Scientists. 3rd. ed. [S.1.]: CRC Press, 2011.

HOUSEMAN, D. The 4- 'R's' for the 21st Century Grid. Enernex, set. 2013. Disponivel em: <http://www.enernex.com/blog/the-4-rs-for-the-21st-century-grid/>. Acesso em: 23 abr. 2015.

IEC. IEC 61850: International Standard - Communication Networks and Systems for Power Utility Automation, part 7-2. 2a . ed. Geneva: IEC, 2010 b.

IEC. IEC 61850: International Standard - Communication Networks and Systems for Power Utility Automation, part 7-3. 2a . ed. Geneva: IEC, 2010c.

IEC. IEC 61850: International Standard - Communication Networks and Systems for Power Utility Automation, part 7-4. 2a . ed. Geneva: IEC, 2010d.

IEC. IEC 61850: International Standard - Communication Networks and Systems for Power Utility Automation, part 7-1. 2a . ed. Geneva: IEC, $2011 \mathrm{a}$.

IEEE. C37.111-1999 - Common Format for Transient Data Exchange (COMTRADE) for Power Systems. [S.1.]: IEEE, 2013.

IOSERVER. IOSERVER, 2015. Disponivel em: <http://www.ioserver.com/>. Acesso em: 21 Maio 2015.

KAGAN, N. Redes Elétricas Inteligentes no Brasil: Análise de Custos e Benefícios de um Plano Nacional de Implantação. $1^{a}$. ed. Rio de Janeiro: Synergia, 2013.

KAGAN, N. et al. Estimation of Short Duration Voltage Variations in Medium Voltage and Subtransmission Networks. CIRED, 16th International Conference on Electricity Distribution. Barcelona: [s.n.]. 2003. p. 12-15.

KEZUNOVIC, M.; LUO, X. Automated Analysis of Protective Relay Data. 18th International Conference and Exhibition on Electricity Distribution, CIRED 2005. Turin: IET. 2005. p. 5.

LIVANI, H.; EVRENOSOGLU, C. Y. A fault classification method in power systems using DWT and SVM classifier. Transmission and Distribution Conference and Exposition (T\&D). [S.1.]: IEEE. 2012. p. 1-5.

MATRIKON. IEC 61850 OPC Server, 2015. Disponivel em: $<$ https://www.matrikonopc.com/opc-drivers/opc-iec-61850/base-driver-details.aspx $>$. Acesso em: 21 Maio 2015.

MCARTHUR, S. D. J. et al. Expert Systems and Model Based Reasoning for Protection Performance Analysis. IEE Colloquium on Artificial Intelligence Applications in Power Systems. London: [s.n.]. 1996. 
MIRZAEI, M. et al. Review of Fault Location Methods for Distribution Power System. Australian Journal of Basic and Applied Sciences, v. 3, p. 2670-2676, 2009.

OLIVEIRA, C. C. B. et al. Introdução a Sistemas Elétricos de Potência: Componentes Simétricas. $2^{a}$. ed. São Paulo: Edgard Blücher, 2000.

OPC FOUNDATION. The Interoperability Standard for Industrial Automation, 2015. Disponivel em: <www.opcfoundation.org > Acesso em: 21 Maio 2015.

POPOVIC, T.; KEZUNOVIC, M. Measures of Value. IEEE Power and Energy Magazine, Sep-Oct 2012.

POPOVIC, T.; KEZUNOVIC, M.; KRSTAJIC, B. Smart grid data analytics for digital protective relay event recordings. Journal Information Systems Frontiers, New York, 08 June 2013. 10.

REFERENCE FOR BUSINESS. Reference for Business: Encyclopedia of Business. Reference for Business, $\mathbf{2}^{\mathbf{a}}$ ed. Disponivel em: $<$ http://www.referenceforbusiness.com/encyclopedia/Ent-Fac/Expert-Systems.html>. Acesso em: 27 mar. 2015.

RUSH, P. Proteção e Automação de Redes: Conceito e Aplicação. 1ª ed. São Paulo: Edgard Blücher, 2011.

SCHWEITZER ENGINEERING LABORATORIES. Redes de Comunicação em Subestações de Energia Elétrica - Norma IEC 61850. Revista O Setor Elétrico, Automação de Subestações, p. 56-61, Junho 2010.

SENGER, E. C. et al. Automated Fault Location System for Primary Distribution Networks. IEEE Transactions on Power Delivery, v. 20, April 2005.

SHERWALI, H. H.; CROSSlEY, P. A. Expert System for Fault Location and Protection Analysis. 4th International Conference on Power System Control and Management. London: IEEE. 1996. p. 181-186.

SIEMENS. Manual: SIPROTEC - Proteção Diferencial 7UT612. [S.1.]: [s.n.], v. 4.0, 2008.

SOUZA, R. R. D. A. Expert-Rete: Um Motor de Inferência para Agentes Cognitivos. 2005: 121 f. Dissertação (Mestrado em Redes de Computadores) - Núcleo de Pesquisa em Redes de Computadores, Universidade Salvador, Salvador, 2005.

SRINIVASAN, S.; KUMAR, R.; VAIN, J. Integration of IEC 61850 and OPC UA for Smart Grid Automation. Innovative Smart Grid Technologies - Asia (ISGT Asia). Bangalore: IEEE. 2013. p. 1-5.

SU, Y. C.; WANG, X. M. Research of Data Acquisition Method on Smart Substation. International Conference on Power System Technology (POWERCON). Hangzhou: IEEE. 2010. p. 1-4. 
TORABI, S. M. Fault location and classification in distribution systems using clark transformation and neural network. 16th Conference on Electrical Power Distribution Networks (EPDC). Bandar Abbas: IEEE. 2011. p. 1-8.

TRIANGLE MICROWORKS. SCADA Data Gateway, 2015. Disponivel em: $<$ https://www.trianglemicroworks.com/products/scada-data-gateway/overview $>$. Acesso em: 21 Maio 2015.

WINGWIT: CONHECIMENTO COMPUTADOR. Diferenças entre Prolog e Lisp. Wingwit, 2015. Disponivel em: <http://pt.wingwit.com/P/computer-programminglanguages/87892.html>. Acesso em: 21 Maio 2015.

XIN, J.; LIAO, Z.; WEN, F. Intelligent Alarm Processing and Fault Diagnosis in Digital Substations. International Conference on Power System Technology. [S.1.]: [s.n.]. 2010.

ZHU, J.; LUBKEMAN, D. L.; GIRGIS, A. A. Automated Fault Location and Diagnosis on Electric Power Distribution Feeders. IEEE Transactions on Power Delivery, v. 12, April 1997. 


\section{APÊNDICE A - Relação de dados de entrada para o sistema especialista}

A seguir é apresentada a relação de dados de entrada utilizados para a implementação do sistema especialista, incluindo os dados de equipamentos cadastrados no banco de dados e os dados provenientes dos IEDs. Quase todos os dados mostrados são aquisitados via IEC 61850, a não ser os dados descritos no item "4.1.2 - Subsistema de armazenamento de dados" como provenientes do banco de dados. Não estão listados os dados de topologia e parâmetros elétricos nesta lista.

Dados relativos à proteção de sobrecorrente instantânea (ANSI 50):

- Estado do funcionamento do nó lógico;

- Estado do Trip da função de sobrecorrente instantânea;

- Estampa de Tempo do Estado do Trip da função de sobrecorrente instantânea [segundos];

- Estado do Pickup da função de sobrecorrente instantânea;

- Estampa de Tempo do Estado do Pickup da função de sobrecorrente instantânea [segundos];

- Estado do Trip do 50-1 bloqueado;

- Valor do ajuste da corrente de pickup [Ampères - secundário do TC];

- Tempo de atraso configurado para operação [segundos];

- Tempo de atraso configurado para partida [segundos];

- Erro admitido para o tempo de atuação do relé de sobrecorrente instantâneo [segundos].

Dados relativos à proteção de sobrecorrente temporizada (ANSI 51):

- Estado do funcionamento do nó lógico;

- Estado do Trip da função de sobrecorrente temporizada;

- Estampa de Tempo do Estado do Trip da função de sobrecorrente temporizada [segundos];

- Estado do Pickup da função de sobrecorrente temporizada; 
- Estampa de Tempo do Estado do Pickup da função de sobrecorrente temporizada [segundos];

- Estado do Trip do 51 bloqueado;

- Valor do ajuste da corrente de pickup [Ampères - secundário do TC];

- Tipo de Curva + Característica da curva (IEC, IEEE, etc + Inversa, Normal Inversa, etc);

- Valor do ajuste do Dial (Multiplicador) de Tempo;

- Erro admitido para o tempo de atuação do relé de sobrecorrente temporizado [segundos];

Dados relativos à proteção diferencial de transformador (ANSI 87T):

- Estado do funcionamento do dispositivo lógico;

- Estado do Trip geral da função diferencial;

- Estampa de Tempo do Estado do Trip geral da função diferencial [segundos];

- Estado do Trip geral da função diferencial na fase A;

- Estado do Trip geral da função diferencial na fase B;

- Estado do Trip geral da função diferencial na fase C;

- Estado do Trip do 87 bloqueado;

- Estado do Bloqueio da segunda harmônica na fase A;

- Estado do Bloqueio da segunda harmônica na fase B;

- Estado do Bloqueio da segunda harmônica na fase C;

- Estado do Bloqueio da quinta harmônica na fase A;

- Estado do Bloqueio da quinta harmônica na fase B;

- Estado do Bloqueio da quinta harmônica na fase $C$;

- Valor do ajuste da inclinação 1 da função [adimensional];

- Valor do ajuste da inclinação 2 da função [adimensional];

- Valor do ajuste do Ponto-Base 1 da função [adimensional - porcentagem da corrente nominal];

- Valor do ajuste do Ponto-Base 2 da função [adimensional - porcentagem da corrente nominal]; 
- Corrente diferencial de pickup baixa [adimensional - porcentagem da corrente nominal] (87-1);

- Corrente diferencial de pickup alta [adimensional - porcentagem da corrente nominal] (87-2);

- Tensão nominal do transformador no lado da alta tensão [kV];

- Tensão nominal do transformador no lado da baixa tensão [kV];

- Potência nominal do transformador [MVA];

- Tempo máximo de operação [segundos];

- Dados de correntes em relés de proteção de sobrecorrente

- Magnitude da corrente de curto-circuito medida na fase A [Ampères - primário do TC];

- Magnitude da corrente de curto-circuito medida na fase B [Ampères - primário do TC];

- Magnitude da corrente de curto-circuito medida na fase $\mathrm{C}$ [Ampères - primário do TC];

- Magnitude da corrente de curto-circuito medida na fase A obtida do arquivo COMTRADE [Ampères - primário do TC];

- Magnitude da corrente de curto-circuito medida na fase B obtida do arquivo COMTRADE [Ampères - primário do TC];

- Magnitude da corrente de curto-circuito medida na fase $\mathrm{C}$ obtida do arquivo COMTRADE [Ampères - primário do TC];

- Ângulo da corrente de curto-circuito medida na fase A [graus];

- Ângulo da corrente de curto-circuito medida na fase B [graus];

- Ângulo da corrente de curto-circuito medida na fase C [graus];

- Ângulo da corrente de curto-circuito medida na fase A obtida do arquivo COMTRADE [graus];

- Ângulo da corrente de curto-circuito medida na fase B obtida do arquivo COMTRADE [graus];

- Ângulo da corrente de curto-circuito medida na fase $\mathrm{C}$ obtida do arquivo COMTRADE [graus];

- Magnitude da corrente pré-falta medida na fase A obtida do arquivo COMTRADE [Ampères - primário do TC]; 
- Magnitude da corrente pré-falta medida na fase B obtida do arquivo COMTRADE [Ampères - primário do TC];

- Magnitude da corrente pré-falta medida na fase $\mathrm{C}$ obtida do arquivo COMTRADE [Ampères - primário do TC];

- Ângulo da corrente pré-falta medida na fase A obtida do arquivo COMTRADE [graus];

- Ângulo da corrente pré-falta medida na fase B obtida do arquivo COMTRADE [graus];

- Ângulo da corrente pré-falta medida na fase $\mathrm{C}$ obtida do arquivo COMTRADE [graus];

- Magnitude da corrente de curto-circuito no neutro [Ampères - primário do TC];

- Magnitude da componente de sequência positiva da corrente de curto-circuito [Ampères - primário do TC];

- Magnitude da componente de sequência negativa da corrente de curto-circuito [Ampères - primário do TC];

- Magnitude da componente de sequência zero da corrente de curto-circuito [Ampères - primário do TC];

- Ângulo da componente de sequência positiva da corrente de curto-circuito [graus];

- Ângulo da componente de sequência negativa da corrente de curto-circuito [graus];

- Ângulo da componente de sequência zero da corrente de curto-circuito [graus];

- Tolerância para medições de corrente [adimensional].

Dados de correntes em relés de proteção diferencial

- Corrente de restrição na fase A [porcentagem da corrente nominal];

- Corrente de restrição na fase B [porcentagem da corrente nominal];

- Corrente de restrição na fase C [porcentagem da corrente nominal];

- Corrente diferencial na fase A [porcentagem da corrente nominal];

- Corrente diferencial na fase B [porcentagem da corrente nominal];

- Corrente diferencial na fase C [porcentagem da corrente nominal]; 
- Magnitude da corrente na fase A no lado da alta tensão [Ampères - primário do $\mathrm{TC}]$;

- Magnitude da corrente na fase B no lado da alta tensão [Ampères - primário do TC];

- Magnitude da corrente na fase $\mathrm{C}$ no lado da alta tensão [Ampères - primário do TC];

- Magnitude da corrente na fase A no lado da baixa tensão [Ampères - primário do TC];

- Magnitude da corrente na fase B no lado da baixa tensão [Ampères - primário do TC];

- Magnitude da corrente na fase $\mathrm{C}$ no lado da baixa tensão [Ampères - primário do TC];

- Ângulo da corrente na fase A no lado da alta tensão [graus]

- Ângulo da corrente na fase B no lado da alta tensão [graus]

- Ângulo da corrente na fase $\mathrm{C}$ no lado da alta tensão [graus]

- Ângulo da corrente na fase A no lado da baixa tensão [graus]

- Ângulo da corrente na fase B no lado da baixa tensão [graus]

- Ângulo da corrente na fase $\mathrm{C}$ no lado da baixa tensão [graus]

Dados relativos ao disjuntores

- Estado do funcionamento do nó lógico;

- Nome do disjuntor;

- Estado do disjuntor;

- Estado do polo A do disjuntor;

- Estado do polo B do disjuntor;

- Estado do polo C do disjuntor;

- Estampa de Tempo geral da abertura do disjuntor [segundos];

- Estampa de Tempo da abertura da fase A obtida do arquivo COMTRADE [segundos]

- Estampa de Tempo da abertura da fase B obtida do arquivo COMTRADE [segundos] 
- Estampa de Tempo da abertura da fase $\mathrm{C}$ obtida do arquivo COMTRADE [segundos]

- Indicação se ocorreu falha do disjuntor;

- Tempo máximo admitido para abertura do disjuntor [segundos];

- Tempo máximo admitido entre aberturas dos polos do disjuntor para não ser considerado discordância de polos [segundos];

- Posição da Chave 43LR (Local/Remota);

Dados relativos ao relé de religamento (ANSI 79)

- Estado do funcionamento do nó lógico;

- Estado da Operação do Relé 79 (comando usado para fechar o disjuntor);

- Estampa de Tempo do Estado da Operação do Relé 79 [segundos];

- Estado do auto-religamento (1-Pronto; 2-Em progresso; 3-Sucesso);

- Estado do bloqueio do relé 79;

- Contador de religamentos;

- Tempo da primeira tentativa de religamento [segundos];

- Tempo da segunda tentativa de religamento [segundos];

- Tempo da terceira tentativa de religamento [segundos];

- Tempo da quarta tentativa de religamento [segundos];

- Número de religamentos;

Dados relativos ao relé de bloqueio auxiliar para transformador (ANSI 86T)

- Estado do funcionamento do nó lógico;

- Estado da atuação do Relé 86T;

- Indicação de falha na supervisão da bobina 86T;

Outros dados

- Data do evento com horário;

- Horário que foi feita a aquisição de dados do relé [segundos];

- Identificação do relé; 
- Indicação de qual evento de proteção disparou o sistema especialista;

- Identificação da subestação;

- Estado do comando geral de Trip do relé;

- Estampa de Tempo do estado do comando geral de Trip do relé;

- Rótulo para nomeação do arquivo gerado com o relatório do Sistema Especialista;

- Relação do Transformador de Corrente de fase;

- Relação do Transformador de Corrente de neutro; 